\title{
The behaviour and ecology of Austrolittorina antipodum and Austrolittorina cincta: models for marine reserve connectivity studies
}

By

Jennifer Vander Veur

\begin{abstract}
A thesis
Submitted to the Victoria University of Wellington in fulfillment of the requirements for the degree of Masters of Science in Marine Biology
\end{abstract}

Victoria University of Wellington

2011 



\section{$\underline{\text { Abstract }}$}

Determining the magnitude of dispersal and connectivity between populations has important implications for marine conservation. Species with limited dispersal capabilities exhibit restricted gene flow leading to isolation and, ultimately, differentiated populations. In this ecological study I investigated the gastropods Austrolittorina antipodum (Philippi, 1847) and Austrolittorina cincta (Quoy and Gaimard, 1833) to determine how ecology and behaviour influence the dispersal and connectivity of these species. The aim of this study was to determine population size and structure, settlement, fecundity, and adult movement rates. Methodologies included: population surveys, deployment of settlement pads and adult density manipulations, dissections, and a tagging study. These elements of a species ecology and behaviour can enhance or restrict population connectivity by: cohort partitioning resulting from habitat requirements, fluctuating settlement due to variable larval mortality or adult densities impacting dispersal, skewed sex ratios and effective populations sizes altering larval production, and adult movement leading to behavioural isolation or facilitating gene flow, along with other possible effects.

Population surveys revealed both species had a Vermeij (1972) “type 1 distribution” (shell size increasing from the low to high shore), with the highest density of individuals on the low shore and the majority of mature adults on the high shore. Overall, A. antipodum was 16 times more abundant than $A$. cincta. Shifts to a smaller mean size of both species, along all shore heights following periods of peak settlement indicates settlers are potentially triggering competitive interactions or ontogenetic migrations in other cohorts. 
Settlement surveys revealed that peak settlement for Austrolittorina spp. was from February to April, declining at the beginning of March. Multiple peaks in settlement may act as a buffer limiting the potential of stochastic events to hinder dispersal during reproductive seasons. Settlement rates were not affected by adult density in control treatments; however, settlement was higher on pads deployed within adult populations compared to pads deployed adjacent to adult populations, suggesting the presences of adults has some effect on settlement.

Fecundity results revealed A. antipodum to have more mature females than A. cincta, with males of both species reaching sexual maturity before females. Sex ratios of both species were skewed towards more females, with effective population sizes that included approximately $88 \%$ of each species population. A. antipodum's larger population may be due to variation between the species' demographics, such as the distribution of mature females and juveniles leading to greater spawning success and juvenile survivorship.

Tagging transplant/translocation experiments used to examine movement revealed that both species traveled similar distances. On average A. antipodum traveled $24.1 \mathrm{~m}(\underline{+23.5 \mathrm{~m})}$ and A. cincta traveled $18.7 \mathrm{~m}( \pm 16 \mathrm{~m})$ in eight months. There was no evidence of behavioural isolation occurring between low and high shore individuals. The wide ranging movements of adults indicated adults have the potential to maintain population connectivity on small scales.

The findings of this study suggest both species facilitate dispersal with multiple peaks in settlement, large effective populations, and high adult mobility. Behavioural variation between the species appears to affect population connectivity, with the distribution of $A$. antipodum demographics potentially enhancing connectivity. 


\section{This thesis is dedicated to Isis}

And to my parents, friends, and family who have all supported me in making my dreams come true, all my love and infinite gratitude. 


\section{Acknowledgements}

I would like to thank all those who supported me in my research including: my advisor James Bell, Nicole Phillips, Bruce Marshall, John Vander Sham, Nokuthaba Sibanda, Fiona Hodge, Jason Maddock-Aukino 'my lovely field assistant', Mordecai Ogada, and administrative staff including Celia Smith for all their assistance. I would also like to thank my parents and brother Shem for supporting me in numerous ways and for helping me pay for school. I could not have done this without the support and encouragement of my parents and

family, who I am eternally gratefully too. I would also like to thank all of the periwinkles that died during the course of my study, thank you for your sacrifice. 


\section{Table of Contents}

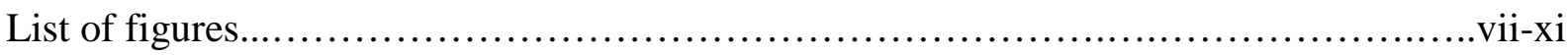

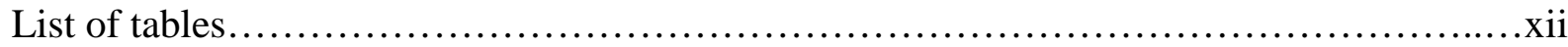

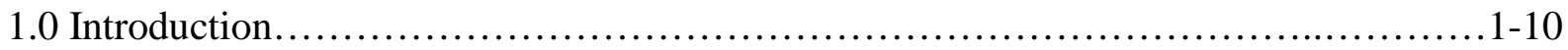

1.1 Population size and structure introduction................................11-13

1.2 Settlement introduction...............................................14-17

1.3 Fecundity introduction................................................18-21

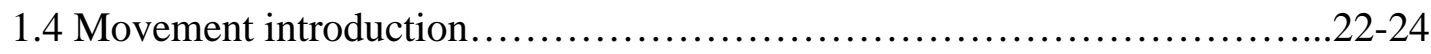

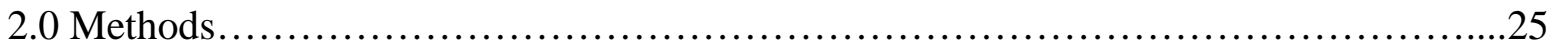

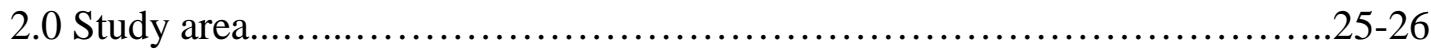

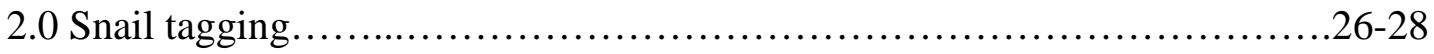

2.1 Population size and structure methods.................................29-30

2.2 Settlement methods....................................................31-35

2.3 Fecundity methods .........................................................

2.4 Movement methods....................................................39-43

2.5 Data analysis........................................................ $44-45$

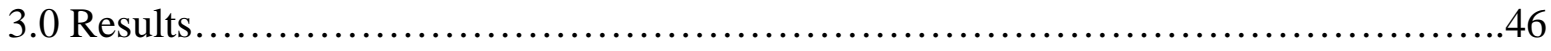

3.1 Population size and structure results....................................6-65

3.2 Settlement results.................................................66-81

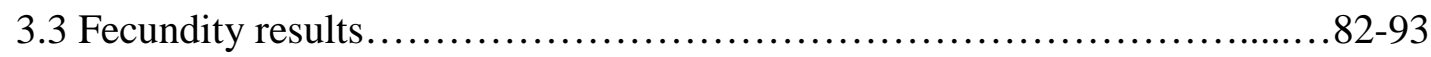

3.4 Movement results.......................................................

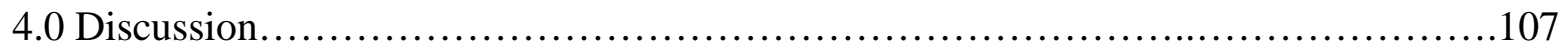

4.1 Population size and structure discussion............................107-116

4.2 Settlement discussion...........................................117-124 
4.3 Fecundity discussion..........................................

4.4 Movement discussion..........................................132-141

5.0 Conclusion.......................................................... 142-151

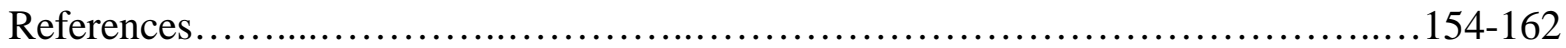

Appendix................................................................ 163-174 


\section{List of figures}

Figure 1. Flow diagram of components of this thesis (contained in white boxes), illustrating how they are integrated and the associated aims (contained in colored boxes)..................9

Figure 2. Map of study sites and replicates along the Island Bay coastline, New Zealand......25

Figure 3. The total number of each species collected from each survey round, December 2008

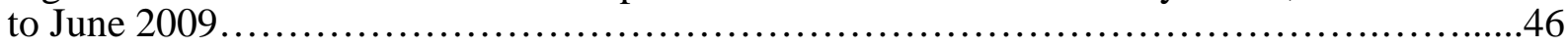

Figure 4. Mean number of each species collected from each site during each round February-

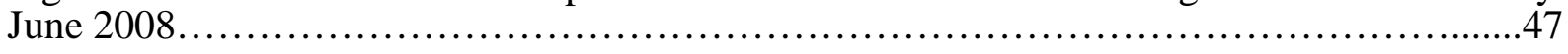

Figure 5. The proportion of each species found on each shore height during each survey

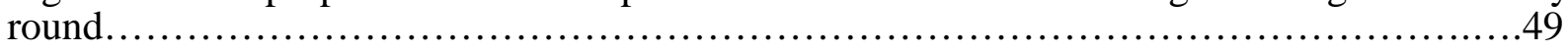

Figure 6. The abundance of each species at each of the main sites along each shore height for February- June 2008 surveys.............................................................. 51

Figure 7. Mean abundance of A. antipodum along each shore height, for all sampling rounds,

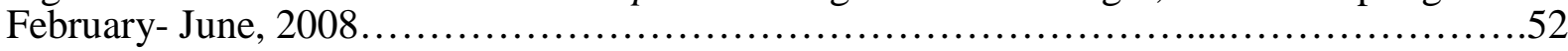

Figure 8. Mean abundance of $A$. cincta along each shore level, for all sites and sampling

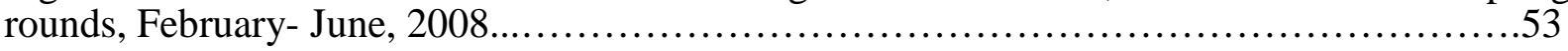

Figure 9. Size distribution of both species for all data (all rounds, sites and shore levels).......54

Figure 10. Size distribution for A. antipodum (blue line) and A. cincta (brown line) for the low, mid, and high shore across all sites for all rounds.,,,..................................54

Figure 11. Range and mean sizes for each species during all survey rounds at each shore

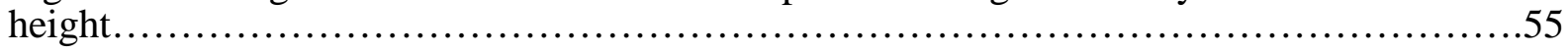


Figure 12. A. antipodum average size along each shore height for each sampling round,

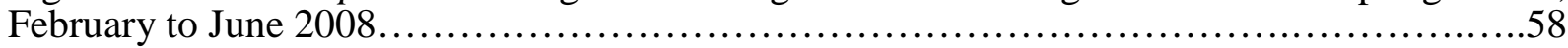

Figure 13. A. cincta average size of snails at each site along each shore height for each

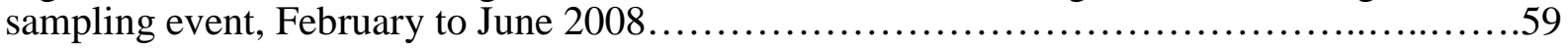

Figure 14. Temporal behavioural variance of A. antipodum and A. cincta, February -June

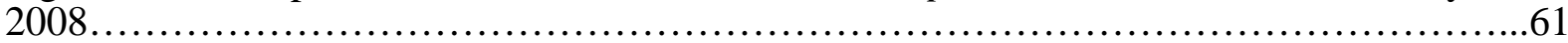

Figure 15. A. antipodum and A. cincta mean number of solo snails, pairs, groups, mixed groups along each shore height (pooled sites) for each sampling round......................62

Figure 16. The total number of Austrolittorina recruits collected during each sampling interval combined across all sites....................................................66

Figure 17. The mean number of Austrolittorina settlers from December 2007- June 2008...69

Figure 18. Total Austrolittorina settlement at each of the three sites during each sampling round, pooling all replicate sites.

Figure 19. Comparison of the average number of Austrolittorina settlers for all settlement pads

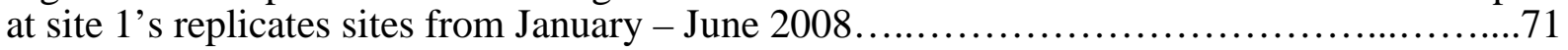

Figure 20. Comparison of the average number of Austrolittorina settlers for all settlement pads at site 2's replicates sites from January - June2008.................................71

Figure 21. Comparison of the average number of Austrolittorina settlers for all settlement pads

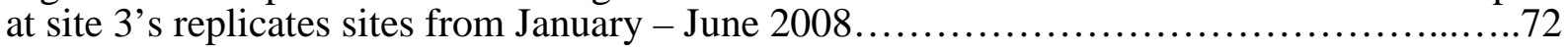

Figure 22. Total Austrolittorina settlement by site and density treatment January- March 2008.

Figure 23. Average Austrolittorina settlement by site and density treatment January- March 2008. 
Figure 24. Total number of Austrolittorina recruits, Eatoniella species, and unknown prosobranch present during each round Dec. 2007- June 2008

Figure 25. Total number of pads with Austrolittorina recruits and environmental factors of algae and sand Dec. 2007- June 2008. 78

Figure 26. Total number of settlement pads with presence of Austrolittorina settlers, other snails, barnacles, bivalves, worms and crustaceans Dec. 2007-June 2008. .79

Figure 27. Total Austrolittorina settlement correlated to moon phase for the entire sample period, Dec. 15, 2007- June 30, 2008. .80

Figure 28. Distribution of $A$. antipodum and $A$. cincta among the reproductive classifications, all sites pooled. 83

Figure 29. A. antipodum reproductive class average size on low and high shores across all sites.

Figure 30. Size distribution of A. antipodum for all reproductive classes by site and shore height. .89

Figure 31. A. cincta reproductive class average size on low and high shores across all sites. .90

Figure 32. Size distribution of $A$. cincta for all reproductive classes by site and shore height .91

Figure 43. The final distance traveled from the release site, progress towards home made (shore level of origin), and cumulative distance traveled for each species from AprilDecember 2008, for184 days

Figure 34. A. antipodum final distance from release site for each of the reproductive classifications on the low and high shore. 
Figure 35. A. antipodum cumulative distance traveled for each reproductive classification along the low and high shore.

Figure 36. A. antipodum transplant treatment movements from April - December 2008 for the Final Distance From Release Site (FDFRS), Progress Towards Home (PTH), and Cumulative Distance (CD) ................................................................... 101

Figure 37. A. cincta final distance from release site for each of the reproductive classifications on the low and high shore... 103

Figure 38. A. cincta cumulative distance traveled for each reproductive classification along the low and high shore... 104

Figure 39. A. cincta transplant treatment movements from April - December 2008 for the Final Distance From Release Site (FDFRS), Progress Towards Home (PTH), and Cumulative Distance (CD). 105

Appendix 1. List of movement calculations used $151-152$

Appendix 2. Population size and structure statistical results. $153-154$

Appendix 3. Table of average size of each species, at each shore height, for all replicate sites. 155

Appendix 4. Settlement complete statistical results .156

Appendix 5. Table of sex ratios and demographic comparisons for each species, at each site, in each size class

Appendix 6. Fecundity complete statistical results. .158 
Appendix 7. Table of each reproductive classifications distribution among the small,

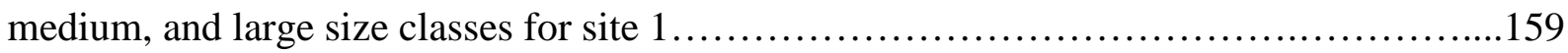

Appendix 8. Table of each reproductive classifications distribution among the small,

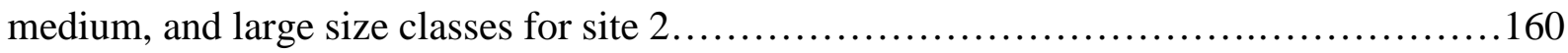

Appendix 9. Table of each reproductive classifications distribution among the small,

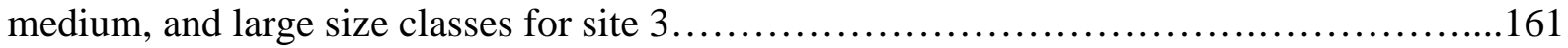

Appendix 10. Movement complete statistical results....................................162 


\section{$\underline{\text { List of tables }}$}

Table 1. Total number of each species collected from each shore height of each site for all

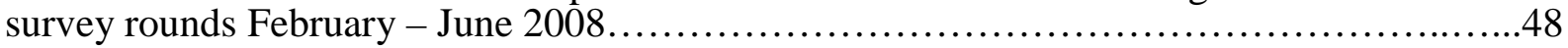

Table 2. Proportion of each species within $1 \mathrm{~mm}$ size ranges, for all sites...................56

Table 3. The total number of settlement pads recovered, total pads lost, and the number of Austrolittorina recruits recovered for each of the data sets and each site....................68

Table 4. Differences in the ecological and environmental factors among the sites, the lowest and highest ranked sites in addition to Kruskal-Wallis results are presented................77

Table 5. Distribution of snails dissected at each site among the various reproductive classifications and size distributions. Totals are presented in bold........................82

Table 6. Variation in demographic ratios between both species. Abbreviations and symbols for the ratios include the following: MF-Mature Female, MM- Mature Male, F- Female, M-

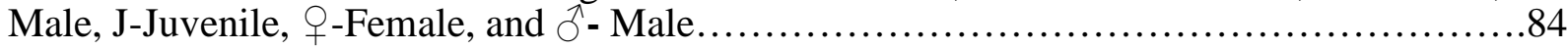

Table 7. Female to male sex ratios for both Austrolittorina species at all sites along the low and high shore. The most skewed ratio is found along the low shore at site 2 where no male $A$. antipodum were found

Table 8. Average for each of the three distance calculations traveled by A. antipodum, for each of reproductive class, within each transplant treatment, April- December 2008...........95

Table 9. Average for each of the three distance calculations traveled by A. cincta, for each of reproductive class, within each transplant treatment, April- December 2008.................96

Table 10. Summary of the similarities and disparities between A. antipodum and A. cincta, both significant and non-significant. 


\section{$\underline{1.0 \text { Introduction }}$}

Since the 1980's there has been a growing concern that traditional management regimes are failing to meet their aims of sustainable use and marine protection (Keller and Kenchinton, 1991). In response to this concern there has been an increasing number of Marine Protected Areas (MPAs) designated throughout the world. These protected areas are a useful management tool not only for single-species conservation, but entire ecosystems, and numerous benefits such as spillover have been documented (Palumbi, 2001; Kelly et al., 2002). However, if marine managers are to properly implement this management tool knowing how and where to apply it is essential to ensuring its effectiveness. An important element of knowing how and where to use MPAs lies in population connectivity (both ecological and genetic), which needs to be among the primary parameters considered (Agardy, 1994; Bohonak, 1999).

Fundamental to the success of MPAs is a thorough understanding of the behaviour and ecology of individual species, such as a species dispersal, gene flow, and connectivity. The focus of this thesis is on dispersal and connectivity in terms of ecology rather than genetics. Understanding how dispersal and connectivity effect populations within, outside, and between these reserves is fundamental to evaluating the effectiveness of these areas. A species life history and behavioural characteristics directly affect the conservation strategy for that species. In order to design and structure a successful MPA, information on individual species characteristics and behaviour, as well as how they fit into the larger ecology is needed, so as to incorporate all habitat types needed to sustain the organisms within it (Jones and Carptenter, 2009). Many marine species go through changes in life stages and ontogenic 
migrations complicating the process. Movement from nursery to adult habitats can be a key link in maintaining connectivity (Gillanders et al., 2003). Ecological studies can help provide the framework needed to design reserves which facilitate connectivity, while assisting managers in making effective management decisions (Agardy, 1994).

The present study will investigate the basic ecology and behavioural traits of two intertidal gastropods, Austrolittorina antipodum and Austrolittorina cincta, which may influence the dispersal, population structure, and connectivity of these species. This information is important as part of a larger study, with $\mathrm{PhD}$ candidate Pelayo Salinas, which is using these two snail species to examine population connectivity in order to inform MPA placement. My study includes investigations of the population size and structure, settlement, fecundity, and adult movement of these species. These subjects were chosen to examine factors of population structure and dispersal that might cause differences in the genetic structure of these species. For example, if one species is found to move less and have less genetic variation there may be a correlation between each species movement rates and the genetic diversity. In this way variations in these species ecology and behaviour may explain the genetic difference between these species.

Population size and structure studies help investigators begin to understand the niche species occupy and offer a basic overview of a species’ ecology as a foundation to build upon. These studies also provide estimates of population sizes, information on habitat use and zonation, and help identify potential cohort or size partitioning (Vermeij, 1972;

Rochette et al., 2001). Small populations sizes can inhibit reproductive success, creating a negative feedback loop, of low reproductive success leading to low recruitment, perpetuating small population sizes; these small population sizes can also limit the gene pool, which again, 
can limit the longevity of a population (Stoner and Ray-Culp, 2000). Information on habitat use can also help in understanding the genetic structure of populations and connectivity, as specific microhabitat associations can limit conspecific interactions, potentially leading to the creation of ecotypes (Fernández et al., 2005). Size partitioning and the distribution of different demographics not only shapes populations, but can change throughout a species' life history, potentially enhancing the success of a species and helping define the roles a species plays within its community (Grech, 1989; Hobday, 1995; Dill et al., 2003). By understanding the population dynamics of species with different life stages managers can better understand how marine systems function on multiple levels, influences on dispersal, and design management plans that facilitate connectivity.

Settlement research provides information on the number of potential recruits entering populations, seasonality, preferred settlement sites, and possible effects of conspecifics density (Hasting and Harrison, 1994; McGrath, 1997; Strathmann et al., 2002). All of this information is useful in estimating dispersal and connectivity, adding to the need for settlement studies (Warner and Cowen, 2002). Understanding the seasonality and why certain settlement sites are favored over others helps tease apart confounding factors, such as low settlement resulting from low production or due to temporal or spacial fluctuations in settlement (Strathmann, 1985). The extent of settlement helps researchers comprehend the processes shaping populations, quantify larval mortality, and define the degree to which larval dispersal distances are correlated to gene flow (Vermeij, 1972; Strathmann, 1985; Mitton et al., 1989; Paulay and Meyer, 2006).

Natural selection and mate choice may override the homogenizing effects of gene flow, making studies of fecundity and sex ratios important when interpreting population 
structures and connectivity (Endler, 1973; Fernández et al., 2005). Fecundity research helps define the factors that influence connectivity by: establishing demographic distributions, sex ratios, effective population estimates, and can be used in conjunction with settlement surveys to estimate larval production and mortality (Hollander et al., 2005). Examining the fecundity of snails from different shore height may reveal differences in reproduction, and will help decipher if differences in behaviour and timing of reproduction have the potential to lead to incipient speciation (Cruz et al., 2004; Panova et al., 2006). Fecundity information also helps determine the life history of species' and the differences between these sympatric species which may explain population structure, distribution patterns, and potential differences in connectivity.

Gene flow and dispersal may be limited by adult behaviour and movement studies may reveal potential implications of adult movement on connectivity. Adult movements related to reproduction and adult dispersal can possibly enhance or restrict connectivity (Takada, 2003; Ito and Wada, 2006). Limited adult movement can lead to reproductive isolation and intensify a species reliance on larvae for dispersal (Johannesson et al., 1995; Pechenick, 1999). If adults on the high shore do not reproduce with adults from the low shore there is the potential for incipient speciation to occur via behavioural isolation (Fernández et al., 2005; Ito and Wada, 2006). Understanding the reproductive cycles and movements of these species will aid in estimates of dispersal and interpreting genetics.

The four main chapters in this thesis focus on gaining a basic understanding of the ecology and behaviours of these species. The ecological component of this study examines population size and structure, growth rates, and reproduction while behaviour is investigated in terms of settlement processes, habitat utilization/ zonation, and adult movement. 
Examining the population size and structure, settlement patterns, fecundity, and adult movement will provide insight into the niche these species hold and how they behave within it.

\section{Background}

Austrolittorina belong to a subfamily of the Littorina family, which are a diverse group of intertidal snails found throughout the world and commonly also known as periwinkles (Reid, 2004). Although, there is a large body of knowledge on most littorinid species, there is limited information available on the life-history and ecology of New Zealand Austrolittorinids. Reid (2002) noted the potential of using the Littorinidae family as a model system for studying evolution in a phylogenetic context due to the fact that most littorinid species taxonomy, life history, ecology, and geographical distribution are relatively well understood. Austrolittorina antipodum and A. cincta were chosen for this study as they exhibit similar characteristics as sister species. Both have planktotrophic larvae, are sympatric throughout most of their ranges, and are supra-abundant species (Pilkington, 1971; Reid, 2001). Furthermore, knowledge of $A$. antipodum and A. cincta can be used in conjunction with genetic studies to understand how a species behaviour and dispersal influence its population connectivity. For example, natal homing of pelagic dispersed larvae potentially limiting population connectivity (Thorrold et al., 2001).

Austrolittorina antipodum and A. cincta are found throughout New Zealand within the intertidal region. The geographic distribution, morphology, and phylogeny of these species have been described in detail by Reid (2004). The phylogeny of these species has changed over time and they were previously grouped with similar Australian species, only recently being recognized as unique species in their own right. Previous research has shown 
these species are generalist herbivores feeding on lichen, Ulva, Enteromorpha, diatoms, and Auckland populations of $A$. antipodum were found to be most abundant along the Salicornia belt (Powell, 1933; Morton, 1975). These species have also been observed grazing on Porphyra virididentata and Durvillaea Antarctica which had washed ashore, and an unidentified filamentous alga (personal observation).

Members of the Littorinidae family are dioecous, using internal fertilization within a promiscuous mating system (Fretter and Graham, 1994; Reid, 1996; Ito and Wada, 2006). Austrolittorina antipodum and A. cincta are both oviparious and have planktotrophic larvae. These species release planktonic egg capsules that become free-swimming veligers, feeding for 1-2 months in the plankton before the veliger metamorphoses settling onto benthic substrates (Pilkington, 1971). Morphological studies conducted by Reid (2002) found A. antipodum and A. cincta to be part of a smaller group of littorinids possessing an egg grove which loops through the capsule gland. The most in depth study of these species’ reproduction was conducted by Pilkington (1971). This research included work on pairing and spawning, descriptions of egg capsules and veligers, egg abundance, and environmental parameters influencing spawning. Pilkington (1971) found the environmental parameters that trigger spawning to be rough seas and high salinities in pools; she also found that these species can rapidly respond to these triggers, quickly releasing eggs once the appropriate environmental conditions are detected. Research is still needed on population sizes and structure, fecundity, sex ratios, settlement and adult movement of these species (Figure 1). The following research will attempt to these fill gaps in our knowledge of these species, such that this information can be linked to genetic data to detect the processes governing the connectivity of populations in the future. 
In addition to examining these aspects of A. antipodum and A .cincta's behaviour and ecology this study will provide a baseline for these species prior to the designation of the Tapaturanga Marine Reserve which now encompasses all of the sites used in this study. Baseline studies of species in marine reserves can prove to be of critical importance in comprehending the impacts and effectiveness of marine reserves (Edgar et al., 2004). The results of this study may show that the ecology and behaviour of a species have more of a bearing on population connectivity than physical processes, illustrating the need to consider these forces when attempting to explain genetic patterns and when designing marine reserves.

This study will be used in conjunction with genetic studies carried out by $\mathrm{PhD}$ candidate Pelayo Salinas. The results of these two studies will be used concurrently to demonstrate the relationships between populations and the underlying factors influencing the extent of connectivity. The ecological and behavioural similarities and/or differences between these two species will substantiate whether individual traits of the species are responsible for the genetic variation observed or if other factors such as physical process (i.e. water currents) dictate dispersal and connectivity.

\section{$\underline{\text { Population study aims }}$}

Population surveys will be used to estimate the relative size of each species population at Island Bay sites and their vertical distribution along the shore. This study will help uncover potential differences in habitat use, size distributions, and behaviours (i.e. the number of solo and grouped snails). In addition, this study will establish a baseline for these species populations within the newly designated Tapaturanga Marine Reserve. 


\section{$\underline{\text { Settlement study aims }}$}

Settlement pads will be deployed to determine the settlement rates of austrolittorinids along the coast of Island Bay, New Zealand. This research will describe the temporal and spatial variability in the settlement of $A$. antipodum and $A$. cincta and investigate the effect of adult density on settlement rates. In an attempt to avoid competition it is potentially more beneficial to settle in less quality habitat below the adult population than within densely populated adult habitat. To examine the potential tradeoff between settling within or adjacent to the adult population, some of the settlement pads will be placed within the adult population while others will be lower on the shore below adult populations. Examining the composition of other species collected on the settlement pads as well as the amount of algae and sand will help determine if any of these ecological or environmental factors from settlement pads significantly influence Austrolittorina settlement.

\section{$\underline{\text { Fecundity study aims }}$}

Investigating the fecundity of these species will be used to assess the amount of larval production, sex ratios and demographic distributions, estimate effective population sizes, and will aid in interpreting the movement of individuals. In particular the fecundity of individuals from the low and high shore will be compared, to determine if there are differences in fecundity due to shore height, and examine the possibility of behavioural isolation leading to separate reproductive populations on one shore. 


\section{Movement study aims}

The extent of each species' mobility will be examined for three size classes of snails to determine if movement varies due to species or size. Transplantation and translocations will reveal if either species or particular individuals prefer a certain shore height, and if individuals will return to their shore level of origin. The cumulative distance traveled will provide an indication of adults ability to disperse, and if movement patterns signify behaviours that could restrict gene flow. 


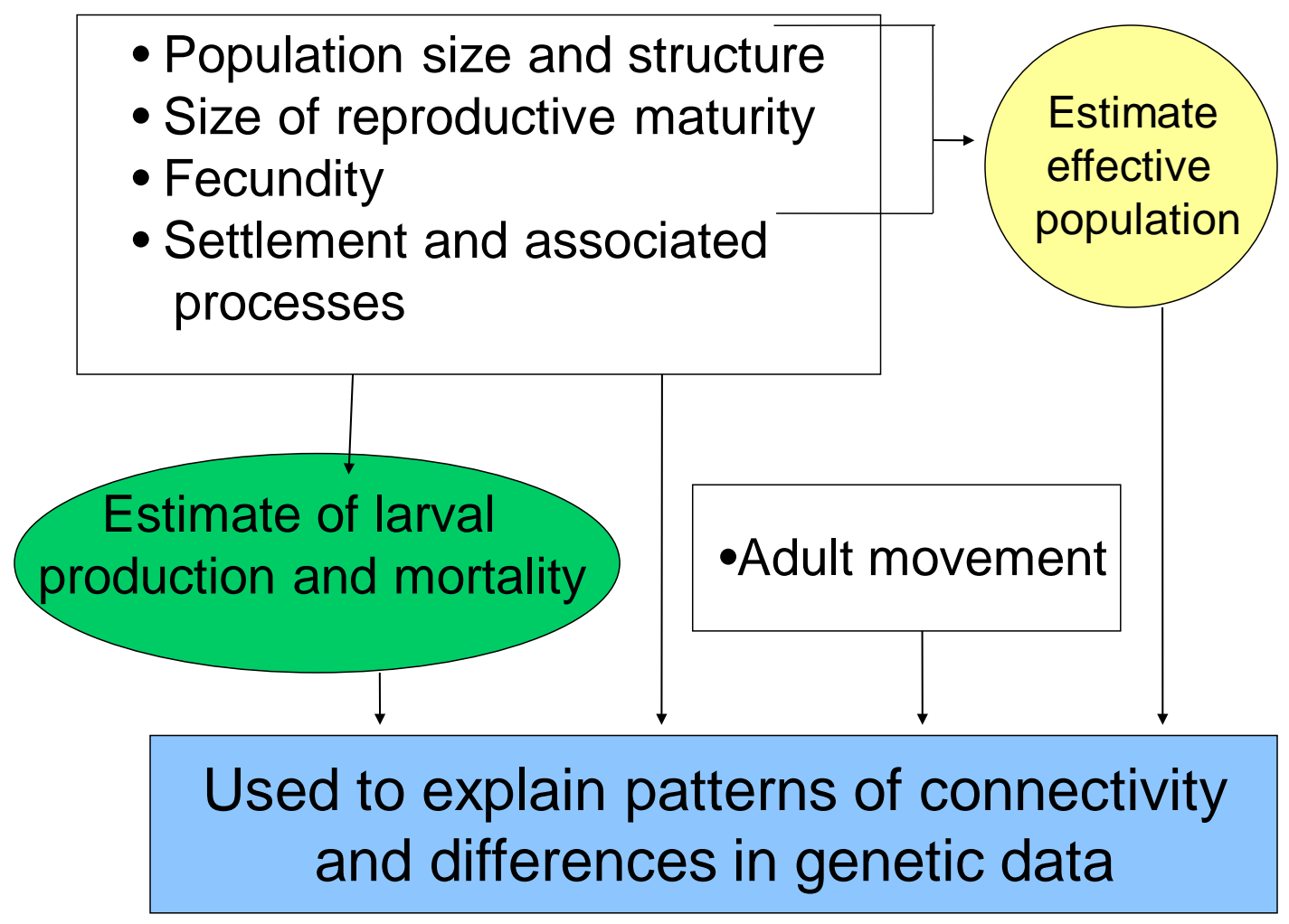

Figure 1. Flow diagram of components of this thesis (contained in white boxes), illustrating how they are integrated and the associated aims (contained in colored boxes). 


\subsection{Population size and structure introduction}

In ecological studies abundance and population structure data can be used to identify factors influencing distribution patterns and illuminate aspects of a species' ecology. Population size and structure studies provide information on the number of individuals in population, their size and potentially demographic distributions, and can identify any differences in habitat use. In this section I examined different characteristics of two Austrolittorina species present along the Island Bay coastline including abundance, spatial distribution, habitat use and potential habitat partitioning, shore level distributions, and behavioural differences.

The relative abundance, spatial variability, and shore level distribution of each species is potentially linked to diet, habitat use, behavioural differences, reproductive success, and larval supply (Vermeij, 1972; Erlandsson et al., 1999). While the diet and geographic distribution of these species has been previously studied, little work has focused on potential habitat partitioning, any differences in sizes in relation to exposure gradients, and differences in the behaviour of these species (Batham, 1958; Morton and Miller, 1968; Morton, 1975). Vertical transects conducted at three sites from February - June 2008 were used to identify the factors influencing the distributions of these species. These surveys will help shed light on how these two species are able to live sympatrically and if habitat partitioning is occurring. Specifically this study of Island Bay populations aims to determine: population size estimates for each species, differences in distribution patterns, and differences in pairing (pairs are defined as two individuals in which one was on top of the other in a position that would indicate possible copulation) and aggregating behaviours.

Quantifying each species’ abundance at numerous sites might reveal differences in habitat use, shore height preference, and help indentify unfavorable habitat conditions which 
may help explain lower recruitment, fecundity, and movement at certain sites. Habitat variability among the sites and shore heights might identify the factors affecting the abundance of these species and slight disparities in their habitat use. In Kawerua, New Zealand A. antipodum was found at sheltered boulder sites as well as at exposed sites, while A. cincta was only found at exposed sites (Hayward, 1987). These species may be segregating themselves along the shore, either by species, size, or both. Littorinids living in the same environment have been known to form distinct distribution patterns in the absence of physical barriers (Wilding et al., 2001). These distributions include separating themselves by any number of ways including: species occupying different areas of the shore (i.e. one species found on the low shore and one found on the high shore), creating shore level shell size gradients, developing different behavioural morphs within a species, evolving unique ecotypes, and demonstrating reproductive isolation via behavioural isolation (Vermeij, 1972; Erlandsson et al., 1999; Rochette et al., 2003; Takada, 2003). Austrolittorina living on the Island Bay coast are potentially utilizing different microhabitats, shore height and vertical gradients, and distinctive behaviours to minimize intra- and inter-specific competition. The basic population information gained by these surveys will be used as a framework to understand patterns found in concurrent studies on these species settlement, fecundity, and movement, by providing population size estimates, the relative abundance of species and sizes along the shore, and any correlations with environmental conditions. 


\section{$\underline{\text { Population study aims }}$}

- Estimate population size and shoreline distribution

- Uncover potential differences between species habitat use, size

distributions, and behaviour (i.e. the number of solo and grouped snails)

- Establish a baseline for these species populations within the newly designated Tapaturanga Marine Reserve 


\subsection{Settlement introduction}

Many benthic marine species have pelagic larvae which will metamorphosis from a planktonic life form to benthic form, where it will seek out suitable adult habitat. Species with planktonic larvae may have small recruitment events (in terms of numbers) in some years and then experience sporadic larger inundations (Strathmann, 1985). A large influx of recruits, or lack thereof, can have important and lasting effects on the local population and overall community structure. Determining settlement rates of A. antipodum and A. cincta is needed, and as Cresse (1988) points out there is limited information available on the microhabitats chosen by these species and the processes that affect recently settled New Zealand molluscs. Populations experiencing years of low recruitment coupled with high mortality and predation can lead to negative allee effects on reproductive behaviour, exacerbating the problem (Stoner and Ray-Culp, 2000).

Littorinids and other intertidal gastropods can affect local community structure through direct predation on algal species and competition with other benthic invertebrates, and variation in the recruitment of these species can alter the dynamic equilibrium within these communities (Underwood, 1978; Cresse, 1988; Underwood et. al 2008). Studies on the settlement rates of species contribute to the overall understanding of ecosystem processes (by revealing intra- and interspecific interactions affecting populations), increase the understanding of families and species, and can aid in understanding factors affecting settlement processes and population connectivity; all of which may have impacts on marine conservation and reserve design (Hastings and Harrison, 1994; Stathmann et al., 2002;

Warner and Cowen, 2002). 
Marine ecosystem processes and function are dynamic making them difficult to accurately model (Palumbi, 2003). Ecological studies on specific elements of marine systems aid in developing a more comprehensive knowledge, more precise models, and improved management of the marine environment (Crowe and Underwood, 1999). The key to obtaining the information to create better models are obtained by studies of species within these environments, their ecology and their interactions with other species. In order to effectively protect the marine environment we must define the roles a species plays within their environment and this can only be achieved by understanding the basic ecology of each species (Bohonak, 1999). This study will contribute to the overall understanding of $A$. antipodum and A. cincta's ecology by defining the settlement season, the influence of adult density, and general ecological and environmental factors which might affect the settlement of these species.

Insights into how larval behaviours, community composition, environmental conditions, and adult populations influence settlement are all necessary to fully comprehend the role larval dispersal plays in population connectivity (Stathmann et al., 2002; Warner and Cowen, 2002). Recent research indicates larvae are not always merely passive particles, but can actively navigate to settle in preferred habitats following a variety of environmental, biotic, and conspecific cues (DiBacco and Levin, 2000; Thorrold et. al 2002; Zecherl, 2005). As the larvae of more and more species are shown to be actively determining the location of their settlement site there is a growing interest in determining what sites they are selecting and what is guiding them to these sites.

Struthsaker and Costlow (1968) proposed that the most important factor in larval settlement is the availability of suitable habitat for settlement. Previous research on littorinids 
suggests larvae avoid settling into areas of high adult density or settle below (lower on the shore) the adult population, as a way of resource partitioning between cohorts, in order to avoid overexploitation of resources (Reid and Williams, 2004 ). Juveniles may settle in unsuitable areas or in less favorable habitats for adults, such as within the barnacle zone or on less populated areas of the shoreline. Austrolittorina antipodum adults have been shown to aggregate in more favorable microhabitats, such as cracks and crevices, with higher densities of snails indicating higher quality habitat (Foster, 1966). This suggests it would be advantageous for recruiting A. antipodum to settle into or adjacent to areas with high adult density, where they will be within or close to high quality habitat. The question, therefore is whether it is more beneficial for recruits to settle in areas of quality habitat where there are higher densities of adults and competition for resources, to settle in areas of lower quality habitat with less adult competition, or adjacent to the preferred habitat already occupied by adults? Austrolittorina populations with high densities of adults may not only indicate higher habitat quality, but may also provide stronger conspecific cues for settling recruits. Chemical and olfactory cues from a variety of sources, including conspecific adults, have been documented as cues that guide larvae to suitable settlement areas, inducing behavioural responses from these larvae (Gebauer, 2002; Krug and Zimmer, 2004; Santagata, 2004). This study explores the influence of the adult density on the settlement rates of $A$.

antipodum and A. cincta; by deploying settlement pads within and adjacent to adult populations and by performing in situ density manipulations of adults surround the settlement pads. 


\section{Settlement study aims}

- Describe the temporal and spatial variability in the settlement of $A$. antipodum and $A$. cincta along the Island Bay coast

- Examine the potential tradeoff between settling within or adjacent to the adult population

- Perform adult density manipulations around settlement pads

- Determine if ecological or environmental factors from settlement pads reveal any significant influence of Austrolittorina settlement 


\section{$\underline{1.3 \text { Fecundity introduction }}$}

The fecundity and reproductive success of individuals within a population can have important implications on the patterns of dispersal and connectivity by affecting the effective population size, larval production and mortality, and potentially the genetic structure of the population. As Bell (2008) points out, more research is needed to determine the influences of reproductive ecology in structuring populations and their genetics. This chapter examines how $A$. antipodum and A. cincta's fecundities influence their population structure (i.e. sex ratios and demographic distribution) and will aid in the interpretation of genetic studies. Here I investigate the fecundity of $A$. antipodum and A. cincta by dissecting snails to: determine their reproductive status, measure sex ratios, the size of reproductive maturity, demographic distribution, effective population size, and to determine if behavioural isolation could potentially lead to reproductive isolation between snails on the low and high shore.

While both of these species ovipariously produce planktotrophic larvae, there are significantly more A. antipodum than A. cincta in the Island Bay populations surveyed. This is potentially due to the low abundances of $A$. cincta leading to negative allee effects, resulting in less effective reproductive behaviours in mating and spawning, which in turn perpetuate the smaller population sizes (Stoner and Ray Culp, 2000; Wilding et, 2001). The smaller population sizes of $A$. cincta compared to A. antipodum may be a result of skewed sex ratios (skewed sex ratios can make finding a mate difficult or there may be few females present to reproduce), few reproductively active adults, attaining larger sizes before reproducing, or behavioural differences leading to less reproductive success, among other potential factors (i.e. food availability, intra- and interspecific competition, high predation, shorter life spans, etc.). 
Examining the fecundity of snails whose movement has been tracked for 8 months will help reveal any correlation between fecundity and the snails’ movements and how behaviours varied with reproductive classifications. Estimates of fecundity will also help determine the effective population size of these species, which can in turn be used to estimate larvae production by calculating the number of females, the number of offspring per female, and the variance in reproductive success (Schmeller and Merilä, 2007). When coupled with the data from the settlement component of this thesis, these estimates can be used to approximate larval mortality, and if low settlement is linked to low production.

The proportion of reproductively active individuals can have important affects on the behaviour of snails and population structure. In addition to the affects of a skewed sex ratio, the proportion of reproductively active adults can: influence mating behaviour, larval production, the abundances' and spatial distribution of age cohorts, the energy expended in attempts to reproduce (i.e. distance traveled to find a mate), effective population size estimates, and indicate potentially higher quality habitat (Nunney and Elam, 1994). Examining the proportion of five reproductive classes (mature females, females, mature males, males, and juveniles), coupled with settlement rates and population structure data will help determine if differences due demographics or shell size structure these populations, and potentially how other factors (such as movement) interact to shape these species populations.

The ratio of females to males in a population has potential implications on sexual selection, the probability of encountering a mate and mating success, the behaviour of snails, and potential influences on genetic diversity (Mäkinen et al., 2007). If there are less males in the population females may not have the luxury of being selective in mate choice (or vica versa), potentially reducing the fitness of offspring. Several species of Littorinid have unique 
ecotypes which display assortative mating, with individuals of the same ecotype choosing to mate with one another over individuals from other ecotypes (Erlandsson et al., 1999; Hollander et al., 2005). If the sex ratio is skewed, finding a mate could be more difficult. Individuals could waste time following the trails of and attempting to mate with the wrong sex, resulting in wasted energy and reducing opportunities for successful mating (Ito and Wada, 2006). Snails may have to travel greater distances, venture into poorer quality habitat or areas of higher predation in search of mates, as seen in other gastropods and some species of Littorinids (Rochette et al., 2001; Koch et al., 2007). A lack of available mates also has the potential to influence genetic diversity with fewer individuals contributing to the gene pool there and an increased probability of a homogeneous gene pool (Stoner and Ray-Culp; 2000).

Reaching sexual maturity and being able to reproduce is one of the requirements for an animal to be considered part of the effective population (Wright, 1938; Schmeller and Merilä, 2007). This study will determine the approximate size at which sexual maturity occurs for each species. The lower population size of $A$. cincta compared to A. antipodum may be due to A. cincta reaching sexual maturity later in life, potentially leading to a smaller effective population size and less offspring produced. The development of reproductive organs may vary with shore height as the resources between these areas vary, and therefore differences between the shore heights will be examined.

Spatial variability in fecundity will help determine differences between the shore heights which are influencing the reproductive status of these species. If differences are found in the size where reproductive maturity is reached for snails at different shore heights, then the distribution of resources to somatic or gonadal growth may vary with shore height, which has been found to occur in other species of the Littorinidae family (Rochette et al., 
2000). Transplantation and translocation experiments, moving tagged individuals between the low and high shores (described in more detail in sections 2.0 and 2.4), should reveal any shore height preferences based on reproductive classification or if there is a potential for distinct reproductive populations on the same shore (Wilding et al.,2001). Examining the reproductive status of snails whose movement has been recorded in the field will help uncover how the behaviours of the different reproductive classes vary. These behaviours may illuminate the potential causes of different population structures and demographics between A. antipodum and A. cincta if found. Dissections of tagged snails will help determine if there behavioural isolation is potentially occurring between the shore levels, and may also reveal resource partitioning between cohorts, movements of reproductively mature adults, and possible seasonal changes in movement and behaviours. Understanding how fecundity varies within and between these species will aid in interpretation of population, settlement, and movement data, as well as estimating the effective populations and deciphering the factors sculpting these populations.

\section{Fecundity study aims}

- Assess each species fecundity, larval production, sex ratios and demographic distributions

- Compare fecundity along low and high shore to investigate differences in reproduction and possibility of behavioural isolation

- Estimate effective population sizes 


\section{$\underline{1.4 \text { Movement introduction }}$}

Estimating the mobility of a species can provide insight into its connectivity. Any differences in the movements of A. antipodum and A. cincta may uncover distinctive patterns of habitat use and behaviour. Littorinids with pelagic larvae can have dispersal rates on the order of thousands of kilometers, while adult movement is generally on scales of meters (Hamilton, 1978; Gillanders et al., 2003). Nevertheless, population connectivity can still be maintained or restricted by the movements of adults facilitating or inhibiting the exchange of genes, or by rafting. Littorinids have been known to maintain their distribution along a specific shore height, within certain environmental conditions and micro-habitats, evolve into distinct morphs and ecotypes, and have separate reproductive populations on the same shore (Johannesson et al., 1995; Williams, 1995; Hollander et al., 2005). Thus, if adults on the same shore only reproduce with certain individuals from a certain shore height, gene pools that are distinctively different maybe maintained on the same shore, potentially resulting in incipient speciation. To determine if the distribution of A. antipodum and A. cincta are maintained by their behaviour and the potential of adults to maintain separate breeding populations, transplant and translocation experiments were performed. Movements' specific to certain environmental conditions or times of the year may indicate the likelihood of these species maintaining or restricting population connectivity through adult movement (i.e. low shore individuals staying on the low shore could limit the extent to which low and high shore individuals would mate, or potentially maintain connectivity through seasonal migrations related to breeding where snails from all shore levels aggregate in one area).

The potential of adult movement to connect Austrolittorina populations was assessed by following the movements of 720 snails (360 A. antipodum and 360 A. cincta) for a period 
of 8 months. This chapter will focus on the movements of 130 snails found on the final movement survey and later dissected. This tagging study was conducted to determine the movement rates and behavioural differences between these species in relation to: temporal and spatial variation, reproductive classification, and transplant treatment. Investigating how these factors affect three aspects of snail movement: the final distance from the release site, progress towards home (original shore height), and the cumulative distance traveled. Determining the movement rates of the different reproductive classes will help identify factors that are important to each of the classes in eliciting behavioural responses that influence snail movement. For example, males that have reached maturity may move more in search of mates, while immature males may move less.

Experimental transplantation and translocation experiments will help determine if the movements of individuals have the potential to influence population and genetic structure. If distinct demographic and genetic structure is found between the species and populations on the same shore, then snails may be behaviourally or physiologically conditioned to live at a specific shore height within certain microhabitats. Behavioural and physiological factors have been found to influence the movement of other littorinids, with snails' movements being directed by: the search for mates, competition avoidance, ontogenic migrations, escape from predation, the search for refuge, enzyme function, desiccation, hunger, spawning, and thermal regulation (Grendon, 1977; Hobday, 1995; Boulding and Harper, 1998; Cotton et al., 2004; Lee and Lim, 2009). The extent of movement by the different transplant treatments and the timing of bursts in movement if found, will also help indicate the impact of environmental conditions on movements and if there are large seasonal migrations. The variability in the final distance from the release site, progress towards home, and cumulative distance traveled 
between different transplant treatments and reproductive classifications will reveal if distinctive preferences for a particular shore height exists.

This movement study will help further understand the behaviours of these species and identify potential causes of variability in the movement of A. antipodum and A. cincta if found. If adult movement proves to be limited then there would be an increased reliance on larvae for dispersal. On the other hand, if adults are found to move large distances this may be important for population connectivity.

\section{$\underline{\text { Movement study aims }}$}

- Quantify the mobility of each species and their three size classes

- Perform transplantation and translocations experiments to test individuals shore preferences, determine if distribution is behaviourally maintained, and examine potential of behavioural isolation

- Cumulative distance traveled will provide an indication of adults ability to disperse, and if movement patterns signify behaviours that could restrict or enhance gene flow 


\section{$\underline{2.0 \text { Methods }}$}

\section{$\underline{\text { Study Area }}$}

All field research was conducted along the Southern Coast of Wellington, New Zealand. The three main sites were each separated by a bay and contained three replicates (a, b, c) (Figure 2). Site 1 is located to the north of the Island Bay aquarium, site 2 is in front of the Victoria University Marine Lab, and site 3 is on the far west tip of Owhiro Bay. These sites were a minimum of distance of $1 \mathrm{~km}$ apart with replicates separated by at least $75 \mathrm{~m}$. These three main sites are similar in habitat, rock type, and slope.

At all sites both species are found from the top of the littoral fringe to the upper portion of the barnacle zone (EHWST to MTL), with A. cincta occupying a wider range of habitat including areas further down the shore and into the kelp (Durvillea) zone (Reid, 2002). The upper shore area is predominately barren rock with a patchy distribution of lichens and vascular plants. The lower shore is more variable, containing numerous species of turf and macro algae, barnacles and other invertebrates, with closer proximity to the ocean and oncoming surf. The mid shore zone sampled in population surveys is a transitional area between the upper and lower shore. This area is submerged by incoming waves more frequently than the upper shore, although the algal cover is less abundant than the low shore. 


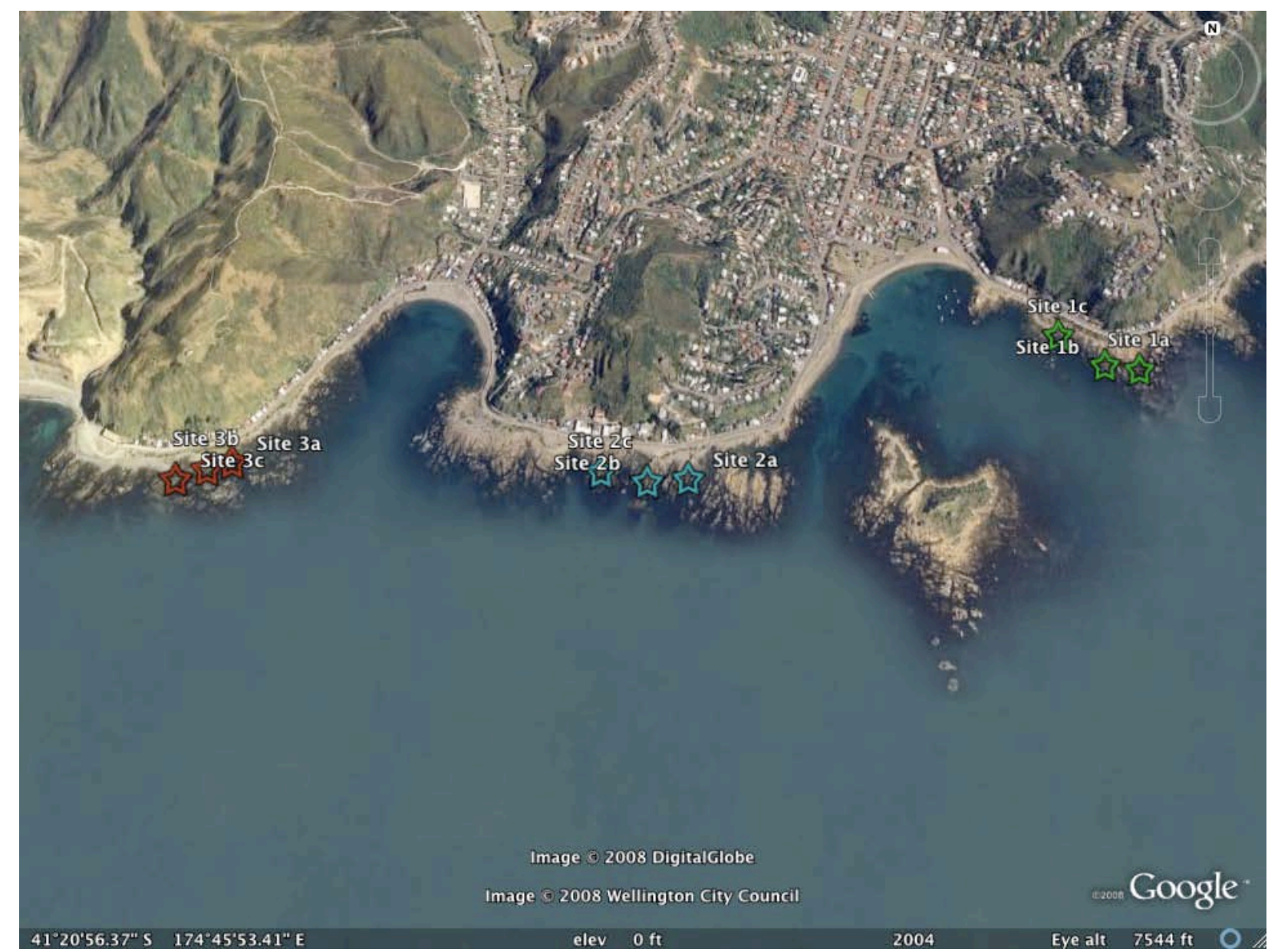

Figure 2. Map of study sites and replicates along the Island Bay coastline, New Zealand. Green stars indicate site one replicates, blue stars indicate site 2 replicates, and red stars indicate site 3 replicates.

\section{$\underline{\text { Snail tagqing }}$}

A pilot tagging study was conducted by tagging 10 snails with one of three methods:

fingernail polish, etched in numbers, or a glued on bee tag (using Superglue (c) and beeworks $₫$ queen bee tags) (Byers and Mitton, 1981). The last method was used for the remainder of the study as it proved to have the highest recovery rate, was least detrimental to the snail, most time efficient, and lasted the longest. Snails were collected from a variety of microhabitats (cracks, overhangs, macro and microalgae, lichen, vertical to horizontal slopes, etc.) along the low and high shore, and taken to the to the laboratory to be tagged. Each snail 
was tagged with a colored, individually numbered tag. It was not possible to record the initial position of each snail. All snails were assigned a home site which was the center coordinates of the release site on the shore level which they were collected from (i.e. the home site for snails collected on the low shore was the defined set of coordinates from the low shore release site). To minimize handling effects snails were tagged within two days of collection and returned to the field within three days. Previous research has show negligible effects from handling if snails are tagged and returned to the shore within a few days (Chapman, 1986; Crowe and Underwood, 1999).

Approximately sixty snails of each species were collected from the low and high shore at each site, with 20 snails representing the three size classes; half of these snails were used as controls and the other half for transplant experimentation (Chapman, 2000). To ensure snails were randomly assigned a transplant treatment snails tagged with an even number were used as controls and odd numbers were transplants. It was not feasible to return individual snails to the exact spot they were collected from and as such control snails were translocated individuals (moved from one area to another area along the same shore height) while treatment snails were transplanted (moved from one shore height to another). Chapman (1986) points out the need to use transplanted and translocated individuals so that the effect of change of habitat is not confounded by the effect of moving animals into a novel area.

Due to the different maximum sizes of each species two different size class scales were developed. Austrolittorina antipodum size classes were as follows: small= $2.5-3.5 \mathrm{~mm}$, medium $=4-5.5 \mathrm{~mm}$, large $=6+\mathrm{mm}$. Austrolittorina cincta size classes were as follows: small= $3-5 \mathrm{~mm}$, medium $=6-9 \mathrm{~mm}$, large $=10+\mathrm{mm}$. A buffer of $1 \mathrm{~mm}$ between size classes was used to ensure snails being compared were adequately disparate and that if minor errors were made in 
field measurements of .25-.5mm snails would still fall into the appropriate size class. Koch et al. (2007) point out the need for size classes to be distinct and using a continuous scale allows for similar sized snails (i.e. small $=<4.5 \mathrm{~mm}$, large $=>4.5 \mathrm{~mm}$ ) to be placed in different classes . This can result in snails from the same cohort being compared to one another instead of pooled and used in comparison with other cohorts, providing inaccurate results.

Research on the family Littorinidae has shown some ecotypes and species inhabiting the same shore will partition themselves on the different shore heights and in some cases exhibit behavioural isolation (Erlandsson et al., 1999; Fernández et al., 2005; Lee and Lim, 2009). To test the hypothesis that $A$. antipodum and $A$. cincta maintain differences in abundance along the shore height through their movements, transplant experiments were preformed. The control snails were re-released at their shore level of origin while the transplant snails were re-released either higher or lower on the shore (Grendon, 1977; Gutierrez, 1988; Rochette et al., 2000; Takada, 2003; Lee and Lim, 2009). Snails from the low shore and high shore were tagged using different colors to easily identify snails and reduce sampling error. The distance snails were transplanted between shore heights varied between sites, reflecting the distance between the low and high shore environmental conditions. At sites 1 and 3 transplanted snails were moved a distance of $15 \mathrm{~m}$ up or down the shore, and a distance of $10 \mathrm{~m}$ at site 2 . 


\section{$\underline{\text { 2.1 Population size and structure methods }}$}

Vertical transects extending from the lower shore up the shore, were used to census $A$. antipodum and A. cincta populations. Transects were $25 \mathrm{~m}$ long by $1 \mathrm{~m}$ wide. This is a popular method for determining the population size and structure of intertidal organisms (see Vermeij, 1972; Grendon, 1977; McGrath, 1997; DeMagalhães, 1998; Chapman, 2000). Various types of data can be collected using this method including: an estimation of population size, vertical stratification of size and/or age classes of species, differences in habitat utilization, and intra- and interspecific associations. A series of five population surveys were conducted from the end of December 2008 to July 2009. The December surveys only included a subset of the sites (1b, 2a-c, and 3b) with the remainder of the surveys including all sites (1a-c, 2a-c, 3a-c). Surveys were conducted in February, March, May, and July approximately 1.5-2 months apart. Due to the limited number of sites in December only the four surveys from February on were analysized.

Three distances from the ocean were surveyed along each transect (low, mid, and high shores) using three $10 \mathrm{~cm}^{2}$ quadrats randomly placed within the $1 \mathrm{~m}$ width of a transect. The distances sampled from the ocean remained consistent between transects and were chosen to represent the different inter-tidal zones, i.e. the barnacle zone and sublittoral fringe. Transects began approximately $5 \mathrm{~m}$ from the MTL and were run perpendicular to the shoreline. Within each quadrat all individuals of both species were collected, placed in a labeled plastic bag and associations with other individuals and habitats were recorded. Associations recorded included: the number of solo snails, the number of pairs (two snails with one on top of the other in a position that would indicate potential copulation), the number of groups or 
aggregations (three or more individuals), and the number of mixed groups or aggregations (containing both species of snails).

Habitat associations recorded included: measurement of the slope of each quadrat, a qualitative estimate of rugosity, as well as, estimating the percent cover of lichen and algae. The slope of each quadrat was measured using a hand held level (Craftsman (C)). Qualitative measurements of rugosity were made by ranking rugosity on the following coarse scale: 1(low)- smooth rock with no cracks, crevices or projections, 2 ( low/medium)- relatively smooth rock with 1 crack, crevice, or projection, 3 (medium)-relatively smooth rock with a few cracks, crevices or projections, 4 (medium/high)- irregular rock with deeper cracks and crevices, and/or large projections, 5 (high)- very irregular rock with numerous cracks, deep crevices, and/or numerous, large projections. Measurements of lichen and algae were also made by estimating the percent cover within each quadrat (Underwood et al., 2008).

Once snails were collected they were aligned, photographed and measured using the Image J photo analysis program (Image J version 1.38, Schmidt and Scheibling, 2007). The length (or height) and width of each snail was measured to have multiple estimates of size and detect any obvious morphological differences (i.e. wider shell sizes along the low shore). No such obvious morphological differences were found. Length is commonly used as the primary measurement of size in littorinid studies and in established distribution patterns for intertidal gastropods, and will be the unit of measurement used to indicate the size of individuals for this and other chapters (Vermeij, 1972; Grendon, 1977; Hughes, 1995). Upon completion of the quadrat snails were returned to their site and shore level of origin. 


\section{$\underline{2.2 \text { Settlement methods }}$}

Settlement was investigated by deploying artificial substrates. In addition adult density manipulations were preformed on the natural substrates surrounding the settlement plates. The settlement plates used were made of mesh scouring pads attached directly to the rock, and will be referred to as settlement pads or pads from here on. Below each of the population survey sites (see map and study area section 2.0), 6 settlement pads were deployed, for a total of 54 pads per survey round. Preliminary population surveys revealed a higher proportion of small individuals along the low shore for both species. Reid and Williams (2004) noted juveniles of these species occur below adults and within the barnacle zone. Therefore, settlement pads were placed along the low shore, within the zone of the highest abundance of small snails and among barnacles (Chamaesipho spp.). To examine the extent of settlement within and adjacent to adult populations, settlement pads at 5 sites were within the adult population and below adults (lower on the shore) within the barnacle zone at 4 sites (sites within the adult population include sites 1b, 2a-2c, and 3b, sites below the adult population include sites 1a, 1c, 3a, and 3c).

Prior to deploying settlement pads a pilot study was conducted to determine the most suitable material for the construction of the settlement plates and the appropriate deployment length. Materials tested included: flat square pieces of PVC plastic (textured and smooth), pieces of terracotta ceramic pads, fragments of stone tiles, and square pieces of scouring pads. These materials were bolted to the rock substrate at two sites, sites $1 \mathrm{a}$ and $2 \mathrm{~b}$. The deployment duration test included testing four sampling regimes: daily, weekly, bi-weekly 
and monthly. This pilot study indicated the optimal material to be the scouring pads. This material is durable, provides structural complexity for the small recruiting snails, is flexible enough to endure wave impact, and can be thoroughly inspected to ensure the removal of all individuals. The most effective sampling regime to be biweekly deployments of the settlement pads, as deployment for shorter time frames often yield little to no snails, and deployments for longer limited the precision of estimating peak times of settlement.

The settlement pads were 50 x 50 mm square scouring pads (Sergio et al. 2008; McCulloch and Shanks, 2003). Each settlement pad was bolted to the rock with a single bolt through the middle of the pad. While drilling holes to attach the settlement pads to the rock substrate, large pieces of rock would sometimes breakaway, making it impossible to deploy pads in a uniform pattern; however, the 6 holes drilled at each site were on rock faces oriented in the same direction. Settlement pads were oriented to face land so that out going waves would push pads against the rock and be less likely to rip them away. The approximate direction of each sites settlement pads are: NW for site 1a, site 1b N, site 1c NE, site 2a NE, site $2 \mathrm{~b}$ and 2c N, site $3 \mathrm{a} \mathrm{N}$, and NE for sites $3 \mathrm{~b}$ and 3c. At each site settlement pads were placed on average approximately $1 \mathrm{~m}$ apart, although the distance between pads varied from $0.6 \mathrm{~m}-3.2 \mathrm{~m}$ between pads at one site. All settlement pads where placed within $2 \mathrm{~m}$ of the water at low tide. At sites 1b, 2a-2c, and 3b pads were deployed in areas among snails, and at sites 1a, 1c, 3a, and 3c pads were deployed below the Austrolittorina in the area, within the barnacle zone. At sites where the settlement pads were deployed below the adult population, the distance from the settlement pads center bolt to the nearest adult was recorded when pads were deployed and collected. This sampling strategy was used to capture any recruiting snails 
that may be settling below the adult population as other species of Littorinids are known to recruit within the barnacle zone (DeMagalhaes, 1998).

Pilkington (1971) found Austrolittorina veligers to be abundant in plankton hauls between December and June. For this reason, settlement pads were only deployed from December to June for at total of 10 sampling rounds. Between December and January only 5 sites were established and sampled, from February on settlement pads were deployed at all 9 sites. The pads were collected bimonthly from December 2007-March 2008. Settlement pads were deployed for the entire months of April to June, due to the severity and increasing frequencies of winter storms and swell. As a result of the differences in deployment time of the pads, and difference in when sites were established, two subsets of the data were created. One data set included all data from the end of January on, when all of the sites were established, excluding the first two sampling rounds as only 5 of the 9 sites were established during these rounds. The second data set only included the results from the end of January to through the end of March when all pads were deployed for an equal length of time.

Upon collection pads were taken to the lab for processing. A $200 \mu \mathrm{m}$ sieve was used to collect all of the snails rinsed out of the scouring pads. Under running water all of the material collected by the settlement pads was flushed out. Each pad was separated into three or more layers, and each layer was inspected under a microscope to ensure all snails and material was removed. The contents of each settlement pad were inspected under a dissecting microscope and all Austrolittorina found were counted and collected. As noted by Pilkington (1971) these species were not able to be distinguished at settlement sizes. Other data was recorded to determine the effects of biological community and the environmental conditions on settlement rates were collected from each pad. This data included: an estimate of the 
amount of sand and algae, and presences/absence data of other snail species, barnacle cypid larvae, bivalves (typically cockles and mussels), crustaceans and worms. A grid of $1 \mathrm{x} 1 \mathrm{~cm}$ cells was drawn on the bottom of a petri dish with permanent marker was used to examine the contents of settlement pads, and to make estimates of abundance. Estimates of sand and algae were qualitative rankings on a scale of $0-3$, based on the number of grid cells containing sand or algae. Definitions of ranking are as follows: 0- none present, 1- little present (i.e. sand or algae present in $1 / 3$ of the cells), 2 - medium amounts (i.e. sand or algae present in 1/3-2/3 of the cells), and 3-large amounts (i.e. sand or algae present in $>2 / 3$ of the cells). One other species of gastropod was also abundant, and the number of this species of Eatoniella present on each pad was also recorded to determine if the suspected negative correlation was found. This species of Eatoniella was conspicuously absent when larger numbers of Austrolittorina were found on pads and present in larger numbers when Austrolittorina were not present. This apparent pattern began to emerge during the pilot study and counts of these species were incorporated into the methods to evaluate the potential correlation between the settlement of these species.

To examine the influence of adult density on the settlement of Austrolittorina in situ adult density manipulations were performed, and settlement rates of each species under various adult population densities were determined. Individuals were removed from $20 \mathrm{~cm} \mathrm{x}$ $20 \mathrm{~cm}$ quadrats centered around each settlement pad to observe the effect of decreasing density on settlement. Manipulations at all sites consisted of three treatments: 1) removing all of the individuals within the quadrat centered around the settlement plate, 2-removing every other individual within the quadrat effectively removing half of the snails present, and 3-a control in which the density was not altered, all snails were counted but not removed. At each 
site two settlement pads were assigned to each of the density manipulation treatments (complete removal and removal of half of the snails) and two were controls (no snails removed). In order to maintain treatments snails were cleared from the area around the pads every 3-5 days. For the $2^{\text {nd }}$ density treatment after the initial manipulation the number of snails was counted and subsequent clearing events removed every other snail until density was approximately the same as previously recorded values. 


\section{$\underline{2.3 \text { Fecundity }}$}

\subsubsection{Collection, preservation, and dissection}

Austrolittorina antipodum and A. cincta were collected from the low and high intertidal zones of all sites along the Wellington coast (figure 2). New Zealand Austrolittorinids are reported to spawn from November-March, based on these findings tagged snails were collected for dissection in late December during the middle of the spawning season (Pilkington, 1971). Previously tagged snails were collect on December 20, 2008 and dissected after eight months in the field. All snail dissections were conducted using a Stemi SV8 dissecting microscope manufactured by Zeiss.

The shell of the snail was cracked using a small vice, the individual was removed, placed under a dissecting microscope, sexed, and assigned to a reproductive class. Sex determination in Littorinids is primarily based on the presence or absence of a penis for males, and the presence of eggs or a well developed pallial oviduct and/or accessory glands in females, and individuals lacking either of these organs were considered immature juveniles (Struthsaker, 1966; Hughes and Roberts, 1980; Johannesson et al., 1995; Takada, 2003).

Dissected snails were classified based on their sex and reproductive status into one of five categories: 1) mature male, 2) male, 3) mature female, 4) female, 5) juvenile. These classes were defined using criteria established by Rochette et al (2003) where the distinction between immature and mature adults was based on the developmental stage (i.e. size and swelling) of the penis and seminal vesicle for males and the pallial oviduct for females, and juveniles had not develop gender-specific organs.

The sex ratio was examined to determine if either species deviated from a 1:1 sex ratio (Takada, 2003). The sex ratios and proportion of mature females to females, mature males to 
males, and female to males and juveniles were calculated for each site and shore size class (Appendix 5). Snails across a range of sizes were dissected to determine any differences in the size of reproductive maturity between sites and shore heights. Although Reid (2004) notes the mature shell heights of $A$. antipodum to be $5.4-13.7 \mathrm{~mm}$, and $A$. cincta to be $8.9-20.2$ $\mathrm{mm}$, different shore heights were examined to see if there was any variation in the size of reproductive maturity between the low and high shore. Previous research has shown that some species of littorinids show variation in resource allocation for somatic and gonadal growth at different shore heights, and other species have shown behavioural isolation maintaining distinct gene pools on one shore (Erlandsson et al., 1999; Rochette et al., 2000). The tagged snails dissected contained a haphazard sampling of representatives from each of the size classes at each site and transplant treatment; although all size classes were represented sample sizes varied between them as dissected snails were all remaining tagged snails from each site.

\subsubsection{Effective population estimates}

The effective population refers to the proportion of the population that is included in the breeding population, accounting for any skewed sex ratios. Estimates of the effective

population $\left(\mathrm{N}_{\mathrm{e}}\right)$ for each species followed the methods established by Wright (1938). Wright's equation used to account for difference in the number of males $\left(\mathrm{N}_{\mathrm{m}}\right)$ and females $\left(\mathrm{N}_{\mathrm{f}}\right)$ in the effective population is:

$$
N_{e}=\frac{4 N_{m}+N_{f}}{N_{m}+N_{f}}
$$


Wright's complete calculation requires an estimation of fecundity and the number of gametes produced by parents, a calculation of the harmonic mean (an estimation of the mean population size using the results of population surveys), calculation of gene frequencies and life span estimates. Due to the data requirements of these methods a simplified method will be used to estimate the effective population of these species. Sex ratios will be accounted for using Wright's equation, and the harmonic mean for each species will be calculated. The effective population for each species will be extrapolation of Wright's calculation to the harmonic mean of each species. 


\section{$\underline{2.4 \text { Movement methods }}$}

Adult movement was investigated by tracking 130 tagged individuals of both species at three sites, 1a, 2a, and 3b (for locations see figure 2, and tagging procedures are described in the methods section 2.0). Shore level preferences of snails were investigated using reciprocal transfer experiments, transplanting and translocating snails between the low and high shores. Although the movements of 720 tagged snails were recorded, this analysis focuses on the movement of snails which were found on the final sampling event, captured and reproductive classification was successfully determined (methods and definitions of reproductive classification provided in section 2.3). Following this criteria a total of 130 snails were examined.

At the time of initial release, 30 snails of each species, from each shore height were lined up in rows with snails approximately $1 \mathrm{~cm}$ apart facing the same direction, for both low and high shore release sites (assignments for transplant treatments are described in snail tagging procedures section 2.0). The initial positions were measured using linear measurements from two stationary reference bolts at each site. To examine the potential of handling effects on behaviour, the initial measurements of movements along the high shore were sampled at different time intervals. Movement observations were made at the high shore at site 1 one day after release, site 2's high shore 2 days post release, and site 3's high shore 3 days after release and at all sites low shores after 5 days to measure the initial movement rates. These initial movements were taken at different times to not only detect handling effects but to observe if there were any immediate large movements. Research on the Littorina family has shown that different snail species can react differently due to the handling 
effects of tagging (Petraitis, 1982; Chapman, 1986; Crow and Underwood, 1999; Chapman, 1999). For a number of Littorinids there is a lag time of two to four days before handled snails resume normal behaviour with the dislodgment of snails eliciting a stronger behavioural response for some snails (Petraitis, 1982; Crow and Underwood, 1999; Lee and Lim, 2009). Post-release monitoring continued at all sites after 10 days, 1 month, 2 months and 8 months after the initial release in April. Short-term and long-term movements were examined as previous research has shown differences in movement due to the time frame in which measurements were made (Chapman, 2000).

Once tagged individuals were detected during recapture events a measurement from each reference bolt was taken, the direction of travel from the release site was recorded, along with notes pertaining to that individual (i.e. close proximity to water or lichen). If snails had to be picked up to be correctly identified, they were replaced as close as possible to their previous position. In cases where that was not possible (for example a vertical rock face) the distance they were moved from their previous position was recorded. Extra care was taken to search a wide area around the release site to find any far moving individuals, as well as checking in crevices, overhangs, as tagged individuals were sometimes found buried in groups of snails. Upon taking the final measurements of snails recaptured in December they were collected for dissection.

\subsubsection{Movement calculations}

Using triangulation techniques, after Sebastian et al. (2002) the straight length distances traveled between each sampling event was calculated for all recaptured snails. Reference angles for the time of release were calculated using the Law of Cosines $\left(c^{2}=a^{2}+b^{2}-2 a b \cos \right.$ 
C). Distances calculated for movement in ' $\mathrm{X}$ ' and ' $\mathrm{Y}$ ' directions used the Law of Sines ([sin $\mathrm{A} / \mathrm{a}]=[\sin \mathrm{B} / \mathrm{b}]=[\sin \mathrm{C} / \mathrm{c}]$ ), with formulas containing a 'if//then' statement to indicate if the movement was in an up shore (+) or down shore (-). The calculated 'straight-line' distance travelled between transplant and recovery were calculated using the Pythagorean Theorem $\left(a^{2}+b^{2}=c^{2}\right)$. One set of calculations was made for each recapture event and the calculations per snail varied with the number of times periwinkles were recaptured; the complete list of formulas used is listed in appendix 1.

Three primary aspects of movement were investigated: the snail's final distance from the release site (FDFRS), the progress towards home (PTH- defined as the movement back to the shore level snails were collected from, primarily used to assess transplants movement towards or away from their shore level of origin), and the cumulative distance (CD) traveled. An expanded spreadsheet provided by Nicole Phillips from Victoria University of Wellington, was used for all calculations. The final distance from the release site for each snail was calculated to examine the final distance snails were able to travel, indicating the snails' potential to disperse. This calculation was the difference from the initial position at the release site and the distance recorded on their final recapture, which for all snails in this analysis was the final recapture event. The calculation for the final distance from the release site is calculated as:

$$
\text { Final Distance From Release Site }=\sqrt{\left(x_{\text {final }}-x_{\text {initial }}\right)^{2}+\left(y_{\text {final }}-y_{\text {initial }}\right)^{2}}
$$


Where $\mathrm{x}_{\text {final }}$ is the final distance recorded from reference bolt $\mathrm{X}, \mathrm{x}_{\text {initial }}$ is the distance recorded from reference bolt $\mathrm{X}$ after the first recapture event, and $\mathrm{y}_{\text {final }}$ and $\mathrm{y}_{\text {initial }}$ are the final and first distances recorded from reference bolt $\mathrm{Y}$. The 'progress towards home' calculation was used to determine the effect of transplantation on snails, and if snails removed from one shore level and moved to another, would move back towards their original shore level. This calculation will help determine if shore height preferences occur and which factors significantly influence snail movement. Due to the number of snails collected, tagging in the field was not possible and individual's initial position could not be recorded. Instead, the initial positions used were predefined center coordinates for high and low shore release sites. Snails were assigned a coordinate from their shore level of origin, referred to as the snails' home site. Controls were translocated snails and the distance of translocation was not known, introducing an acknowledged source of uncertainty; however, the general trends in the behaviour or transplanted and translocated snails should indicate the importance of occupying a preferred shore height. The calculation for progress towards home:

Progress Towards Home $=$

$$
\sqrt{\left(x_{\text {transplant/translocate }}-x_{\text {home }}\right)^{2}+\left(y_{\text {transplant/translocate }}-y_{\text {home }}\right)^{2}}-\sqrt{\left(x_{\text {final }}-x_{\text {initial }}\right)^{2}+\left(y_{\text {final }}-y_{\text {initial }}\right)^{2}}
$$

The cumulative distance traveled was calculated to examine the potential dispersal abilities of snails, as final distance measurements do not account for total distances traveled. Snails may zigzag across the shore traveling farther distances than the final distance from the release site would indicate. To gain a more accurate understanding of movement capabilities 
the calculation of the cumulative distance traveled was used. The cumulative distance traveled was the sum of each distance traveled per sampling event. The calculation for the distance traveled between sampling events is the same as the final distance from the release site, using the coordinates of the recapture events in the place of the initial and final coordinates from the final distance from release site calculation. This calculation varied with the number of times snails were recaptured. 


\section{$\underline{2.5 \text { Data Analysis }}$}

Ecological studies often yield non-normal data reflecting the variability of natural systems. None of the data collected meet normal distribution requirements and various transformations were attempted to yield normal data (including square root, log, and natural log transformations), however, data remained non-normal. Transformations attempted on data sets included the population survey data, abundance of Austrolittorina settlers and ecological and environmental data collected. Non-parametric Kruskal-Wallis or Mann-Whitney tests were used for all analysis of population abundance and distribution, settlement, fecundity, and movement data to determine which factors significantly influenced the results of these studies. Chi-squared and Pearson's correlation tests were used to examine species associations with sites and categorical data including size classes, reproductive classifications, and environmental and ecological rankings. Data analysis was conducted by the Minitab 14 statistical program. Due to the number of tests conducted, only p-values are listed in the text, the complete results from statistical tests for each study are presented in tables listed in the appendices 2, 4, 6, and 10 .

Population survey data was analyzed using non-parametric Kruskal-Wallis tests comparing the number of each species collected with site, distance from shore, the size of individuals, microhabitat, and associations as the different factors analyzed. The number of Austrolittorina settlers was compared between sampling rounds (the length of time between rounds varied from 2 weeks to one month), sites, plate placement (within and below the adult population), density manipulation treatment, and ecological and environmental parameters. The number of each species within each of the reproductive classes was 
compared among sites, shore heights, size, and transplant treatment using Kruskal-Wallis test. The sex ratios of each species were also compared between the sites and shore heights using chi squared tests. Mann-Whitney and Kruskal-Wallis tests were used to determine how these aspects of movement (FDFRS, PTH, CD) were affected by the following variables: species, site, shore height, reproductive classification, size class, control vs. transplant, transplant treatment (controls and transplants assigned to each shore height), and transplant treatments for each of the reproductive classifications. 


\section{$\underline{3.0 \text { Results }}$}

\subsection{Population size and structure results}

A grand total of 12,988 snails were collected and measured from December 2007 to June 2008 (Figure 3). These snails were collected from 345 out of 369 quadrats, the remaining 24 quadrats (6.5\%) could not be surveyed due to weather constraints. The December surveys were conducted at 5 of the main sites (1b, 2a-c, 3b) with all 45 out of 45 of the quadrats surveyed. This survey had the lowest snail abundance with only 1,427 snails collected, and had the highest number of quadrats without snails (15\%). The remainder of the surveys (Feb. - June) included all 3 sites and all 3 of their replicates (for a total of 9 survey locations) and this subset of the data was analyzed. The February to June surveys yielded a total of 11,561 snails collected from 300 quadrats. During these survey $7.4 \%$ of the quadrats could not be surveyed, which were mainly low shore quadrats. Only 1.5\% (5) quadrats had no snails of either species present. The remainder of analysis will include the results from February to June when all sites and all replicates were established.

Austrolittorina antipodum and A. cincta both showed a Vermeij type 1 distribution, with snail size increasing moving from the low to high shore (Vermeij, 1972). In this type of distribution the shell size of individuals creates a gradient where smaller individuals primarily occupy the low shore, medium sized individuals in the mid shore region and the largest individuals are found predominately on the high shore (see figure 11). Although smaller and larger individuals can be found at the 'uncharacteristic' shore height, this increasing shell size gradient from the low to high shore was the general trend for both species. 


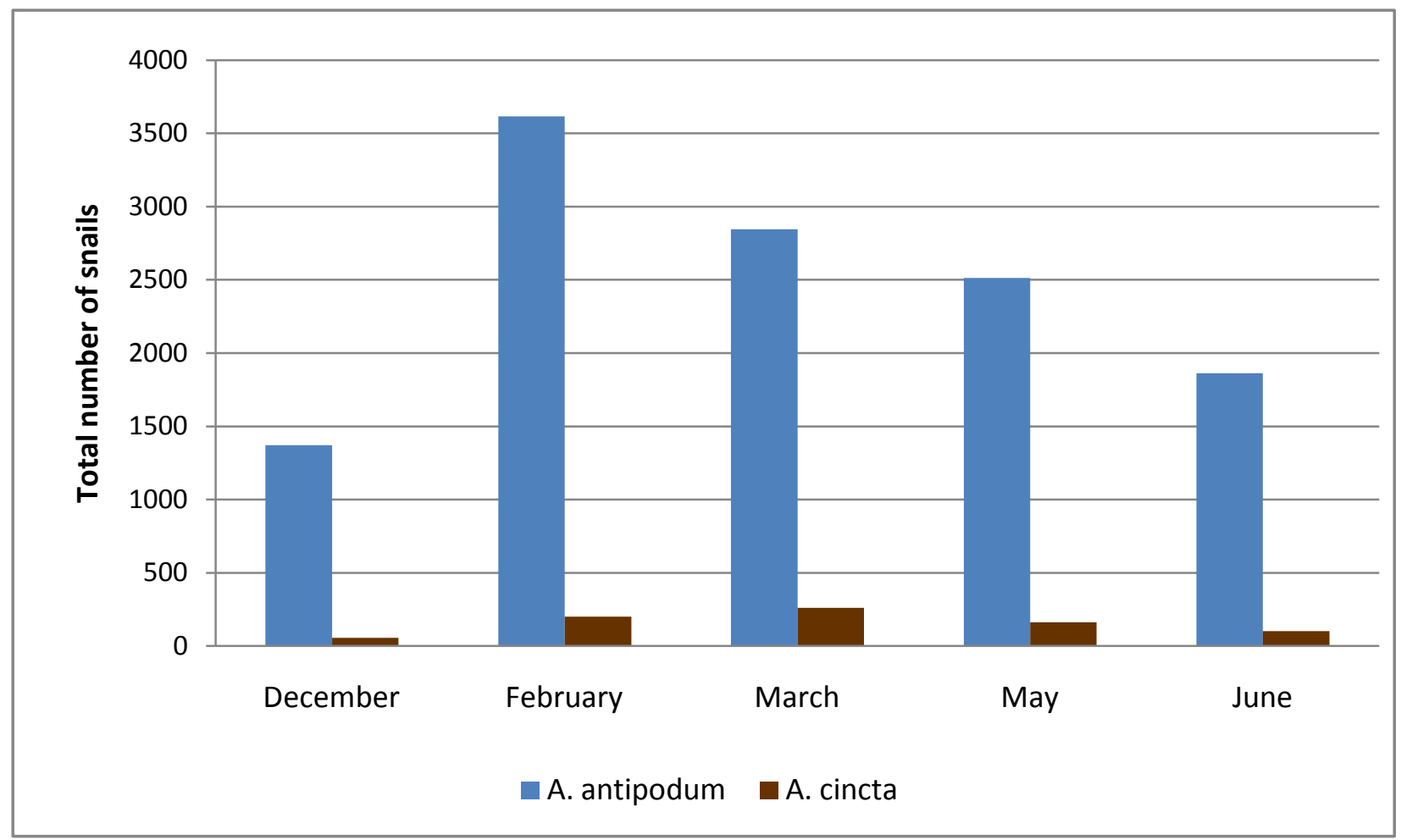

Figure 3. The total number of each species collected from each survey round, December 2008 to June 2009.

\subsubsection{Abundance of both species}

Abundance comparisons are based on the total number of snails per $100 \mathrm{~cm}^{2}$ quadrat within the $1 \mathrm{~m}$ swath of a transect; where individual quadrats were compared at one shore level and other comparisons were between pooled quadrats from the same shore level or site, etc. The overall abundance of $A$. antipodum $(10,838)$ was much higher $A$. cincta $(723)$ with significantly more A. antipodum present $(p<0.001$-complete results for all tests listed in appendix 6). The abundance of $A$. antipodum did not vary significantly between the survey dates $(p=0.284)$, while $A$. cincta were significantly more abundant in March and less abundant in June $(p=0.004)$ (Figure 4). Comparisons of species abundance between the sites showed there were significantly less $A$. cincta at all of the sites, with the least amount found at 
site $2(p=0.002)$. Austrolittorina antipodum was significantly more abundant at site 1 and its lowest abundance was at site 3 , which had the highest abundance of $A$. cincta. In particular A. antipodum were significantly less abundant at site $3 c$ where $A$. cincta was significantly more abundant (Table 1). Austrolittorina cincta was also significantly less abundant than $A$. antipodum at site 2a, with both species being scarce at site $1 \mathrm{~b}$.

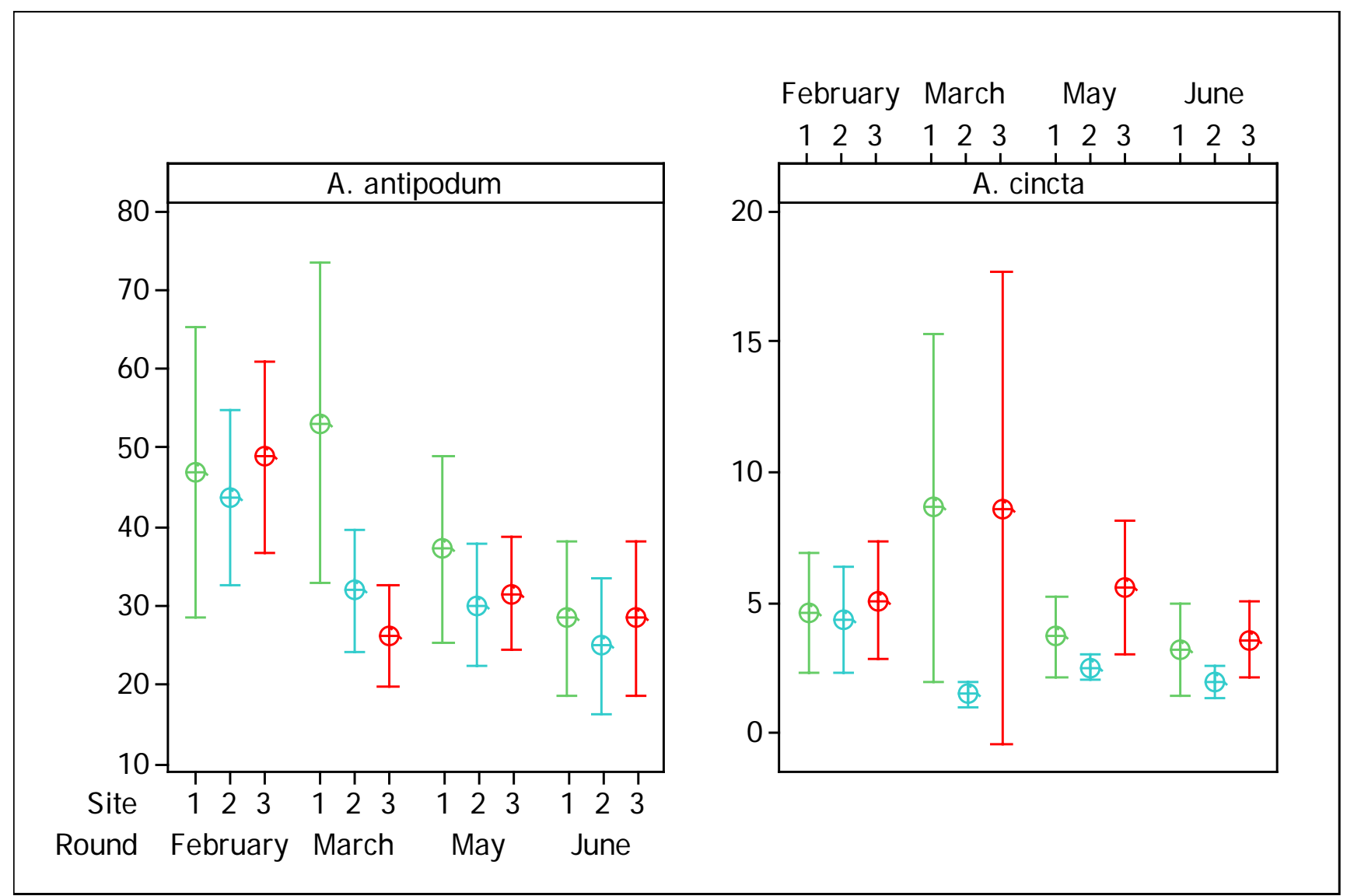

Figure 4. Mean number of each species collected from each site during each round FebruaryJune 2008. Circles indicate the sample mean, while bars indicate the standard error (95\% confidence interval). 
Table 1. Total number of each species collected from each shore height of each site for all survey rounds February - June 2008, totals highlighted in bold and * indicating missing data.

A. antipodum A. cincta

\begin{tabular}{|c|c|c|c|c|c|c|c|c|c|c|}
\hline & \multirow[b]{2}{*}{$\begin{array}{l}\text { Survey } \\
\text { round }\end{array}$} & & & \multirow{2}{*}{$\begin{array}{c}\text { Site } \\
\text { grand } \\
\text { total }\end{array}$} \\
\hline Site & & $\begin{array}{c}\text { Low } \\
\text { shore }\end{array}$ & $\begin{array}{c}\text { Mid } \\
\text { shore }\end{array}$ & $\begin{array}{c}\text { High } \\
\text { shore }\end{array}$ & $\begin{array}{l}\text { Site } \\
\text { total }\end{array}$ & $\begin{array}{l}\text { Low } \\
\text { shore }\end{array}$ & $\begin{array}{c}\text { Mid } \\
\text { shore }\end{array}$ & $\begin{array}{l}\text { High } \\
\text { shore }\end{array}$ & $\begin{array}{c}\text { Site } \\
\text { total }\end{array}$ & \\
\hline \multirow[t]{5}{*}{$1 \mathbf{a}$} & February & 26 & 167 & 97 & 290 & 0 & 12 & 4 & 16 & 306 \\
\hline & March & 180 & 82 & 202 & 464 & 15 & 5 & 7 & 27 & 491 \\
\hline & May & 185 & 49 & 95 & 329 & 21 & 2 & 7 & 30 & 359 \\
\hline & June & 83 & 79 & 58 & 220 & 5 & 6 & 8 & 19 & 239 \\
\hline & 1a Total & 474 & 377 & 452 & 1303 & 41 & 25 & 26 & 92 & 1395 \\
\hline \multirow[t]{5}{*}{ 1b } & February & 119 & 166 & 3 & 288 & 20 & 5 & 0 & 25 & 313 \\
\hline & March & 144 & 52 & 6 & 202 & 63 & 7 & 0 & 70 & 272 \\
\hline & May & $*$ & 98 & 7 & 105 & $*$ & 3 & 0 & 3 & 108 \\
\hline & June & 153 & 51 & 2 & 206 & 12 & 2 & 0 & 14 & 220 \\
\hline & 1b Total & 416 & 367 & 18 & 801 & 95 & 17 & 0 & 112 & 913 \\
\hline \multirow[t]{5}{*}{ 1c } & February & 183 & 262 & 147 & 592 & 14 & 13 & 1 & 28 & 620 \\
\hline & March & 333 & 327 & 108 & 768 & 39 & 10 & 9 & 58 & 826 \\
\hline & May & 181 & 165 & 74 & 420 & 8 & 7 & 0 & 15 & 435 \\
\hline & June & 136 & 120 & 26 & 282 & 4 & 4 & 0 & 8 & 290 \\
\hline & 1c Total & 833 & 874 & 355 & 2062 & 65 & 34 & 10 & 109 & 2171 \\
\hline \multirow[t]{5}{*}{$2 a$} & February & 67 & 55 & 95 & 217 & 0 & 0 & 3 & 3 & 220 \\
\hline & March & 75 & 113 & 67 & 255 & 2 & 2 & 0 & 4 & 259 \\
\hline & May & 132 & 89 & 39 & 260 & 0 & 0 & 0 & 0 & 260 \\
\hline & June & 110 & 55 & 28 & 193 & 7 & 2 & 0 & 9 & 202 \\
\hline & 2a Total & 384 & 312 & 229 & 925 & 9 & 4 & 3 & 16 & 941 \\
\hline \multirow[t]{5}{*}{$2 \mathbf{b}$} & February & 199 & 121 & 83 & 403 & 9 & 9 & 13 & 31 & 434 \\
\hline & March & 116 & 140 & 32 & 288 & 3 & 3 & 0 & 6 & 294 \\
\hline & May & 182 & 76 & 30 & 288 & 8 & 6 & 0 & 14 & 302 \\
\hline & June & 158 & 51 & 28 & 237 & 4 & 3 & 0 & 7 & 244 \\
\hline & 2b Total & 655 & 388 & 173 & 1216 & 24 & 21 & 13 & 58 & 1274 \\
\hline \multirow[t]{5}{*}{ 2c } & February & 196 & 186 & 178 & 560 & 10 & 12 & 0 & 22 & 582 \\
\hline & March & 92 & 183 & 43 & 318 & 4 & 5 & 0 & 9 & 327 \\
\hline & May & 68 & 142 & 53 & 263 & 6 & 0 & 0 & 6 & 269 \\
\hline & June & 97 & 125 & 20 & 242 & 6 & 5 & 0 & 11 & 253 \\
\hline & 2c Total & 453 & 636 & 294 & 1383 & 26 & 22 & 0 & 48 & 1431 \\
\hline \multirow[t]{5}{*}{ 3a } & February & 127 & 113 & 89 & 329 & 3 & 6 & 3 & 12 & 341 \\
\hline & March & $*$ & 54 & 60 & 114 & * & 4 & 4 & 8 & 122 \\
\hline & May & 121 & 40 & 34 & 195 & 0 & 4 & 1 & 5 & 200 \\
\hline & June & 87 & $*$ & 25 & 112 & 3 & $*$ & 7 & 10 & 122 \\
\hline & 3a Total & 335 & 207 & 208 & 750 & 6 & 14 & 15 & 35 & 785 \\
\hline \multirow[t]{5}{*}{ 3b } & February & 184 & 135 & 145 & 464 & 19 & 0 & 2 & 21 & 485 \\
\hline & March & $*$ & 87 & 68 & 155 & * & 0 & 1 & 1 & 156 \\
\hline & May & 89 & 117 & 148 & 354 & 12 & 11 & 9 & 32 & 386 \\
\hline & June & 171 & 72 & 77 & 320 & 11 & 0 & 1 & 12 & 332 \\
\hline & 3b Total & 444 & 411 & 438 & 1293 & 42 & 11 & 13 & 66 & 1359 \\
\hline \multirow[t]{5}{*}{$3 c$} & February & 279 & 130 & 66 & 475 & 32 & 3 & 8 & 43 & 518 \\
\hline & March & 113 & 100 & 68 & 281 & 64 & 3 & 10 & 77 & 358 \\
\hline & May & 81 & 92 & 126 & 299 & 16 & 6 & 35 & 57 & 356 \\
\hline & June & 50 & $*$ & $*$ & 50 & 10 & * & $*$ & 10 & 60 \\
\hline & 3c Total & 523 & 322 & 260 & 1105 & 122 & 12 & 53 & 187 & 1292 \\
\hline \multicolumn{2}{|c|}{ Grand Total } & 4517 & 3894 & 2427 & 10838 & 430 & 160 & 133 & 723 & 11561 \\
\hline
\end{tabular}


To determine if either species was using the shore line differently comparisons of their vertical distribution among the three shore heights (low, mid, and high) were made. There was no significant difference in the abundance of snails along each shore height across all sites for all rounds for either species (A. antipodum $p=0.236$, A. cincta $p=0.243$ ). Austrolittorina antipodum had significant variability in the abundance of snails at each shore height throughout the survey rounds with a decline in the abundance of snails on the low shore in March, a larger abundance of snails on the high shore during the February surveys, and less snails on the high and mid shore during July $(p<0.001)$ (Figure 5). Austrolittorina cincta also showed significant variability in the abundance of snails at each shore height throughout the survey rounds with less snails on the high and mid shore during July and less snails on the high shore during February $(p<0.001)$. 


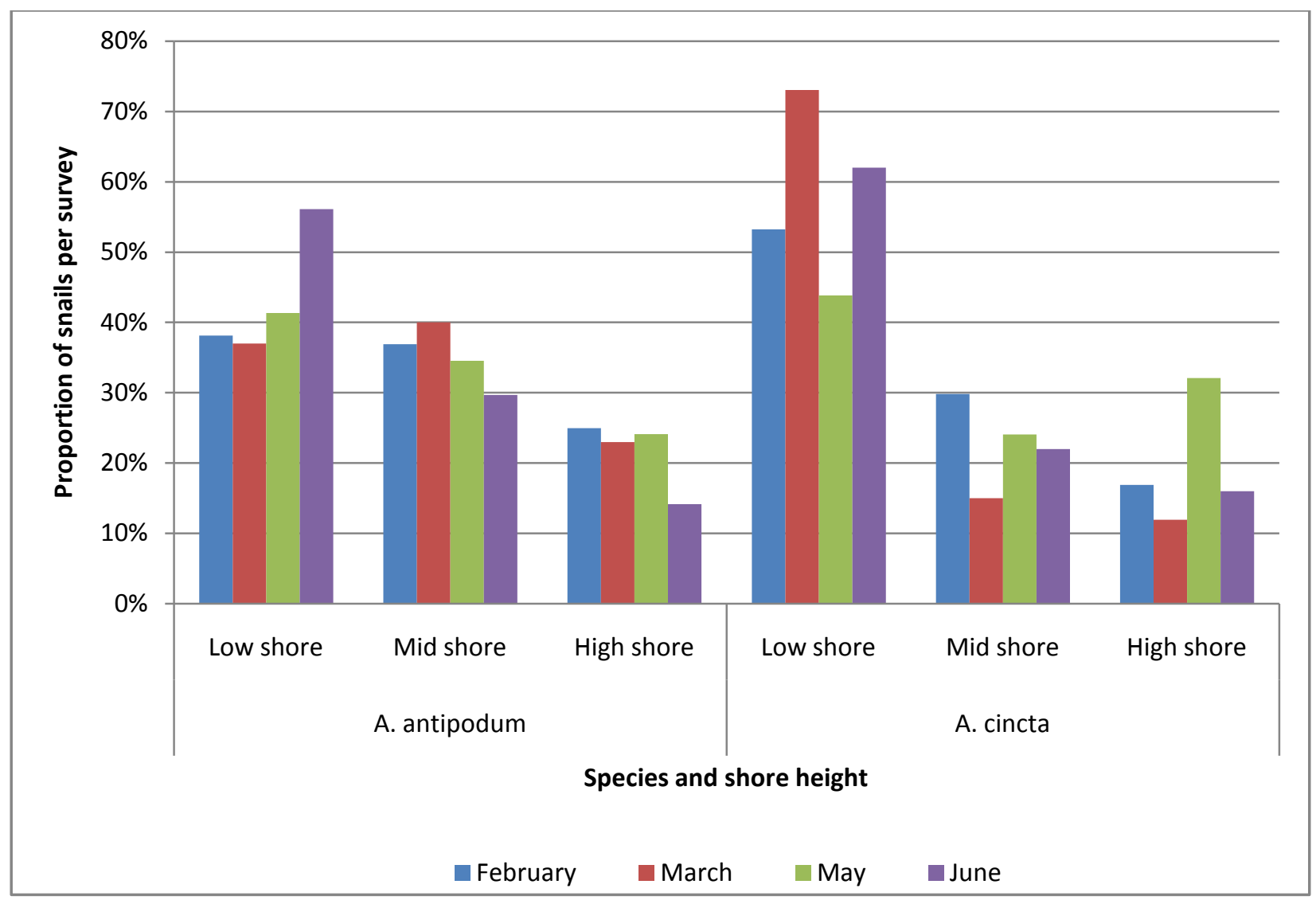

Figure 5. The proportion of each species found on each shore height during each survey round.

The relative abundance of each species along each shore height of all sites was also evaluated. Austrolittorina antipodum was significantly less abundant on the high shore at site 1 , the low and mid shore at site 3 , and were most abundant on the low shore at sites 1 and 2 $(p<0.001)$. Austrolittorina cincta was also less abundant on the high shore at site 1 and the mid shore at site 3 , and was more abundant on the low shore at sites 3 and $1(p<0.001)$ (Figure 6). 


\subsubsection{Abundance of A. antipodum}

Of the three sites, A. antipodum was most abundant at site 1 (4,166 snails) followed by site 2 (3,524 snails) and was least abundant at site 3 (3,148 snails) $(p=0.024)$ (Figure. 4$). \quad$ In particular A. antipodum was found to be significantly less abundant at site 3a and 1b.

To determine the shore level distribution of A. antipodum along the shore, a series of Kruskal-Wallis tests comparing the abundance of snails at each shore height were conducted. As previously noted comparisons of $A$. antipodum abundance across the three shore heights was compared by pooling all sites shore heights and there were no significant differences in the abundance of snails at each shore height (Figure 7). The shore level distribution across each of the sites was also compared and showed significantly less snails found along the high shore of site 1 and low shore of site 3 , and more snails along the low shore of site 1 $(p<0.001)$. 


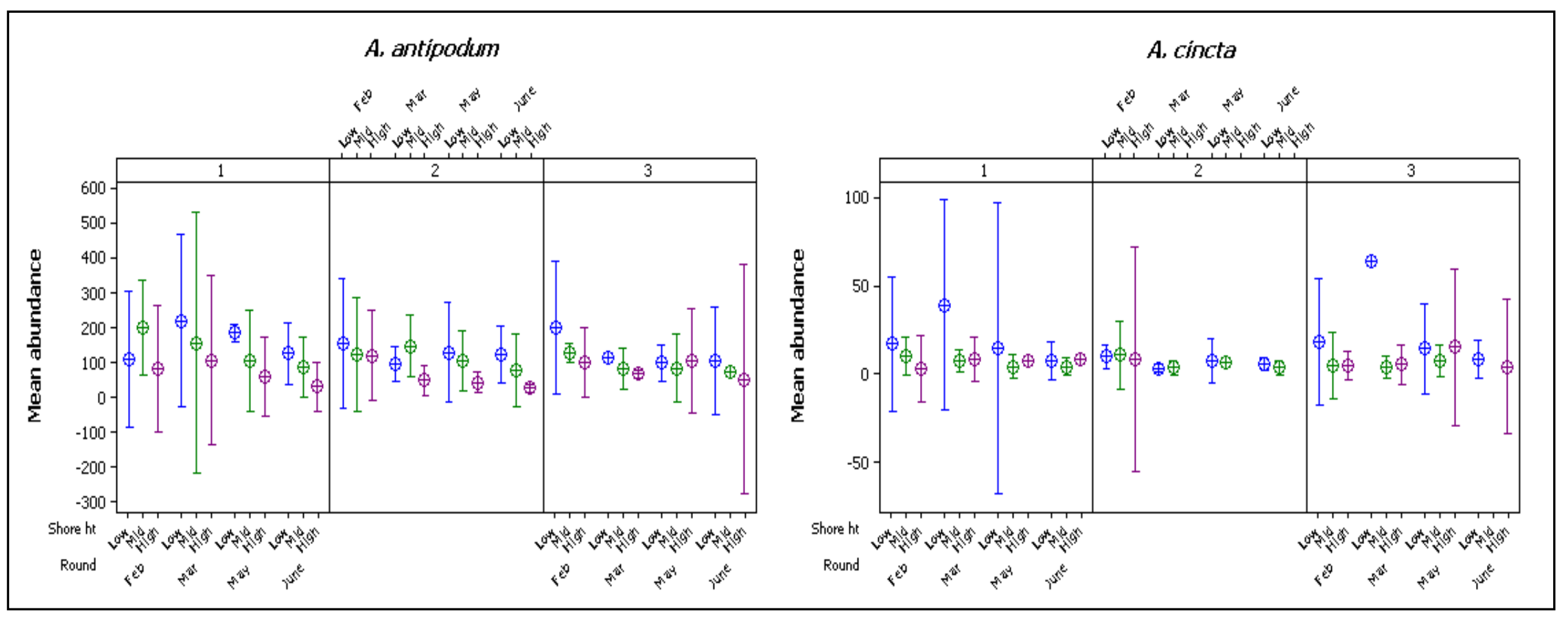

Figure 6. The abundance of each species at each of the main sites along each shore height for February- June 2008 surveys. Circles indicate the sample mean, while bars indicate the standard error (95\% confidence interval).

53 


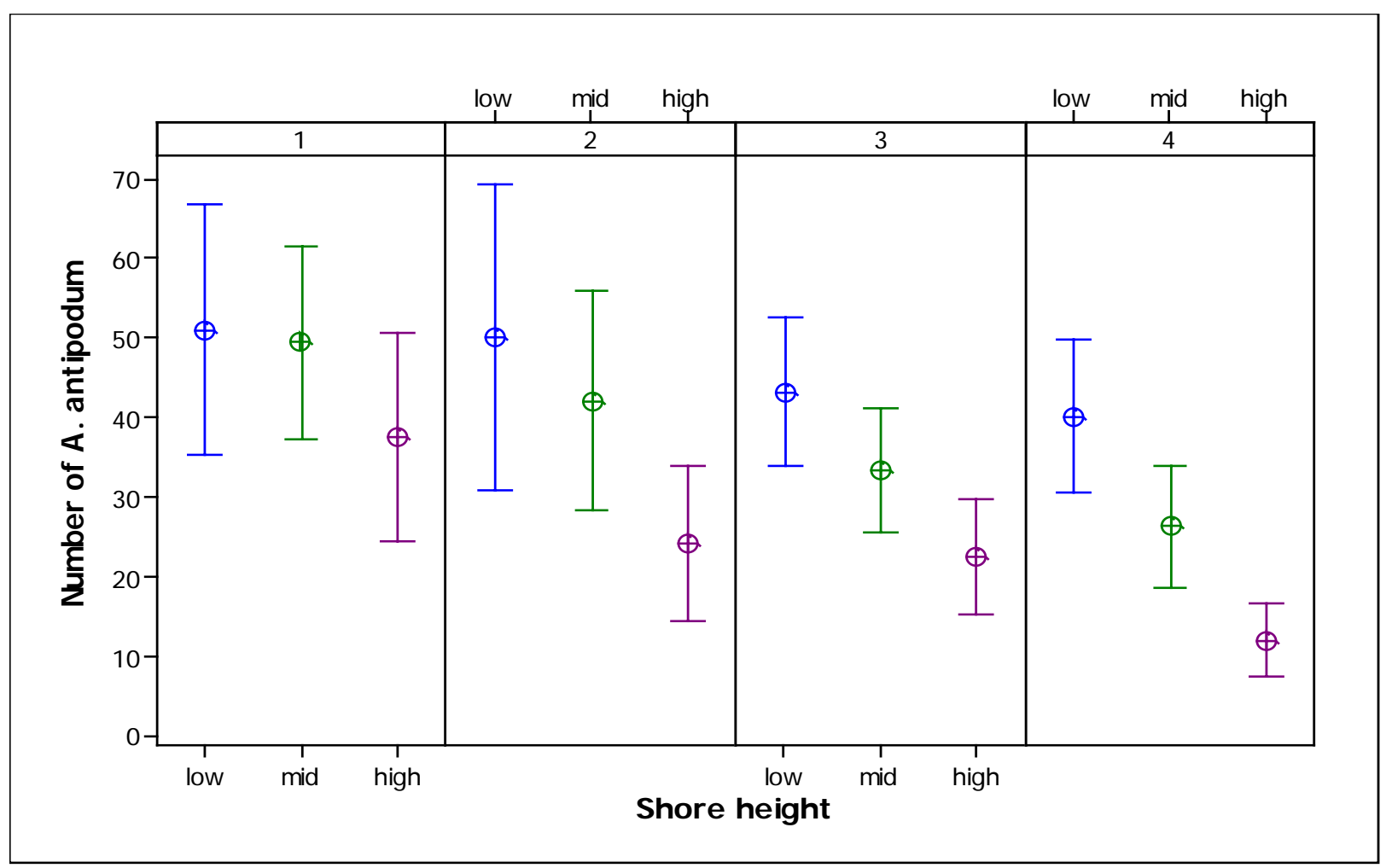

Figure 7. Mean abundance of A. antipodum along each shore height, for all sampling rounds, February- June, 2008. Panels correlate to the sampling round (1- February, 2- March, 3- May, and 4- June), circles the sample mean, and bars are the standard error.

\subsubsection{Abundance of A. cincta}

Austrolittorina cincta was most abundant at site 1 (313 snails) followed by site 3 (288 snails)

and was least abundant at site 2 (122 snails); however, the main significant difference between the abundance of $A$. cincta at the different sites was at site $3(p<0.001)$ (Figure

4). Austrolittorina cincta, like A. antipodum was significantly less abundant at sites 3a and

1b, however, unlike A. antipodum A. cincta was more abundant at sites 3c, 1c, and 3b.

The differences in abundance of $A$. cincta between the three shore heights were not significant, as previously shown (Figure 8). Shore-level distributions across each of the main sites showed no significant difference in the abundance of snails at any of the shore heights $(p=0.219)$ 


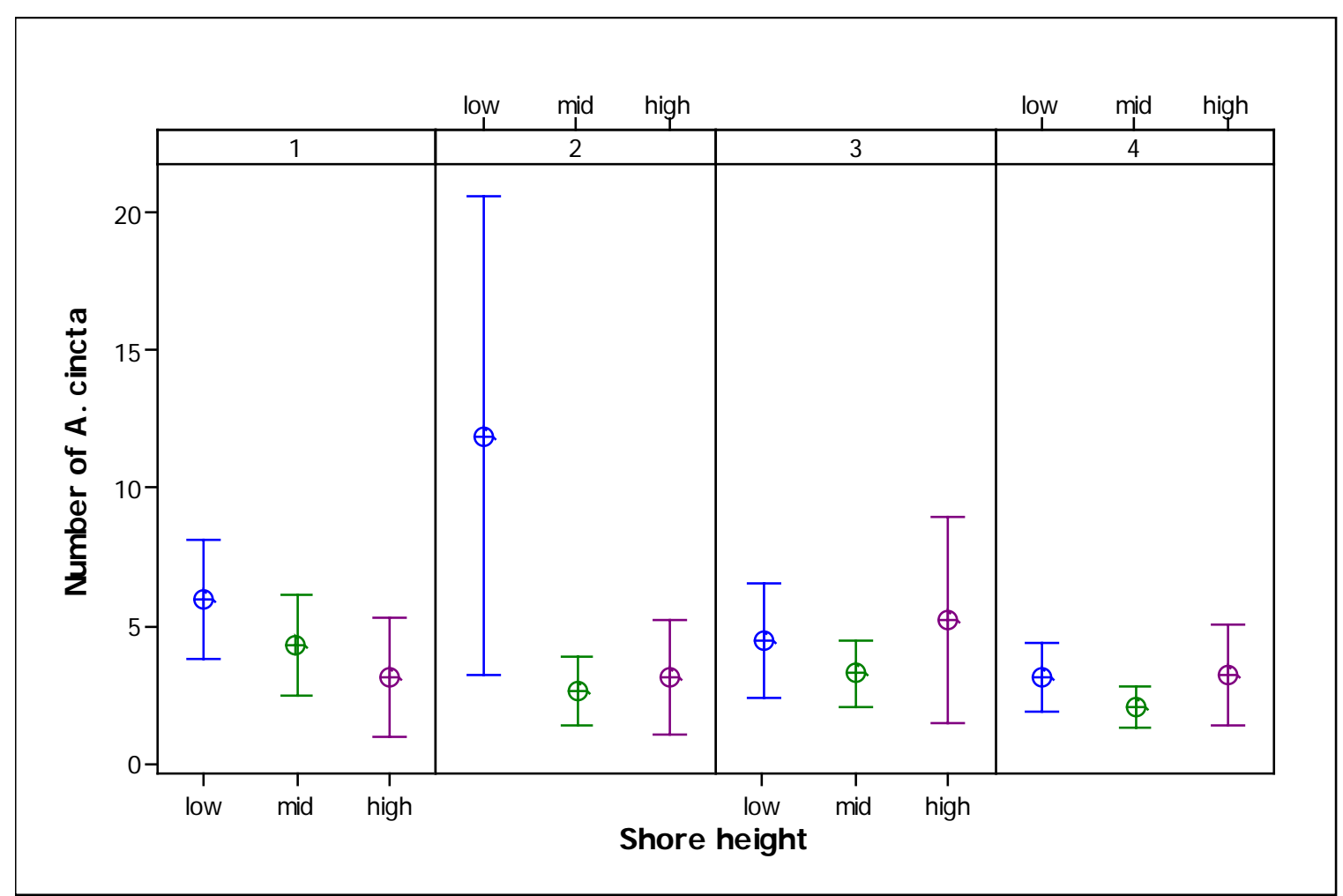

Figure 8. Mean abundance of $A$. cincta along each shore height, for all sampling rounds, February- June, 2008. Panels correlate to the sampling round (1- February, 2- March, 3May, and 4- June). Circles indicate the sample mean, while bars indicate the standard error.

\section{$\underline{\text { 3.1.4 Size distribution }}$}

These two species of Austrolittorina are known to reach different adult sizes with A.

cincta reaching larger sizes. Size frequency distributions for pooled sites showed $A$.

antipodum to have a more bell shaped distribution than $A$. cincta (Figure 9 ). This same

pattern was seen at each of the sites with $A$. cincta having a broader size distribution and less defined shape (Figure 10). Austrolittorina cincta samples had a wide range of sizes and had higher mean sizes at all shore heights at all sampling intervals (Figure 11). The proportion of each species within $1 \mathrm{~mm}$ size ranges in table 2 demonstrates the wider range of sizes for $A$. cincta. 


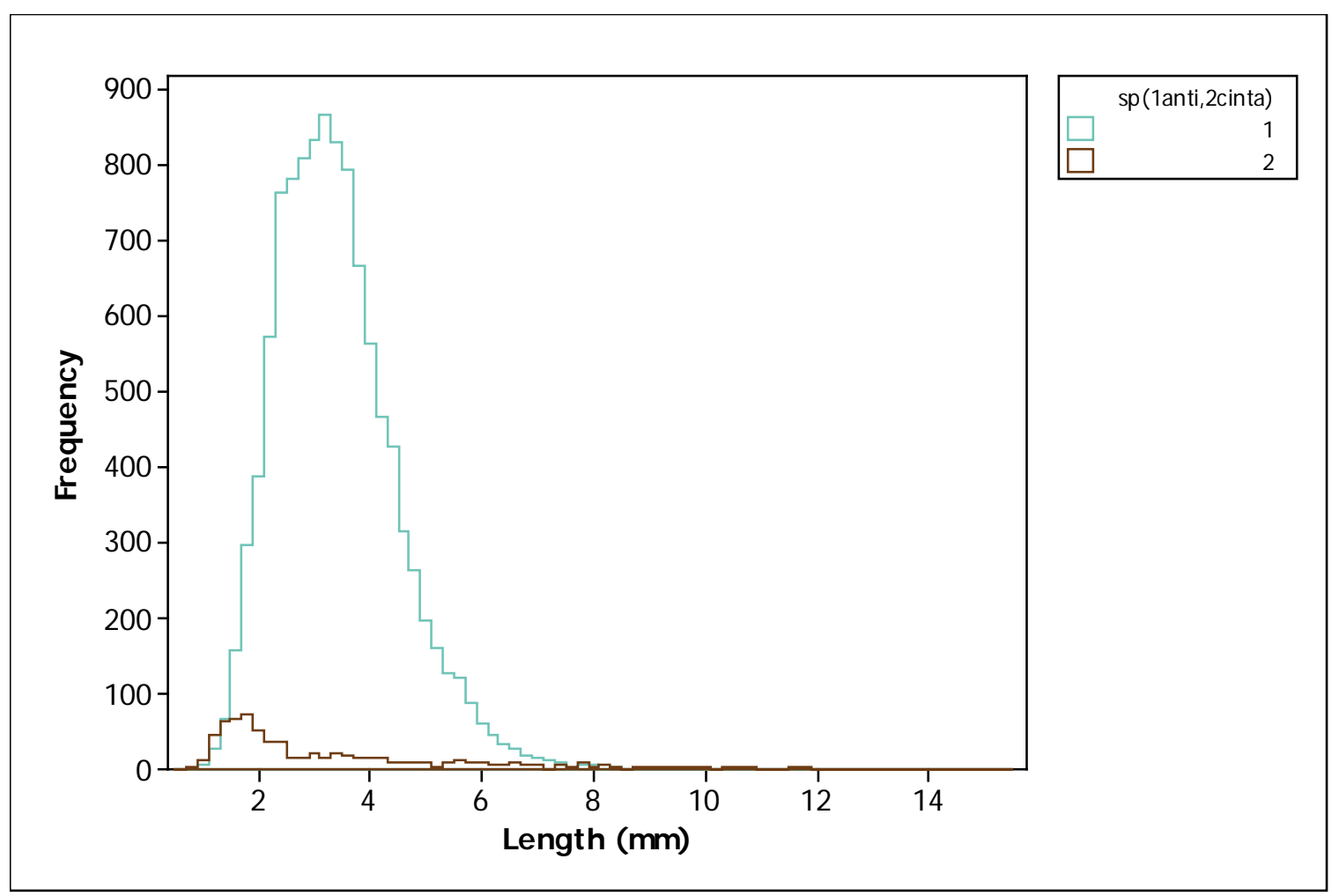

Figure 9. Size distribution of both species for all data (all rounds, sites and shore levels).

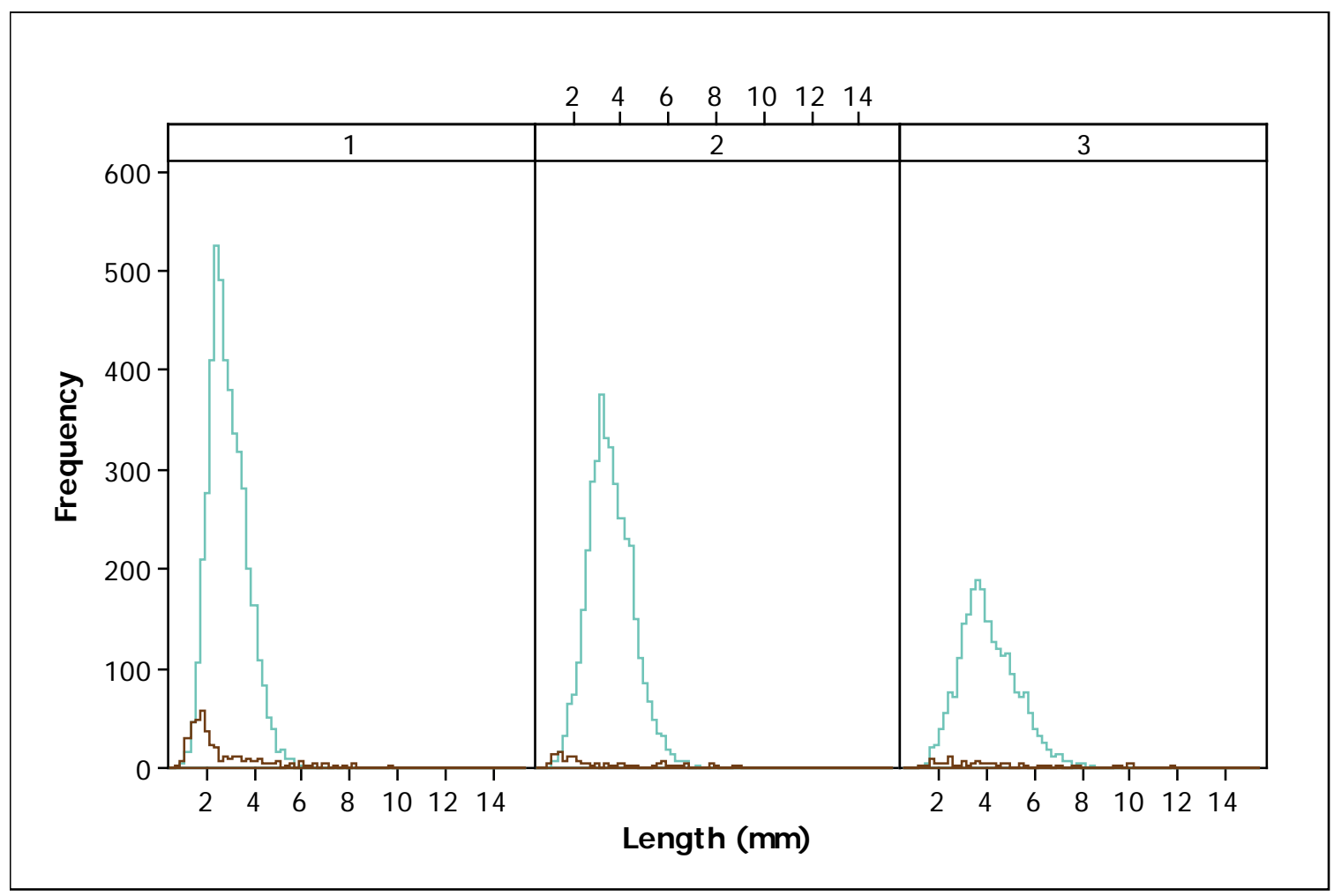

Figure 10. Size distribution for A. antipodum (blue line) and A. cincta (brown line) for the low, mid, and high shore across all sites for all rounds. Panels correspond to the shore height (1- low shore, 2- mid shore, and 3- high shore). 


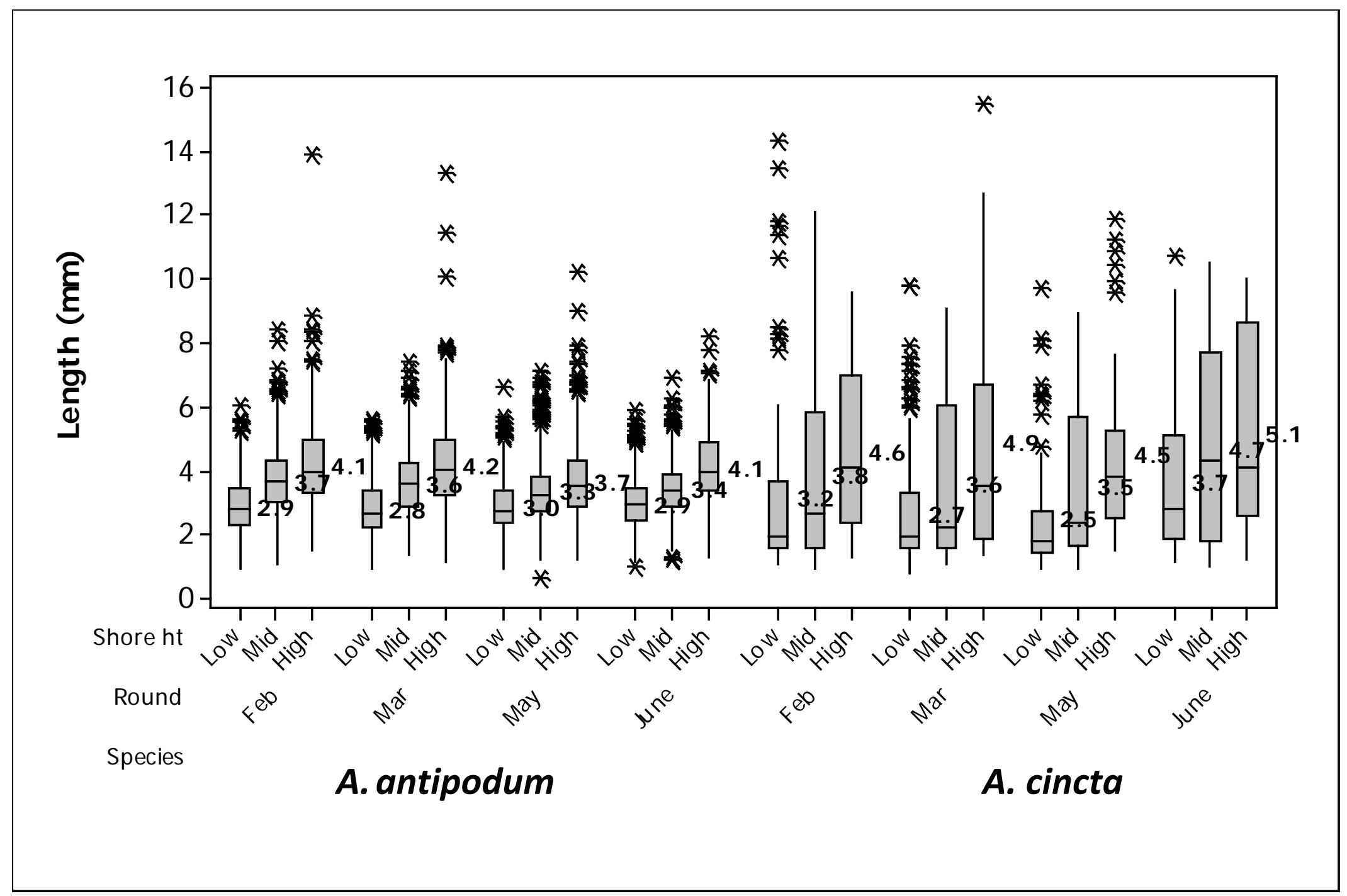

Figure 11. Range and mean sizes for each species during all survey rounds at each shore height. Stars indicate outliers, line above and below grey boxes indicate maximum and minimum data points, grey boxes indicate the middle $50 \%$ of data with middle line indicating the median. 
Table 2. Proportion of each species within $1 \mathrm{~mm}$ size ranges, for all sites.

\begin{tabular}{lcc}
$1 \mathrm{~mm}$ size ranges & A. antipodum & A. cincta \\
\hline \hline$<1 \mathrm{~mm}$ & $0.05 \%$ & $1.11 \%$ \\
$1.0-1.99 \mathrm{~mm}$ & $6.74 \%$ & $39.42 \%$ \\
$2.0-2.99 \mathrm{~mm}$ & $33.07 \%$ & $18.95 \%$ \\
$3.0-3.99 \mathrm{~mm}$ & $35.31 \%$ & $11.48 \%$ \\
$4.0-4.99 \mathrm{~m}$ & $17.11 \%$ & $7.61 \%$ \\
$5.0-5.99 \mathrm{~mm}$ & $5.79 \%$ & $5.53 \%$ \\
$6.0-6.99 \mathrm{~mm}$ & $1.50 \%$ & $4.98 \%$ \\
$7.0-7.99 \mathrm{~mm}$ & $0.29 \%$ & $3.87 \%$ \\
$8.0-8.99 \mathrm{~mm}$ & $0.10 \%$ & $2.35 \%$ \\
$9.0-9.99 \mathrm{~mm}$ & $0.00 \%$ & $1.94 \%$ \\
$10.0-10.99 \mathrm{~mm}$ & $0.02 \%$ & $1.11 \%$ \\
$11.0-11.99 \mathrm{~mm}$ & $0.01 \%$ & $0.97 \%$ \\
$12.0-12.99 \mathrm{~mm}$ & $0.00 \%$ & $0.28 \%$ \\
$13.0-13.99 \mathrm{~mm}$ & $0.02 \%$ & $0.14 \%$ \\
$14.0-14.99 \mathrm{~mm}$ & $0.00 \%$ & $0.14 \%$ \\
$15.0-15.99 \mathrm{~mm}$ & $0.00 \%$ & $0.14 \%$
\end{tabular}

The average size for each species at each shore height for all replicate sites is

presented in appendix 3. This table illustrates that in general A. cincta is larger, however there are exceptions to this general trend where the average size of A. antipodum is larger than A. cincta at some sites shore heights.

\subsubsection{Size distribution of A. antipodum}

The size of $A$. antipodum changed over time, with a decline in the mean size in May and a larger average size in February $(p<0.001)$ (Figure 11). Size also varied spatially, snails were significantly larger at site 3 (in particular site 3a) and smaller at site 2 (in particular site 2c) $(p<0.001)$ (Figure 12). To examine if the size of $A$. antipodum showed a size gradient along the shore, all sites were pooled and the length of snails measured at each shore level was compared. Kruskal-Wallis test showed A. antipodum size significantly varied with shore height, with the average length of snails, increasing moving from the low to high shore 
$(p<0.001)$. The length of snails measured from each quadrat at each shore level was compared among all sites and revealed significantly smaller snails were found on the low shore of site $1 \mathrm{c}$ and larger snails on the high shore of site $2 \mathrm{a}(p<0.001)$.

\subsubsection{Size distribution of A. cincta}

Temporal variance in the average size of $A$. cincta was also seen with larger average sizes in June and smaller average sizes in March $(p<0.001)$ (Figure 11 and 17). Austrolittorina cincta's average size also varied spatially with snails significantly larger at site 3a and smaller at site 1c $(p<0.001)$ (Figure 18). Sites were pooled to investigate the influence of shore height on shell size. Austrolittorina cincta like A. antipodum had a shell size gradient along the shore, with the average length of snails increasing moving from the low to high shore. The average length of snails was significantly smaller on the low shore, and significantly larger on the high shore $(p<0.001)$. The size of snails from quadrats at each shore level was compared among all sites and revealed significantly smaller snails were found on the low shore of site $1 \mathrm{c}$ and larger snails on the high shore of site $3 a(p<0.001)$. 


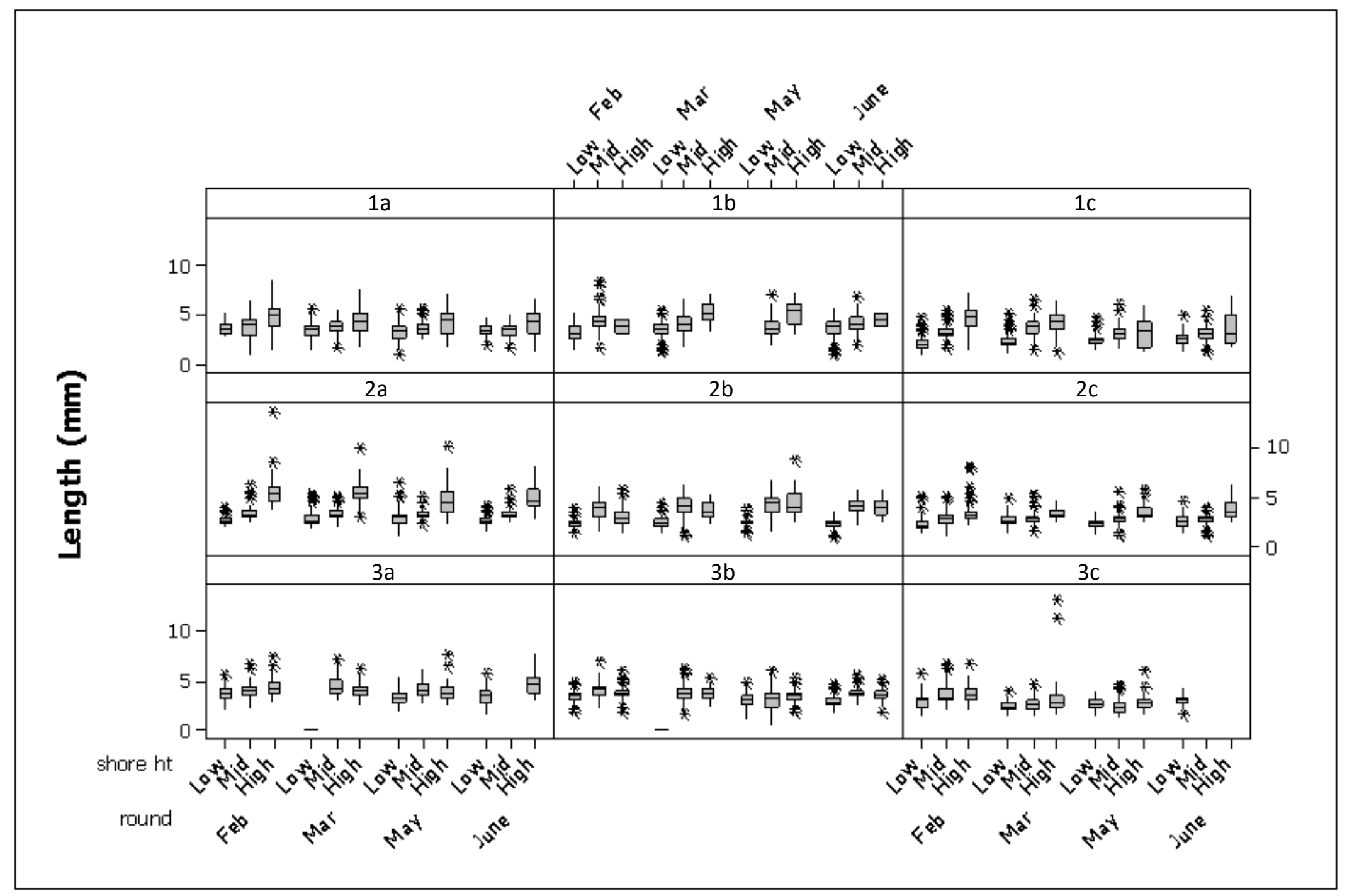

Figure 12. Austrolittorina antipodum average size along each shore height for each sampling round, February to June 2008. Stars indicate outliers, line above and below grey boxes indicate maximum and minimum data points, grey boxes indicate the middle $50 \%$ of data with middle line indicating the median. 


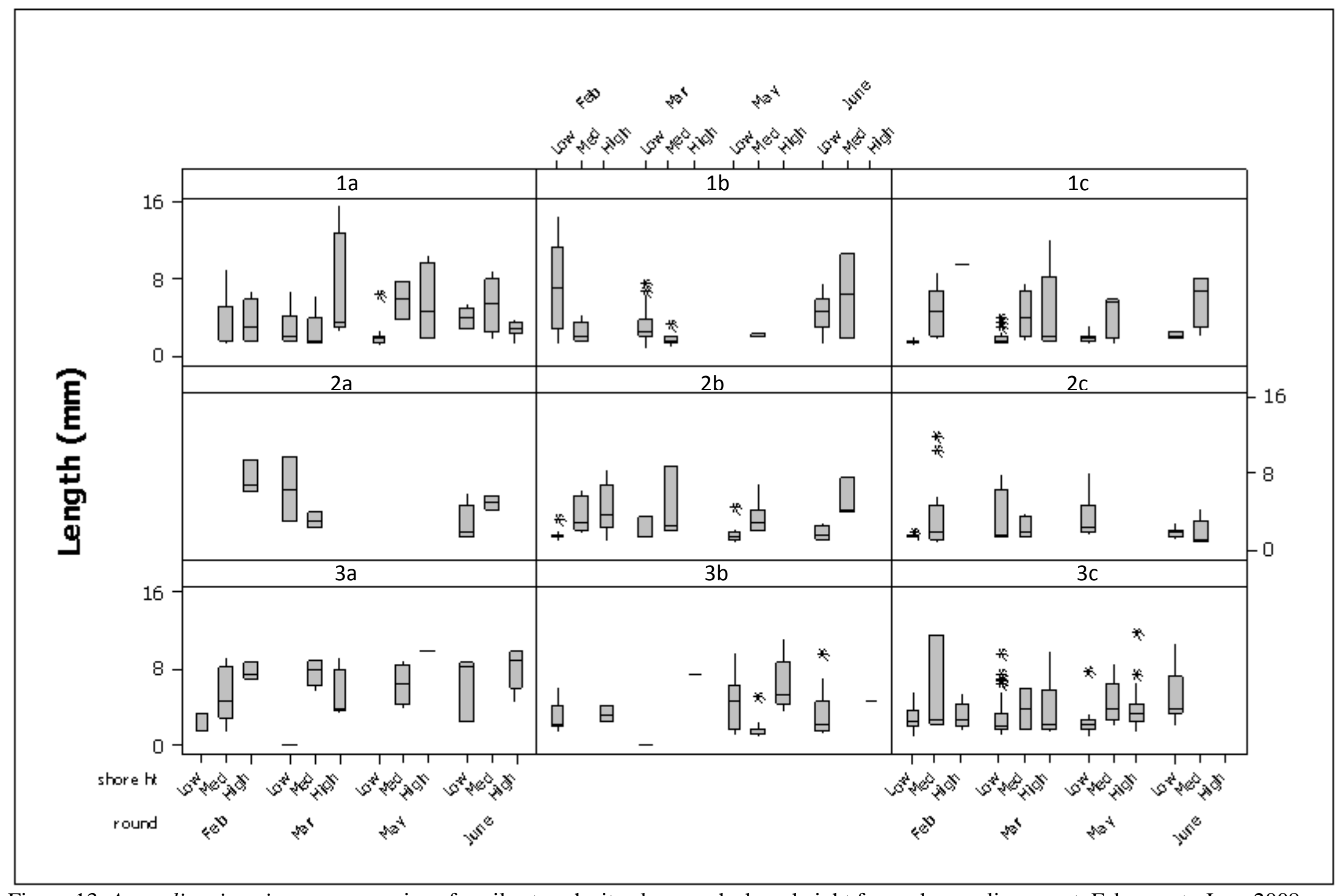

Figure 13. Austrolittorina cincta average size of snails at each site along each shore height for each sampling event, February to June 2008. Stars indicate outliers, line above and below grey boxes indicate maximum and minimum data points, grey boxes indicate the middle $50 \%$ of data with middle line indicating the median. 


\subsubsection{Behavioural differences}

Behaviours recorded during population surveys included the number of solo snails, pairs, groups and the number of mixed groups (both species present in the group) per quadrat.

Comparisons between the species across all sites and shore heights showed no significant difference in the number of solo snails $(p=0.070)$, significantly less pairing by $A$. cincta ( $p=0.003), A$. cincta found significantly more often in groups (which were on average large mixed groups) $(p<0.001, p<0.001)$. Austrolittorina cincta were found in significantly more mixed groups, whereas A. antipodum was more likely to be found in groups with other A. antipodum (Figure 14). During the course of this study A.

antipodum was never found in groups of only A. cincta, while A. cincta was commonly found in groups of A. antipodum. 


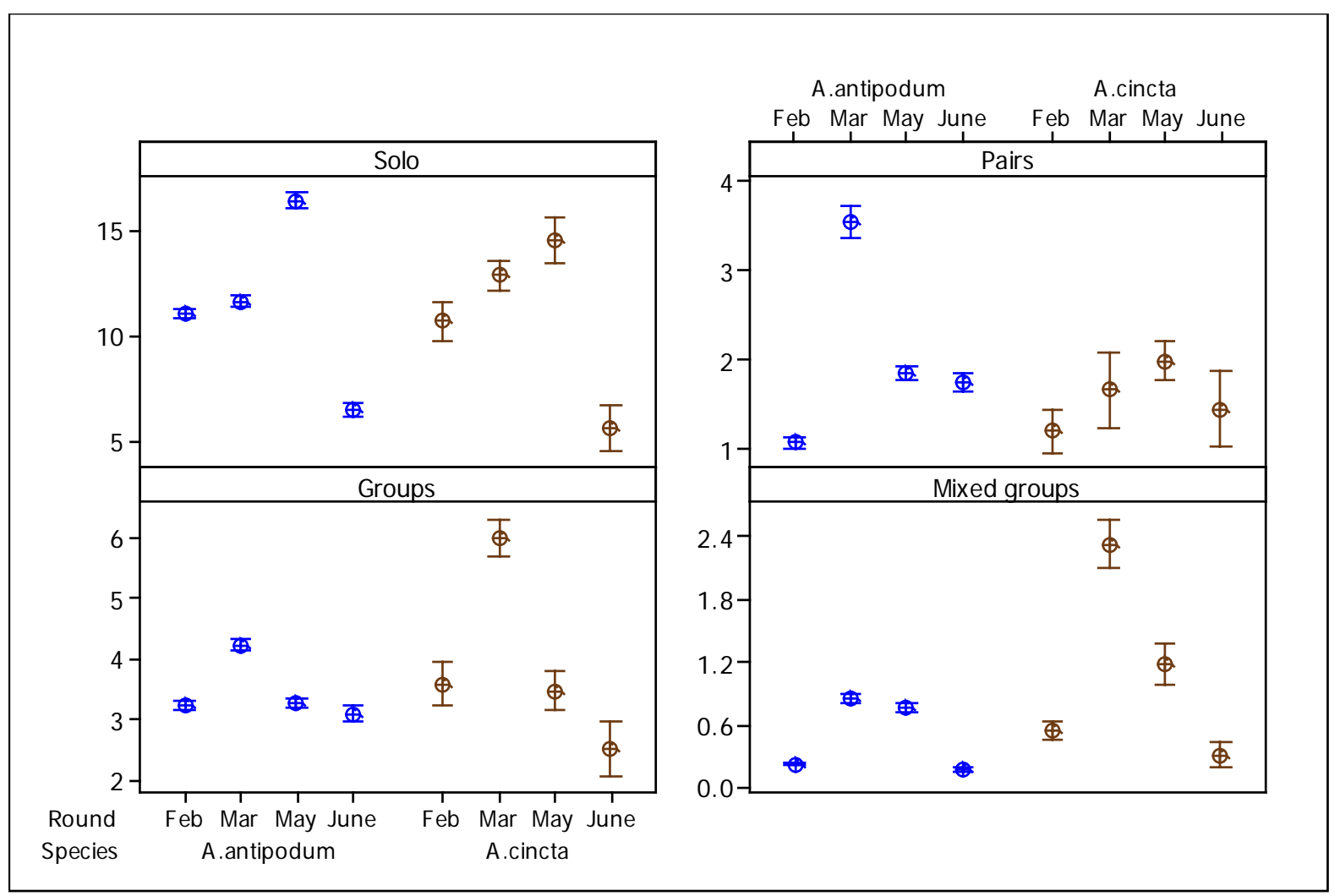

Figure 14. Temporal behavioural variance of A. antipodum and A. cincta, February -June 2008. Circles indicate the sample mean, while bars indicate the standard error $(95 \%$ confidence interval).

Pairing and grouping behaviours of each species' along the shore was also investigated to determine if there was a seasonal variation which may be indicative of potential mating behaviour. Kruskal-Wallis tests were used to compare the temporal variation of each species' behaviour. There was significant temporal variance in the behaviour of both Austrolittorina species among the variables measured. Austrolittorina antipodum had significantly more solo individuals during May (34\%) and less during June (5\%) $(p<0.001)$ (Figure 15). More pairs of A. antipodum were found during March (49\%) and less during February (8\%) $(p<0.001)$. There was a lower number of groups/aggregations in February, with the highest amount of grouping found in March $(p<0.001)$. Austrolittorina cincta also 
had more solo individuals found in May (41\%) and less in June (4\%) $(p<0.001)$. However, more pairs of $A$. cincta were found in May (42\%) and less in March $(28 \%)(p<0.001)$. The number of groups was higher in March, with the fewest groups in June $(p<0.001)$. The number of groups for both species increased until March, when it peaked followed by a subsequent decline (35\% of A. antipodum groups were found in March and 53\% of A. cincta). Both species had the highest amount of mixed groups found in March (63\% of mixed groups found), with the least amount found in June ( $2 \%$ of mixed groups found) ( $p<0.001$, $p<0.001)$.

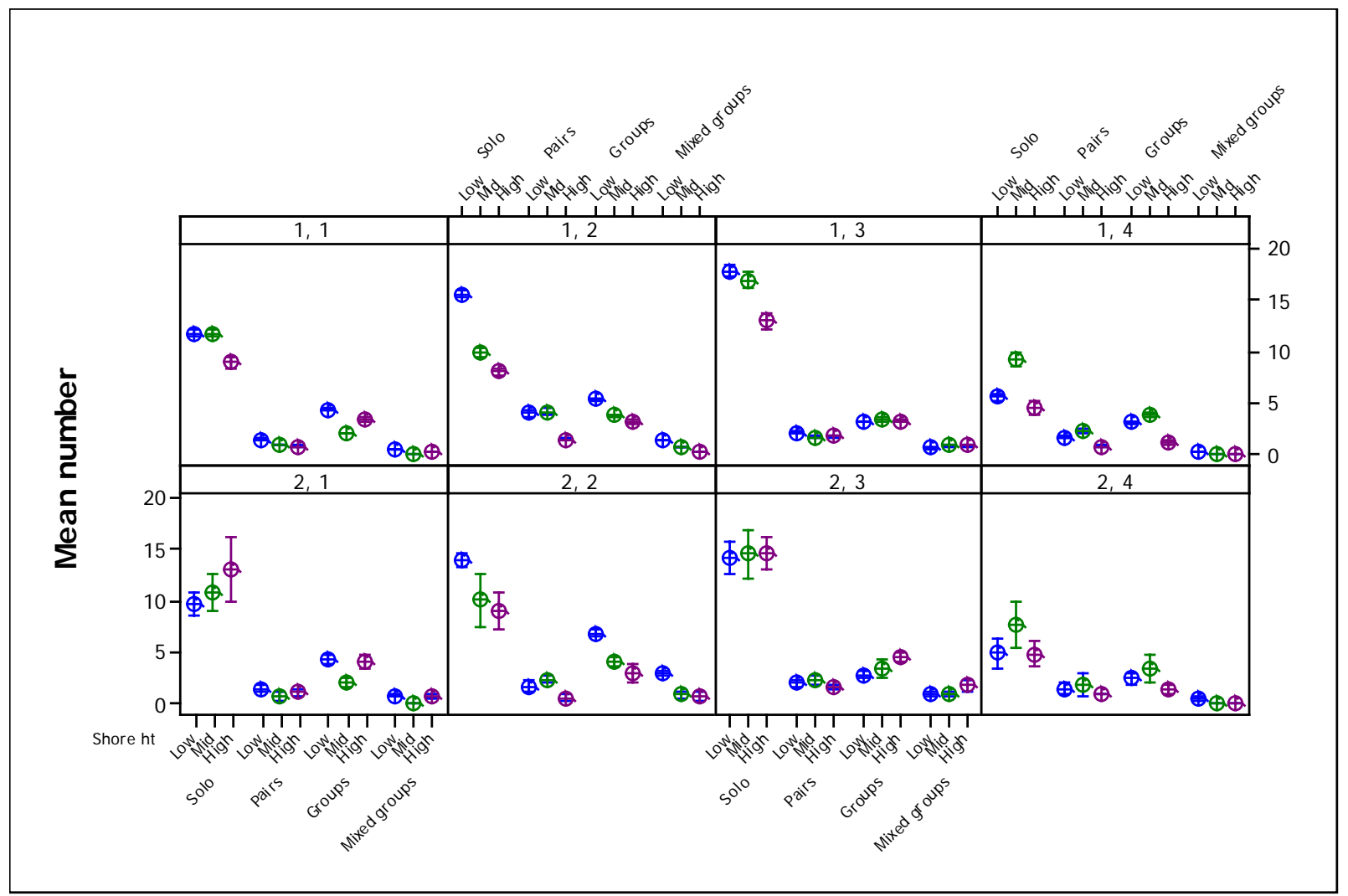

Figure 15. Austrolittorina antipodum and A. cincta mean number of solo snails, pairs, groups, mixed groups along each shore height (pooled sites) for each sampling round. Panel numbering corresponds to the species and behaviours. The first number is the species (1-A. antipodum, 2- A. cincta) and the second number corresponds to the behavioural categories (1solo, 2- pairs, 3-groups, and 4-mixed groups), with colors corresponding to shore height (blue- low shore, green- mid shore, magenta- high shore). 


\subsubsection{Habitat differences}

Habitat characteristics recorded included the degree of the slope, and a ranking of the rugosity, algae, and lichen. Kruskal-Wallis testes were used to compare the ranking of these characteristics among the different sites. The slope of each site was evaluated and overall site 3 had the highest average slope of $40^{\circ}(p<0.001)$. Rugosity was highest at site 3 and lowest at site $1(p<0.001)$. Site 1 had the highest macro algal cover followed by 3 , while site 2 had the lowest $(p<0.001)$. Lichen abundance was highest at site 3 and lowest at site $2(p<0.001)$.

To assess the amount of habitat variability along the shore, habitat characteristics were compared along each shore level across all sites. The mid shore region was found to have a significantly steeper angle, while the low shore was the flattest $(p<0.001)$. The mid shore region also had significantly less rugosity $(p<0.001)$. Macro-algae was significantly more abundant on the low shore and less abundant on the high shore $(p<0.001)$, while lichen showed the opposite results $(p<0.001)$. While not all habitat characteristics were considered here these general characteristics provide a basic evaluation for further more in-depth analysis to build upon.

In order to investigate the habitat characteristics in more depth, the shore heights of all sites were compared to see how individual sites shore heights characteristics varied between all sites replicates. Over all sites and shore heights, the mid shore of site 3a had a significantly steeper slope while sites $1 \mathrm{~b}$ and $2 \mathrm{~b}$ had the gentlest slopes $(p<0.001)$. The high shore of site 2a was the most rugose site, while the high shore of site 1a was the least rugose $(p<0.001)$. The abundance of macro-algae was highest on the low shore of site $3 \mathrm{~b}(p<0.001)$, while lichen was most abundant along the high shore of sites $1 \mathrm{~b}$ and $1 \mathrm{a}(p<0.001)$. 


\section{$\underline{3.2 \text { Settlement results }}$}

Young recruits of various Littorina species have very similar morphological features, so identification to the species level can be problematic, as was the case with these two Austrolittorina species. In order to eliminate this source of error, they were not identified to species level, however this introduces the potential error that both species are not accounted for (Struthsaker, 1966). Pilkington (1971) was also unable to identify juveniles reared in the lab from the veliger stage to the species level until they attained a larger size, generally around $2 \mathrm{~mm}$ or 6-7 whorls. Pilkington addressed this potential issue of not having both species accounted for, and concluded that the lack of a similar unidentified veliger supports the stance that both of the Austrolittorina were represented in the Portobello samples. During the processing of the settlement pads a juvenile prosobranch was detected which resembled and had very similar characteristics to the Austrolittorina settlers. Molluscan taxonomic expert Bruce Marshall, Molluscan Collection Manager for the Te Papa Tongarewa Museum of New Zealand, supports the hypothesis that these unidentified settlers are very likely a species of Austrolittorinids; however, genetic tests are needed to determine the identity of the unknown snails. As a result differences between species settlement rates and peak periods could not be determined, and both species are assumed to be represented by individuals collected on settlement pads, although the proportion of each species is unknown.

Statistical tests on the abundance and correlations were conducted on two sets of this settlement data. The main data set excluding the first two sampling rounds (during the end of December and beginning of January only 5 of the 9 sites were established during these sampling rounds so they were removed from the analysis) and a smaller subset which 
included the data from the end of January through the end of March (when pads were deployed for an equal length of time), with the majority of tests being conducted on the latter data set. This was conducted to correct for variations in the number of sites and duration of settlement pad deployments between the various sites. These two data sets will be referred to as the 'main' and 'subset' data sets from here on, and results will be presented listing the main data set results followed by the subset results. Figure 16, however, shows the total number of Austrolittorina recruits collected for the entire duration of this study with all sites pooled from each round.

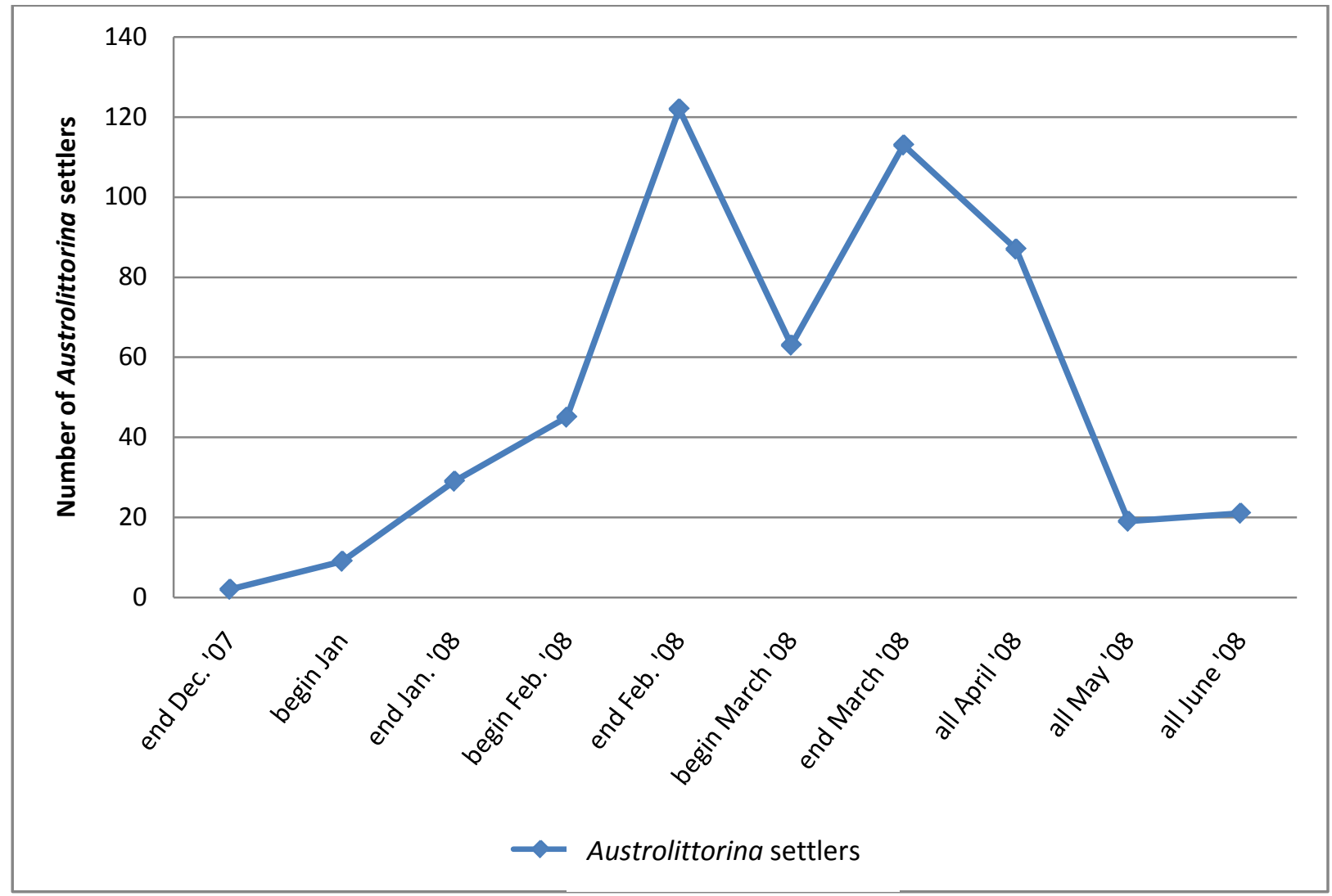

Figure 16. The total number of Austrolittorina settlers collected during each sampling interval combined across all sites. 


\subsubsection{Temporal and spatial differences in settlement}

Settlement plate collections showed the presence of Austrolittorina recruits from December 2007- June 2008, and revealed that peak recruitment occurred at the end of February and the end of March (Figure 22). A total of 510 Austrolittorina recruits were collected during the seven months of settlement plate deployment. Eleven of these settlers were collected during the first two rounds when only 5 of the sites were established and the other 499 were collected once all of the sites were established (Table 3). Sites 1b, 2a, 2b, 2c, 3b where the only sites that had settlement pads for the first two rounds for a total of deployment of 60 pads. All of the pads deployed were collected during the first two rounds, with no pads lost. Settlement pads were lost during some sampling rounds at some sites, with certain sites loosing pads more frequently than others (Table 3).

Kruskal-Wallis tests used to compare the number of Austrolittorina settlers during each round showed a significant difference in both data sets tested with significantly more settlers in February and March $(p<0.001, p<0.001$ - complete results of tests are provided in appendix 4). Individual settlement pads generally only had a few recruits present, ranging from $0-14$, with an average of 2 recruits per plate $( \pm 2.13)$ even during peak times of settlement (Figure 17). Test of individual sites for the main data set showed peak settlement at site 1 during the beginning of February $(p=0.003)$, and during the end of March for sites 2 and $3(p<0.001, p=0.004)$. 
Table 3. The total number of settlement pads recovered, total pads lost, and the number of Austrolittorina recruits recovered for each of the data sets and each site.

\begin{tabular}{|c|c|c|c|c|c|c|c|}
\hline Site & $\begin{array}{l}\text { Plate } \\
\text { deployment }\end{array}$ & $\begin{array}{l}\text { Total \# } \\
\text { pads } \\
\text { recovered } \\
\text { exclude } \\
\text { rd } 1 \& 2\end{array}$ & $\begin{array}{l}\text { Total \# } \\
\text { pads lost } \\
\text { exclude } \\
\text { rd } 1 \& 2\end{array}$ & $\begin{array}{l}\text { Total } \\
\text { recruits } \\
\text { ex rd } 1 \\
\& 2\end{array}$ & $\begin{array}{l}\text { Subset \# } \\
\text { pads } \\
\text { recovered }\end{array}$ & $\begin{array}{c}\text { Subset \# } \\
\text { of lost } \\
\text { pads }\end{array}$ & $\begin{array}{l}\text { Subset } \\
\text { total } \\
\text { recruits }\end{array}$ \\
\hline $1 \mathrm{a}$ & $\begin{array}{l}\text { below adults } \\
\text { within } \\
\text { barnacle } \\
\text { zone }\end{array}$ & 48 & 0 & 59 & 30 & 0 & 41 \\
\hline $1 b$ & $\begin{array}{l}\text { within adult } \\
\text { population }\end{array}$ & 46 & 2 & 73 & 29 & 1 & 63 \\
\hline 1c & $\begin{array}{l}\text { below adults } \\
\text { within } \\
\text { barnacle } \\
\text { zone }\end{array}$ & 46 & 2 & 33 & 30 & 0 & 24 \\
\hline $\begin{array}{c}\text { Site } 1 \\
\text { total }\end{array}$ & & 140 & 4 & 165 & 89 & 1 & 128 \\
\hline $2 \mathrm{a}$ & $\begin{array}{l}\text { within adult } \\
\text { population }\end{array}$ & 43 & 5 & 84 & 29 & 1 & 74 \\
\hline $2 b$ & $\begin{array}{l}\text { within adult } \\
\text { population }\end{array}$ & 45 & 3 & 54 & 28 & 2 & 39 \\
\hline $2 c$ & $\begin{array}{l}\text { within adult } \\
\text { population }\end{array}$ & 40 & 8 & 77 & 27 & 3 & 50 \\
\hline $\begin{array}{c}\text { Site } 2 \\
\text { total }\end{array}$ & & 128 & 16 & 215 & 84 & 6 & 163 \\
\hline $3 a$ & $\begin{array}{l}\text { below adults } \\
\text { within } \\
\text { barnacle } \\
\text { zone }\end{array}$ & 48 & 0 & 55 & 30 & 0 & 26 \\
\hline $3 b$ & $\begin{array}{l}\text { within adult } \\
\text { population }\end{array}$ & 44 & 4 & 29 & 27 & 3 & 22 \\
\hline 3c & $\begin{array}{l}\text { below adults } \\
\text { within } \\
\text { barnacle } \\
\text { zone }\end{array}$ & 34 & 14 & 35 & 26 & 4 & 33 \\
\hline $\begin{array}{c}\text { Site } 3 \\
\text { total }\end{array}$ & & 126 & 18 & 119 & 83 & 7 & 81 \\
\hline $\begin{array}{l}\text { Grand } \\
\text { total }\end{array}$ & & 394 & 38 & 499 & 256 & 14 & 372 \\
\hline
\end{tabular}

Individual snails were not measured during the processing of individual pads, however they were collected and preserved. Later to have a size range of settlers, they were organized 
by size and the 20 largest and smallest individuals were measured. Recruits size ranged from 0.03mm- $0.07 \mathrm{~mm}$ long and $0.02 \mathrm{~mm}-0.06 \mathrm{~mm}$ wide. All snails collected from December through February were towards the smaller end of the size range and the larger cohort of individuals didn't begin showing up until the beginning of March and were present throughout the rest of the sampling.

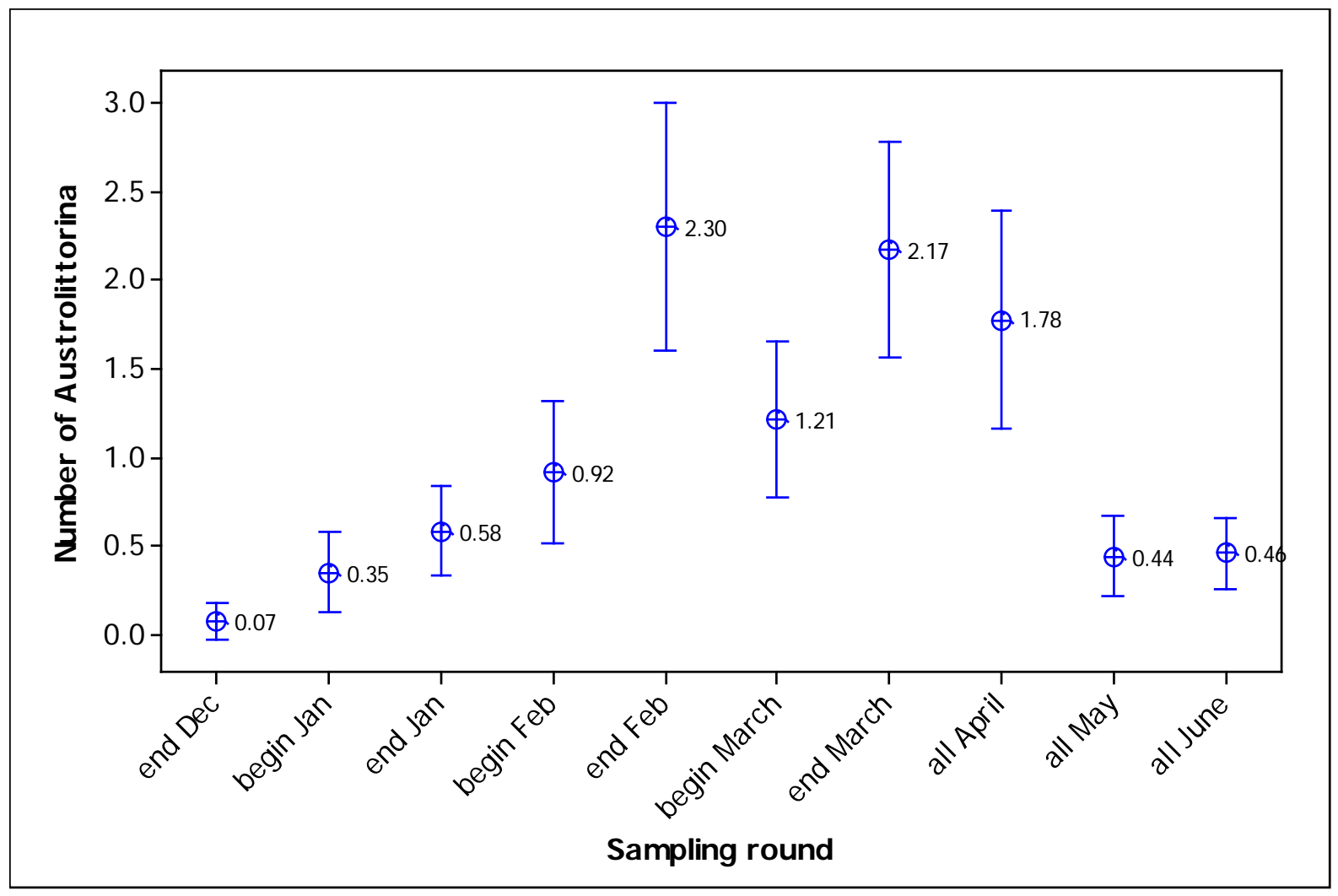

Figure 17. The mean number of Austrolittorina settlers per settlement pad from December 2007- June 2008. Circles indicate the sample mean, while bars indicate the standard error (95\% confidence interval).

The settlement at each of the sites varied with respect to the number of settlers and when the peak settlement period occurred. Settlement was highest site 2, followed by site 1 , and finally site 3 (Figure 18). These sites also differed in periods of peak settlement. 
Settlement was highest at site 1 (40 Austrolittorina settlers) and site 2

(61 Austrolittorina setters) during the end February, while peak settlement at site 3

(31 Austrolittorina setters) was during all of April (Figures 19-21). Although sites differed in times of peak settlement, all sites showed two peaks in the abundance of settlers. Site 1 and 2 had peaks in settlement at similar times, while sites 3 second peak (and highest) in settlement was slightly delayed.

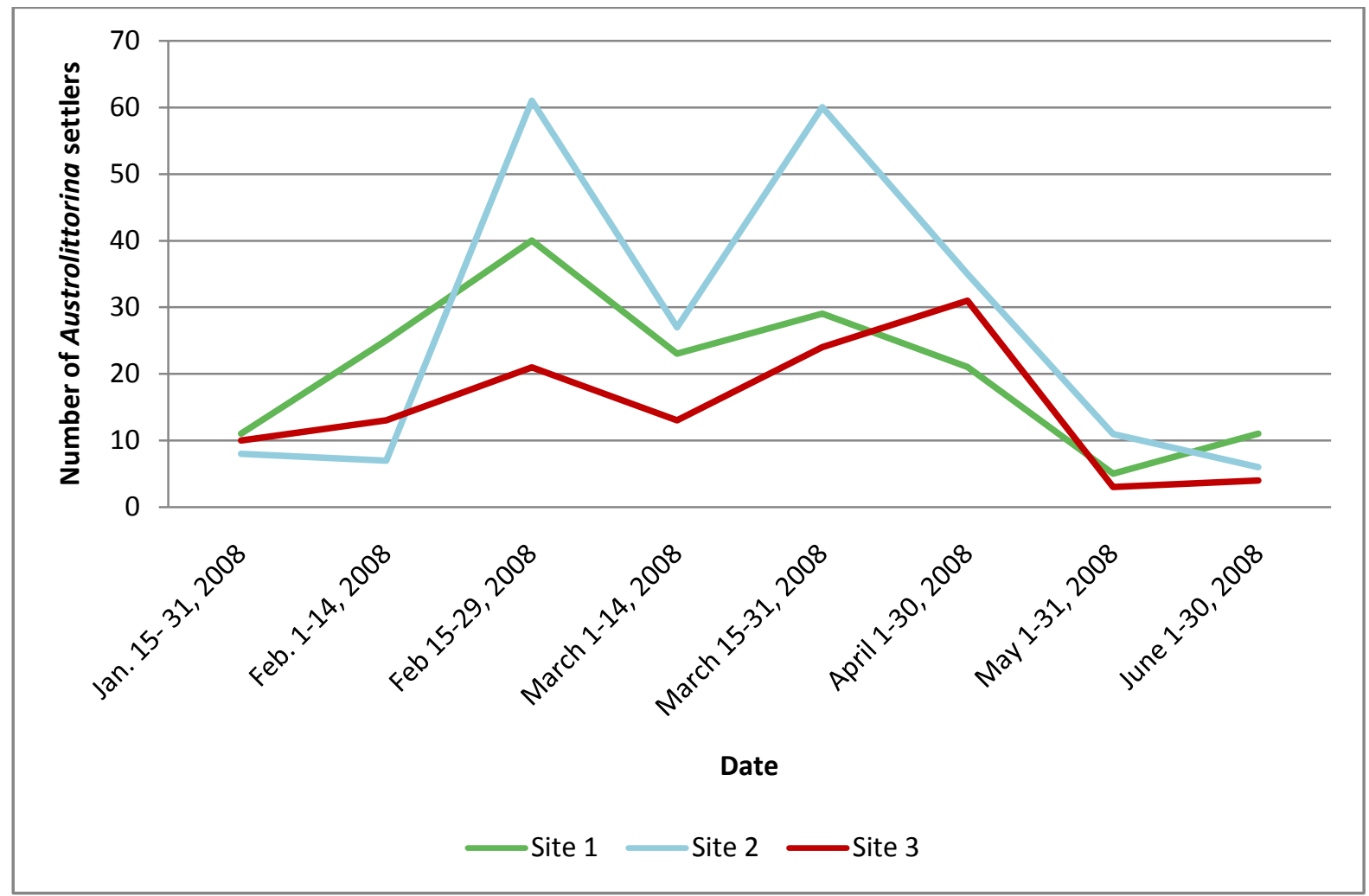

Figure 18. Total Austrolittorina settlement at each of the three sites during each sampling round, pooling all settlement pads and replicate sites. 


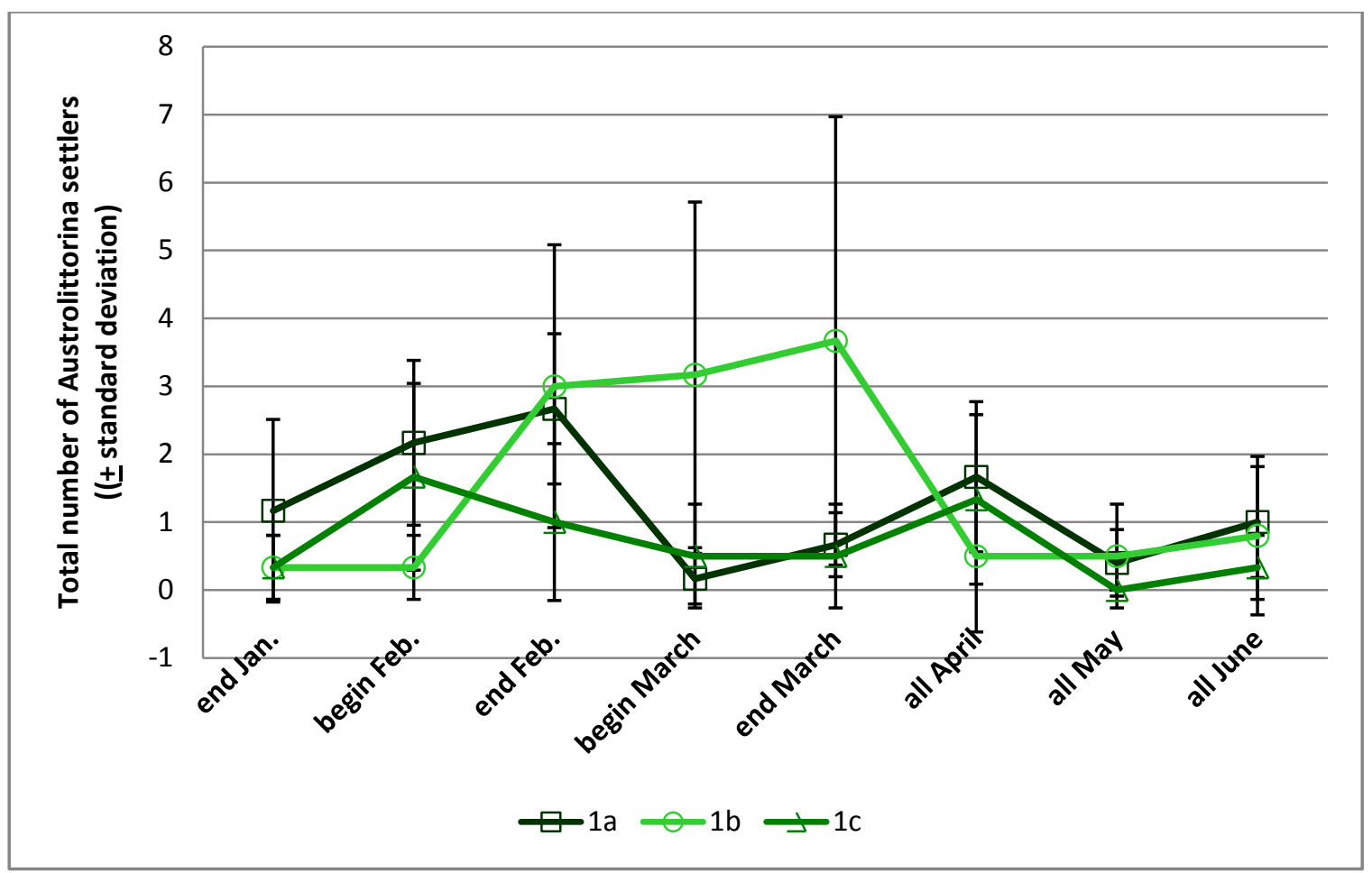

Figure 19. Comparison of the average number of Austrolittorina settlers for all settlement pads at site 1's replicates sites from January - June 2008. The settlement pads at site 1b were deployed within the adult population; pads at sites 1a and 1c were deployed below.

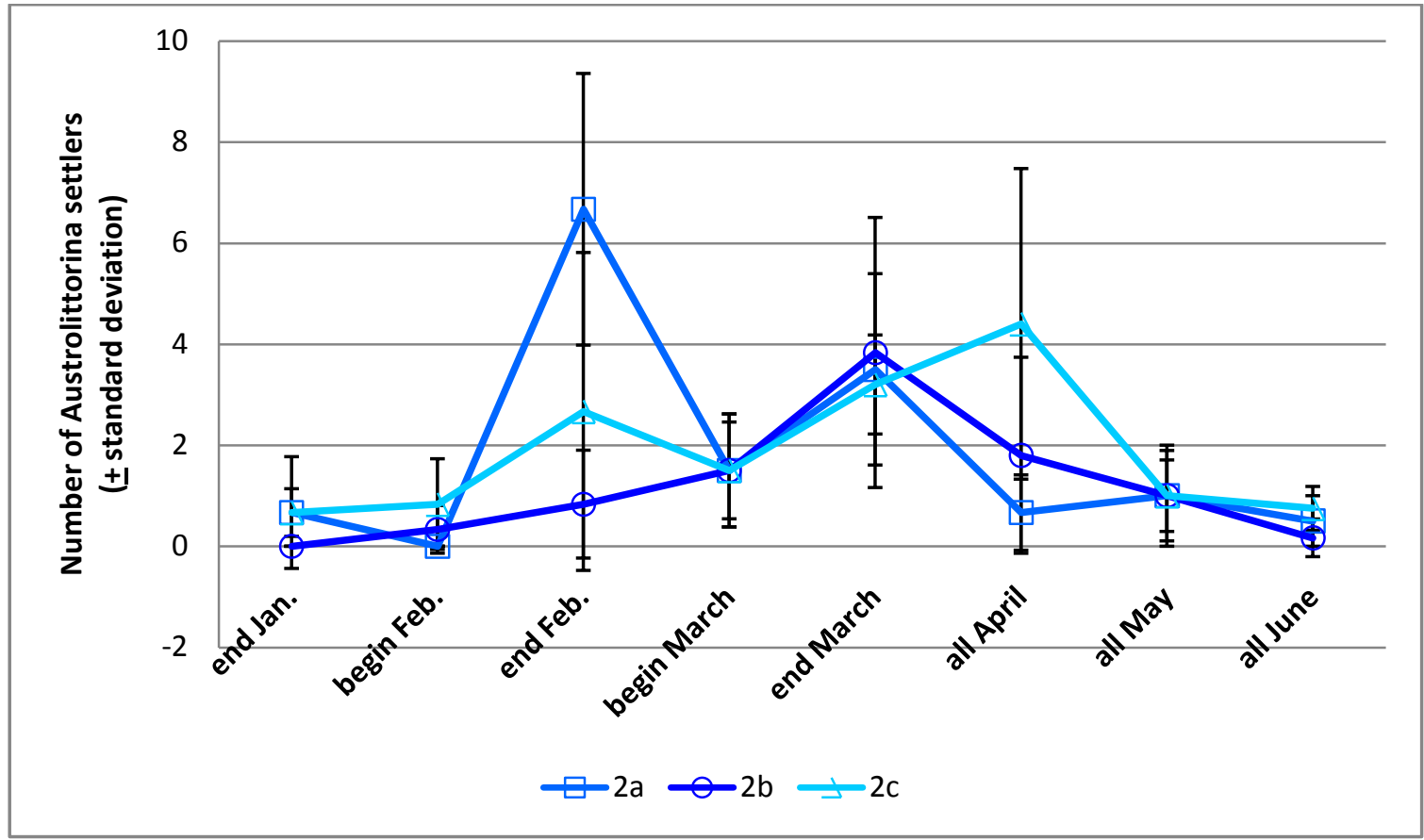

Figure 20. Comparison of the average number of Austrolittorina settlers for all settlement pads at site 2's replicates sites from January - June 2008. All of the settlement pads at site 2 were deployed within the adult population. 


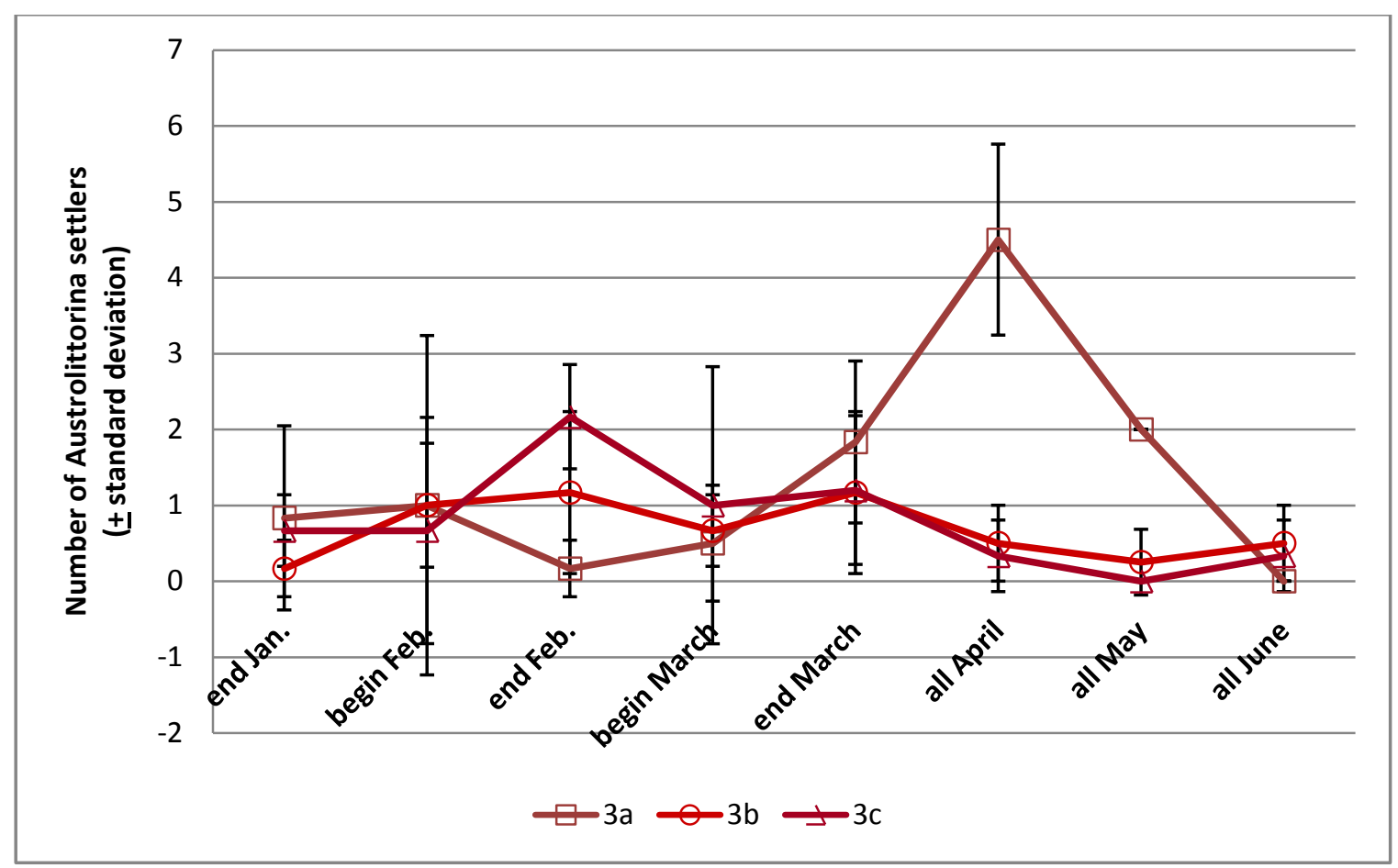

Figure 21. Comparison of the average number of Austrolittorina settlers for all settlement pads at site 3's replicates sites from January - June 2008. Settlement pads at site 3b were deployed within the adult population, and were deployed below the adults at sites 3a and 3c.

Kruskal- Wallis tests of settlement by site showed a significant difference for both data sets (main set $p=0.014$, subset $p=0.032$ ) with site 2 (in particular sites $2 \mathrm{a}$ and $2 \mathrm{c}$, see figure 20) having the overall highest recruitment rates, although the ranking of sites for each data set varied. In order to focus on the variability in settlement due to settlement pad placement a non-parametric two-way test was conducted. A Mann-Whitney test directly compared sites with pads deployed within the adult population and for those deployed below it, and showed no significant difference for the main data $(p=0.118, w=33109.5)$; however, the subset of the data showed significantly less settlement on pads deployed below the adult populations in the barnacles, with more settlers found on pads deployed within the adult population $(p=0.035$, $w=13719.5)$. To ensure there was no preference for snails to recruit below the adult 
population, the number of recruits vs. the distance to adults was tested for the subset of pads deployed below the adults which showed no significant difference $(K W p=0.472, p=0.404)$ or correlation (Pearson's coeff. $=0.017, p=0.833$ ). While the distance from the nearest adult to settlement pads deployed below the population showed no significant affects on settlement along that area of the shore, the comparison between the placement of pads within or below the adult population showed higher rates of settlement within the adult population.

\subsubsection{Density manipulations}

To investigate the relationship between the adult density and recruit settlement, total settlement was compared among each of the density treatments. Results showed no difference in Austrolittorina settlement based on density manipulations preformed for both data sets ( $p=0.803, p=0.350$ ) (Figure 22). There was a large amount of variation between settlement deployments at the exact same location which showed no link to any particular density treatment (Figure 23). The total Austrolittorina settlement was not correlated with any density treatment $(p=0.175, p=0.323)$. 


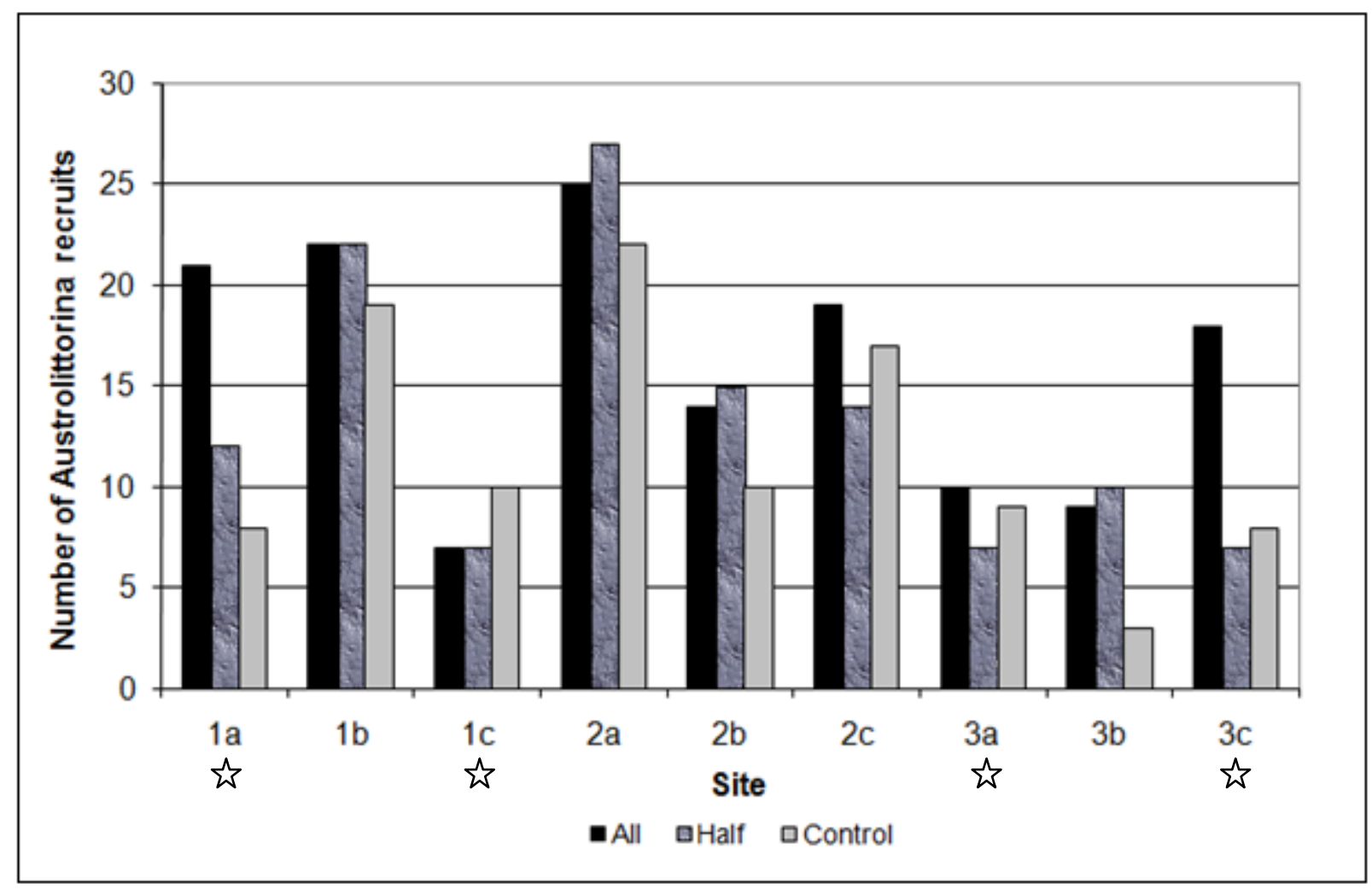

Figure 22. Total Austrolittorina settlement by site and density treatment January- March 2008. Sites with stars below the label indicate sites deployed below the adult population.

Of the nine sites, four had the highest total number of recruits when all adults were removed from the density treatment plots, three sites had highest recruitment when half of the adults were removed, and two sites had highest recruitment among the control plots. The average number of recruits at each site among the three density treatments showed considerable variation. This variation was primarily due to the peak periods of recruitment when a larger than average number of snails were found among all of the density treatments. 


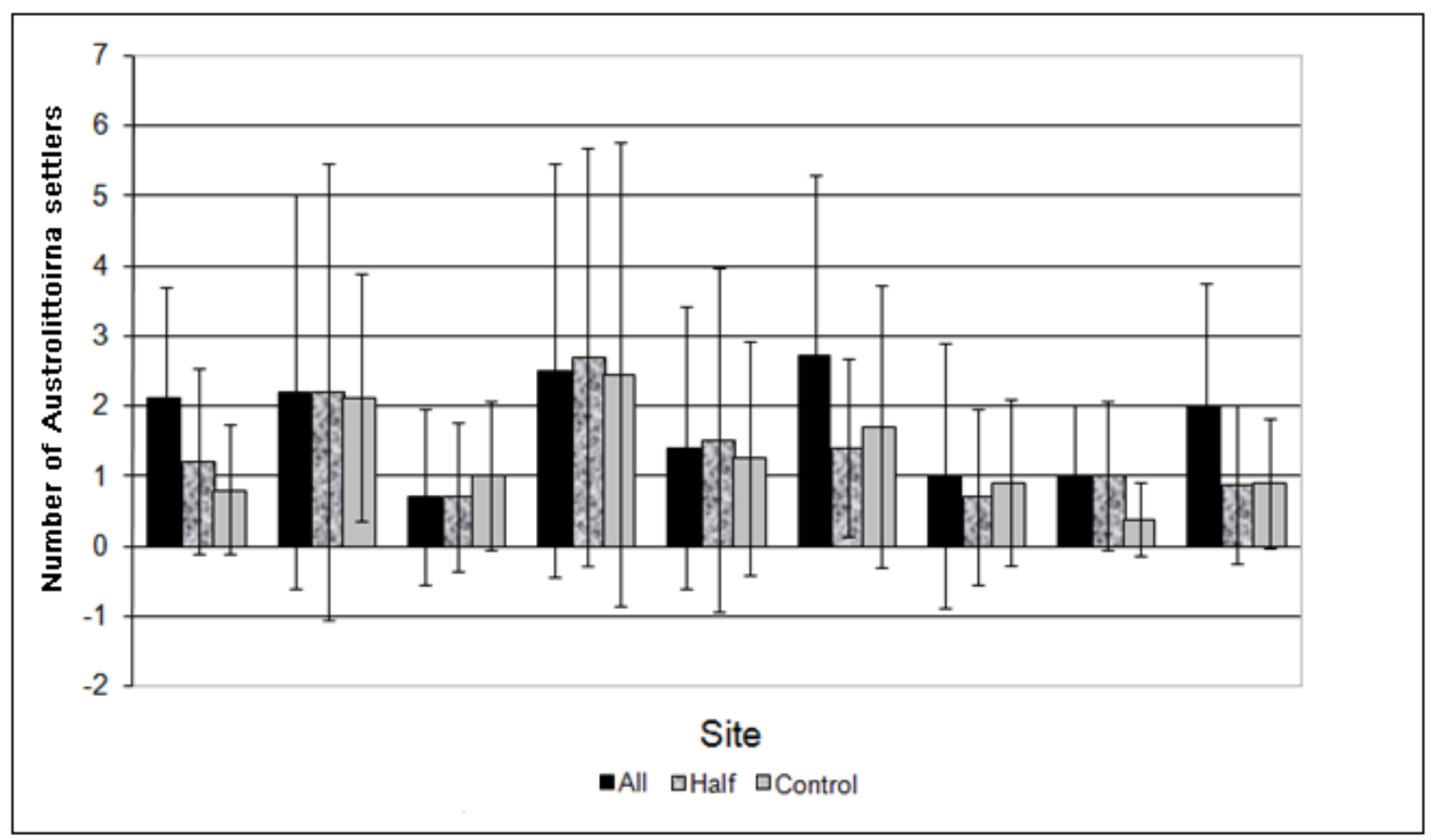

Figure 23. Average Austrolittorina settlement by site and density treatment January- March 2008 (error bars indicating \pm standard deviation).

\subsubsection{Ecological and environmental parameters}

Ecological and environmental factors were examined to determine if there were differences between the sites settlement pads and the number of Austrolittorina recruits. The extent that these factors affect Austrolittorina settlement was investigated by using Pearson correlations test. This test was used to find any correlations between the number of Austrolittorina settlers and: a prosobranch snail Eatoniella spp. (the species believed to have negative correlation with Austrolittorina settler abundance), an unidentified snail believed to be a closely related prosobranch species if not one of the two new Zealand Austrolittorina species, cyprid barnacle larvae, and other family groupings including all other snails, bivalves, worms, crustaceans, and algae as well as the amount of sand retained by the settlement plate (Figures 24-26). Two of these factors showed a correlation when the entire main data set was tested; 
there was a significant correlation between Austrolittorina settlers and the Eatoniella spp. $(p=0.037)$ and the unknown species $(p=0.004)$. The correlation between Austrolittorina settlers and the unknown species strengthens the hypothesis that the unknown species is a species of New Zealand Austrolittorina.

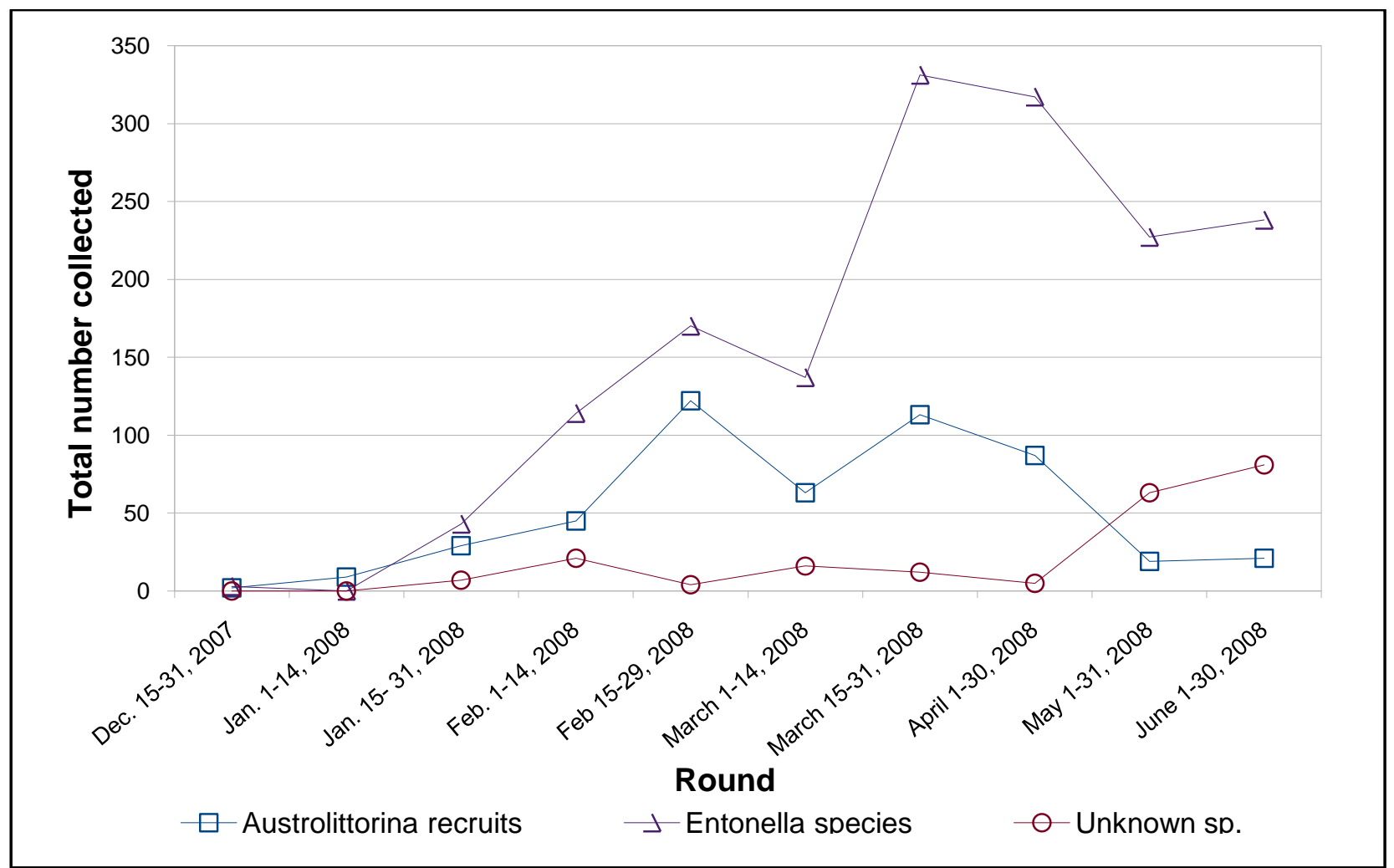

Figure 24. Total number of Austrolittorina settlers, Eatoniella species, and unknown prosobranch present on all settlement pads during each round Dec. 2007- June 2008.

The total number of Austrolittorina settlers collected each sampling round show a similar trend seen in the number of and the number of Eatoniella sp. and an unknown species believed to be a related Austrolittorina sp. collected (Figure 24). While these species showed a similar trend the second peak of Eatoniella sp. was more exaggerated than that of 
the Austrolittorina settlers. The total amount of Austrolittorina settlement was higher at sites 1b, 2a, and 2c. Sites 1a and 2c had the overall largest average number of Eatoniella species, while the unknown species were on average most abundant at site 3a. The suspected negative correlation between Austrolittorina settlers and the Eatoniella sp. was not found, and these species seem to be following similar settling cues or potentially responding to lunar cycles.

Individual sites ecological factors were compared to other sites to detect differences in composition of species collected on settlement pads. Site comparisons showed significant variability in the presences of other snails $(p<0.001)$, barnacles $(p<0.001)$, bivalves $(p<0.001)$, algae $(p<0.001)$, and sand $(p<0.001)$, with no significant differences in the presences of worms $(p=0.055)$ or crustaceans $(p=0.094)$ (Table 4).

Table 4. Differences in the ecological and environmental factors among the sites, the lowest and highest ranked sites in addition to Kruskal-Wallis results are presented.

\begin{tabular}{|c|c|c|c|c|c|c|c|}
\hline $\begin{array}{l}\text { Kruskal- } \\
\text { Wallis results }\end{array}$ & $\begin{array}{l}\text { Other } \\
\text { snails }\end{array}$ & Barnacles & Bivalves & Worms & Crustacean & Algae & Sand \\
\hline $\begin{array}{l}\text { lowest ranked } \\
\text { site } \\
\text { highest ranked }\end{array}$ & $1 b$ & $1 b$ & $3 c$ & 2c & $2 a$ & $2 a$ & $2 a$ \\
\hline site & $1 \mathrm{a}$ & $1 \mathrm{a}$ & 1a \& 3a & $3 b$ & 3a & 1c & 1a \\
\hline p-value & $<0.001$ & $<0.001$ & $<0.001$ & 0.051 & 0.094 & $<0.001$ & $<0.001$ \\
\hline
\end{tabular}

When ecological and environmental parameters were tested using the subset of the data there were the same significant correlations. Kruskal-Wallis test of these variables showed more of the unknown species and Eatoniella species $(p<0.001, p<0.001)$ and algae present at site $1 \mathrm{c}(p<0.001)$, the highest amount of sand at site $2 \mathrm{c}$ and $1 \mathrm{a}(p=0.002)$, and the highest number of the unknown species present at site 3a (Figure 25). Total numbers of settlement pads with each species surveyed show a similar general trend 
among Austrolittorina recruits, other snails, and barnacles, all of which have planktonic larval phases (Figure 26). In general these species' abundance increased in February and March and began to decline in May and June. The number of Austrolittorina settlers and the presences of algae show a similar trend, indicating high algal abundance maybe a cue used by settling recruits.

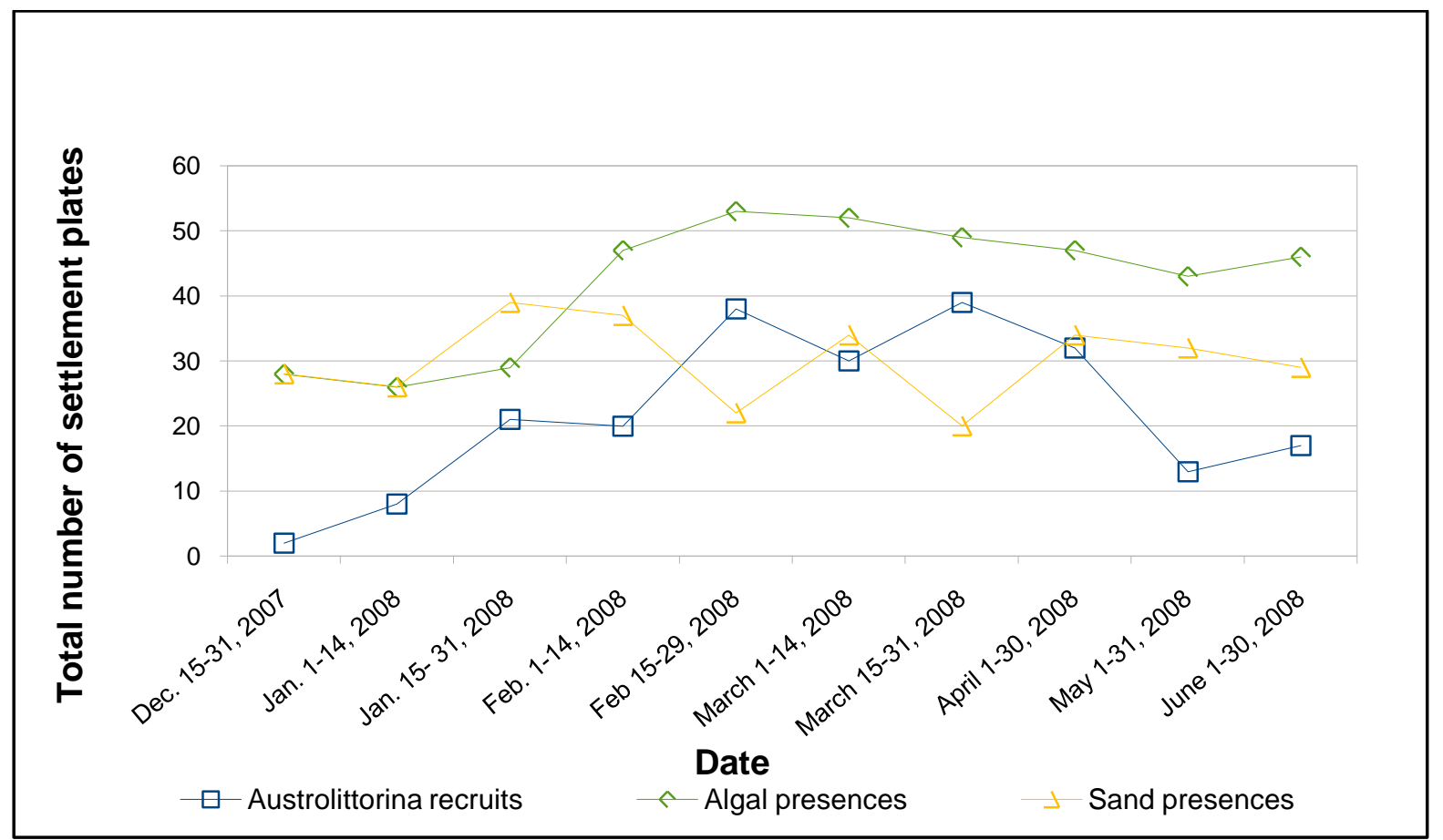

Figure 25. Total number of pads with Austrolittorina recruits and environmental factors of algae and sand Dec. 2007- June 2008. 


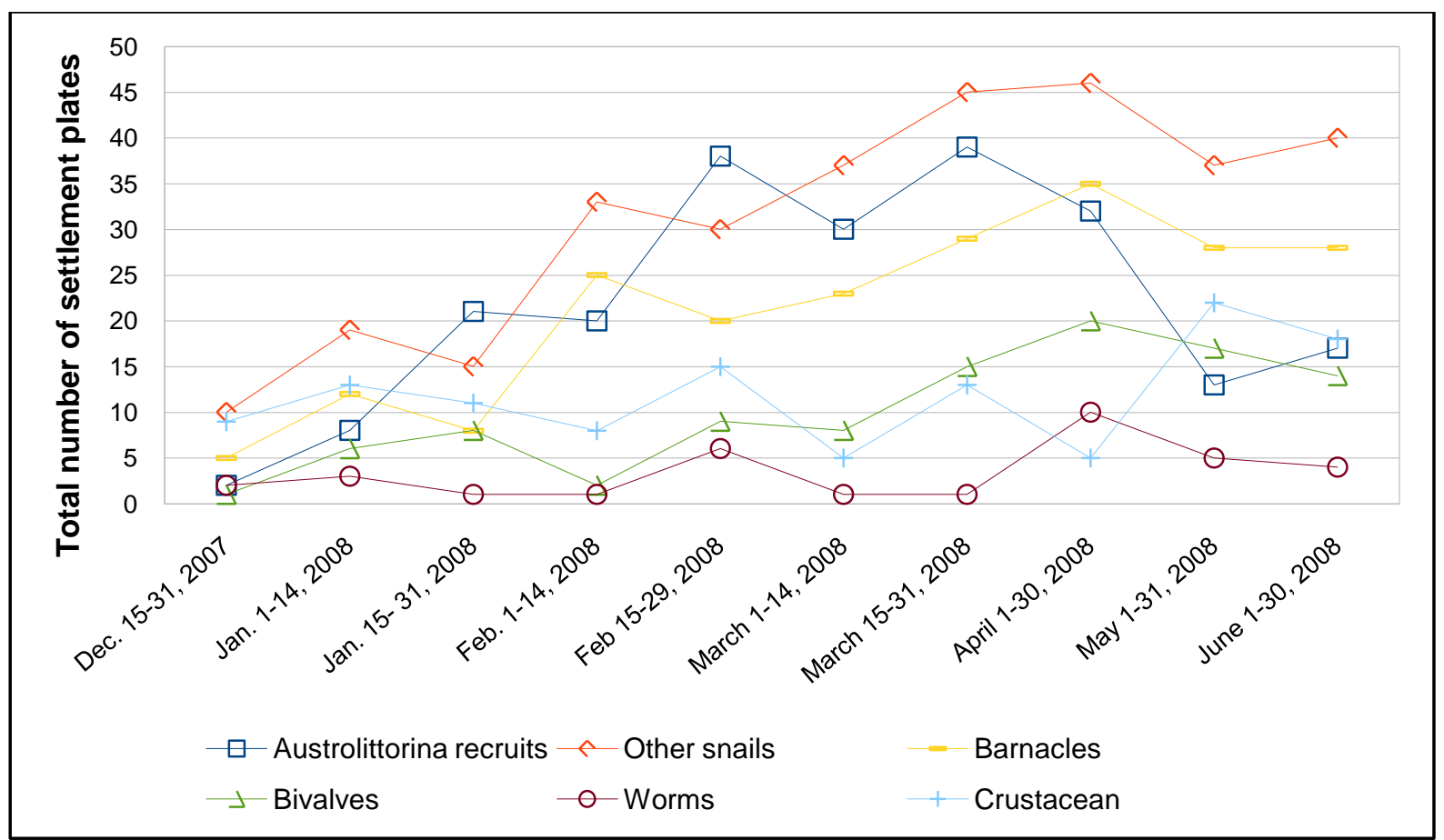

Figure 26. Total number of settlement pads with presence of Austrolittorina settlers, other snails, barnacles, bivalves, worms and crustaceans Dec. 2007-June 2008.

Peak periods of Austrolittorina settlement correspond to declines in sand presence, which may indicate calmer sea conditions. These time frames also align with periods of tidal fluctuations associated with the full moon. Looking further into the possible correlation with the moon phases, reveals that the peak periods of settlement are from pads deployed during time frames around the full moon (Figure 27). 


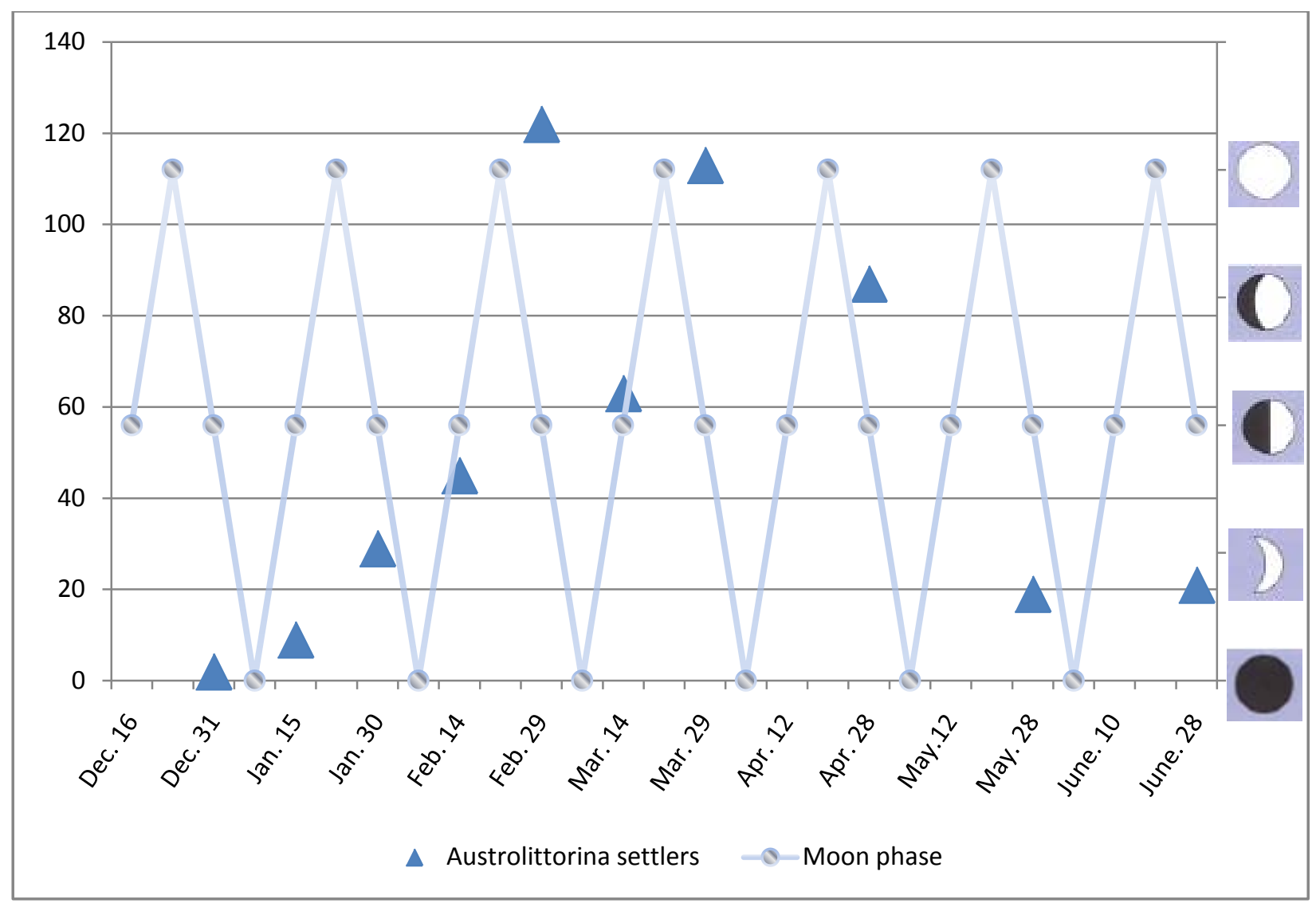

Figure 27. Total Austrolittorina settlement correlated to moon phase for the entire sample period, Dec. 15, 2007- June 30, 2008. 


\section{$\underline{3.3 \text { Fecundity results }}$}

A total of 168 tagged snails were collected after eight months in the field and dissected. Of these snails 82 were A. antipodum (39-site 1, 19 -site 2, 24-site 3) and 86 A. cincta (40-site 1, 22-site 2, 24-site 3) (Table 5). Five snails were of sizes that fell within the buffers between the size classes and were not used for analysis, four of which were A. cincta and one $A$. antipodum. A minimum of five snails in each size class at each site were dissected. Upon collection three A. antipodum lost their tag and could not be individually identified, however they were assigned a special code to account for this and were still used in the analysis of a total of 163 snails.

Dissections revealed A. antipodum to have a highest proportion of females (both mature and not) (53\% $\circ, 37 \%$ o, $10 \%$ juveniles) with a demographic skewed towards more females. Austrolittorina cincta also had more females present, however the demographics were more evenly distributed (48\% $+, 42 \% \hat{\gamma}, 10 \%$ juveniles) (Figure 28). Among the different reproductive classifications $A$. antipodum had the most mature females, followed by mature males, females, juveniles and finally males (Table 5). Austrolittorina cincta on the other hand had the most mature males, mature females, females, and an even number of males and juveniles. Juveniles comprised $10 \%$ of the population sample for both species, while the distribution of these juveniles along the shore varied. Austrolittorina cincta had more juveniles present on the high shore while $A$. antipodum had more juveniles present on the low shore. Sex ratios were also compared between the species to determine if there was a significant demographic variation between the species, sites and shore heights. 
Table 5. Distribution of snails dissected at each site among the various reproductive classifications and size distributions. Totals are presented in bold.

\begin{tabular}{|c|c|c|c|c|c|c|c|c|}
\hline Site & Species & Size class & Mature female & Female & Mature male & Male & Unsexed & Total \\
\hline \multirow[t]{9}{*}{1} & A. antipodum & S & 2 & 1 & 4 & 0 & 1 & 8 \\
\hline & & M & 8 & 0 & 6 & 0 & 1 & 15 \\
\hline & & $\mathrm{L}$ & 5 & 3 & 6 & 2 & 0 & 16 \\
\hline & & $\Sigma$ & 15 & 4 & 16 & 2 & 2 & 39 \\
\hline & A. cincta & $\mathrm{S}$ & 1 & 1 & 1 & 1 & 3 & 7 \\
\hline & & M & 6 & 3 & 6 & 1 & 0 & 16 \\
\hline & & $\mathrm{L}$ & 4 & 4 & 5 & 1 & 0 & 14 \\
\hline & & $\boldsymbol{\Sigma}$ & 11 & 8 & 12 & 3 & 3 & 37 \\
\hline & Both species & Site total & 26 & 12 & 28 & 5 & 5 & 76 \\
\hline \multirow[t]{9}{*}{2} & A. antipodum & S & 1 & 0 & 2 & 0 & 2 & 5 \\
\hline & & M & 5 & 1 & 2 & 1 & 1 & 10 \\
\hline & & $\mathrm{L}$ & 5 & 1 & 0 & 0 & 0 & 6 \\
\hline & & $\Sigma$ & 11 & 2 & 4 & 1 & 3 & 21 \\
\hline & A. cincta & $\mathrm{S}$ & 0 & 1 & 2 & 1 & 1 & 5 \\
\hline & & M & 1 & 0 & 1 & 1 & 2 & 5 \\
\hline & & $\mathrm{L}$ & 7 & 3 & 0 & 0 & 0 & 10 \\
\hline & & $\Sigma$ & 8 & 4 & 3 & 2 & 3 & 20 \\
\hline & Both species & Site total & 19 & 6 & 7 & 3 & 6 & 41 \\
\hline \multirow[t]{9}{*}{3} & A. antipodum & $\mathrm{S}$ & 0 & 1 & 3 & 1 & 2 & 7 \\
\hline & & M & 3 & 6 & 2 & 0 & 1 & 12 \\
\hline & & $\mathrm{L}$ & 2 & 1 & 2 & 0 & 0 & 5 \\
\hline & & $\Sigma$ & 5 & 8 & 7 & 1 & 3 & 24 \\
\hline & A. cincta & S & 0 & 3 & 4 & 1 & 2 & 10 \\
\hline & & M & 1 & 0 & 5 & 1 & 0 & 7 \\
\hline & & $\mathrm{L}$ & 1 & 2 & 1 & 1 & 0 & 5 \\
\hline & & $\Sigma$ & 2 & 5 & 10 & 3 & 2 & 22 \\
\hline & Both species & Site total & 7 & 13 & 17 & 4 & 5 & 46 \\
\hline All sites & A. antipodum & $\mathrm{S}$ & 3 & 2 & 9 & 1 & 5 & 20 \\
\hline \multirow[t]{8}{*}{ Pooled } & & M & 16 & 7 & 10 & 1 & 3 & 37 \\
\hline & & $\mathrm{L}$ & 12 & 5 & 8 & 2 & 0 & 27 \\
\hline & & $\Sigma$ & 31 & 14 & 27 & 4 & 8 & 84 \\
\hline & A. cincta & $\mathrm{S}$ & 1 & 5 & 7 & 3 & 6 & 22 \\
\hline & & M & 8 & 3 & 12 & 3 & 2 & 28 \\
\hline & & $\mathrm{L}$ & 12 & 9 & 6 & 2 & 0 & 29 \\
\hline & & $\boldsymbol{\Sigma}$ & 21 & 17 & 25 & 8 & 8 & 79 \\
\hline & Both species & All sites & 52 & 31 & 52 & 12 & 16 & 163 \\
\hline
\end{tabular}




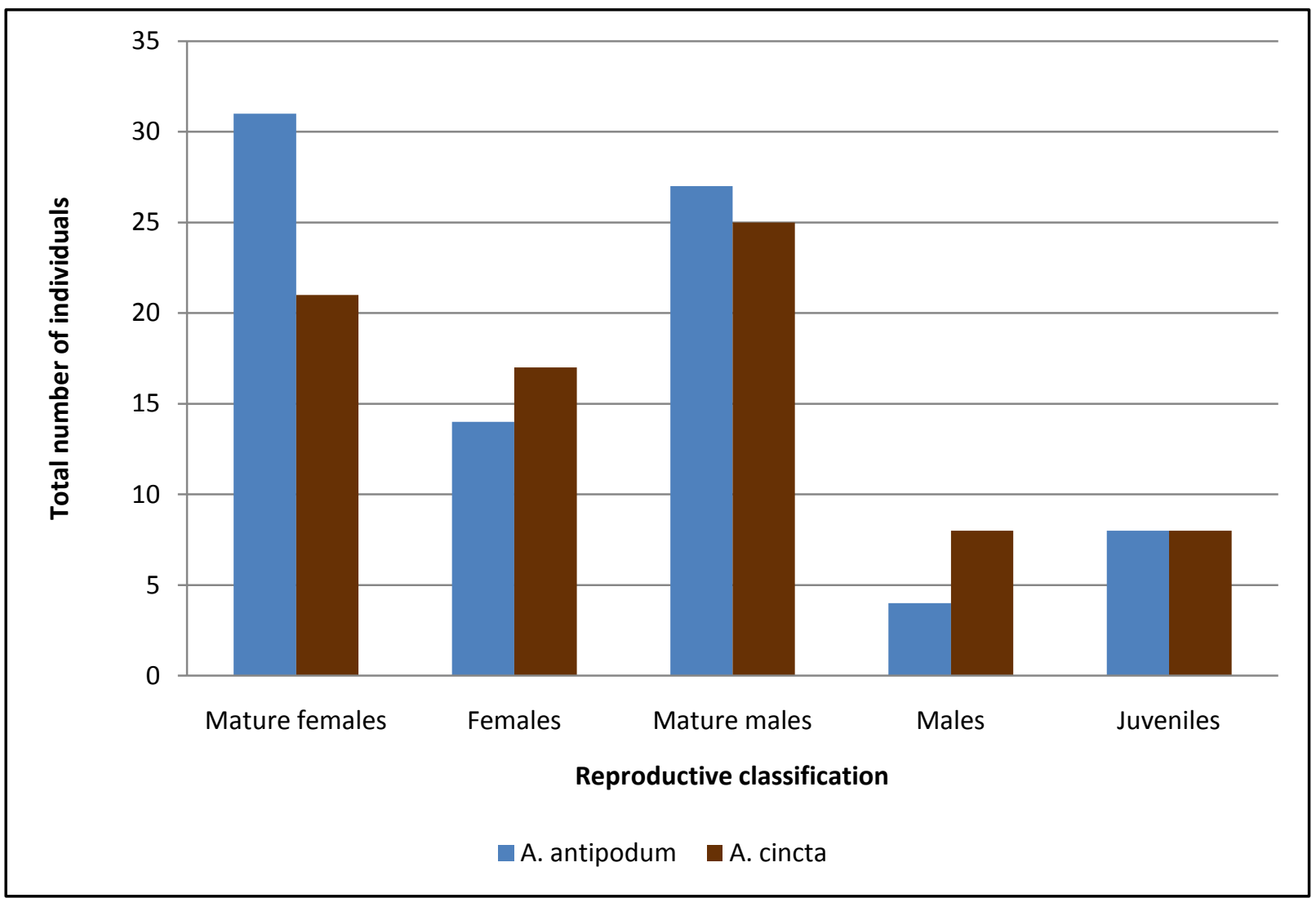

Figure 28. Distribution of $A$. antipodum and $A$. cincta among the reproductive classifications, all sites pooled.

To better understand the demographics of each species the various sex ratios for each of the size classes, at each site, for each species were calculated and are presented in appendix 5 and summarized in table 6. Sex ratios for each species, at each site, were tested to see if they deviate from a 1:1 female to male sex ratio. Chi squared tests confirmed a significant deviation from the 1:1 ratio of $A$. antipodum at sites 2 and 3 , where more females are present $\left(p=0.018 ; \chi^{2}=8.041\right)$. Shore heights were also tested to examine A. antipodum's sex ratio at each site between the low and high shores and confirmed skewed ratios at sites 2 (more females present) and 3 (more males present) on the low shore, and at site 2 on the high shore where there were more males present $\left(p<0.01 ; \chi^{2}=43.356\right)$. 
The Chi squared test for the $A$. cincta sex ratio showed there was a significant deviation from the $1: 1$ sex ratio at sites 2 (more females present) and 3 (more males present) $\left(p<0.01 ; \chi^{2}=22.402\right)$. The sex ratios between the low and high shore where also tested across all sites and showed a deviation in the 1:1 ratio on the low and high shore of site 2 and the low shore of site 3, with site 2 having more females and site 3 having more males present.

Table 6. Variation in demographic ratios between both species. Abbreviations and symbols for the ratios include the following: MF-Mature Female, MM- Mature Male, FFemale, M-Male, J-Juvenile, +-Female, and $\delta$ - Male.

$$
\text { Species MF:MM MF:F MM:M } q: \overbrace{}^{\uparrow} \text { juvenile }
$$
A. antipodum
$37: 32$
69:31 87:13
$54: 37: 9$
A. cincta
$27: 32 \quad 55: 45 \quad 76: 24$
48:42:10

Site specific variation in sex ratios among the low and high shore are presented in table 7. The low shore sample of A. antipodum at site 2 had the most dramatically skewed sex ratio, as no males were present in this sample. The only site and shore level with an even ratio of females to males was among the high shore A. antipodum sampled at site 1 . All of the shore heights and sites sampled showed an even sex ratio or one that favored females among the $A$. antipodum sampled. This was also the case for A. cincta at sites 1 and 2, however, the site 3 samples showed a larger ratio of males than females at both shore heights. 
Table 7. Female to male sex ratios for both Austrolittorina species at all sites along the low and high shore. The most skewed ratio is found along the low shore at site 2 where no male A. antipodum were found.

\begin{tabular}{|c|c|c|c|c|}
\hline Species & Site & $\begin{array}{l}\text { Shore } \\
\text { height }\end{array}$ & 오:수 & $\mathrm{N}$ \\
\hline \multirow{8}{*}{ A. antipodum } & 1 & Low & $48: 43$ & 23 \\
\hline & & High & $50: 50$ & 16 \\
\hline & 2 & Low & 63:00 & 8 \\
\hline & & High & $60: 38$ & 13 \\
\hline & 3 & Low & $60: 23$ & 13 \\
\hline & & High & $45: 45$ & 11 \\
\hline & All sites & Low & $55: 30$ & 44 \\
\hline & & High & $55: 43$ & 34 \\
\hline \multirow[t]{8}{*}{ A. cincta } & 1 & Low & $53: 41$ & 17 \\
\hline & & High & $50: 40$ & 20 \\
\hline & 2 & Low & $66: 11$ & 9 \\
\hline & & High & $54: 36$ & 11 \\
\hline & 3 & Low & $38: 63$ & 8 \\
\hline & & High & $29: 57$ & 14 \\
\hline & All sites & Low & $52: 38$ & 40 \\
\hline & & High & $37: 45$ & 49 \\
\hline
\end{tabular}

Mann-Whitney tests were used to directly compare the A. antipodum and A. cincta's recaptured snails among the different reproductive classifications $(p=0.974)$, sizes classes $(p=0.932)$, sites $(p=0.937)$, shore heights $(p=0.235)$, and transplant treatment $(p>0.01)$. The only significant difference found was among the transplant treatments. Across all sites A. antipodum had higher recovery of transplants (along both shore heights) and more low shore individuals were recovered. Whereas, A. cincta showed higher recovery of controls and more individuals recovered from the high shore.

The number of individuals recovered from each of the size classes along the pooled low and high shores varied for both species, except for among A. cincta along the high shore which showed an even distribution between the three size classes. The highest recovery of $A$. 
antipodum was among the medium size class, while $A$. cincta recovery was highest among the large size class. The average size of individuals within each reproductive class also varied between the species among the different sites and shore heights (appendices 7-9).

The largest average size for mature females and mature males A. antipodum along the low shore was at site 1 ; whereas the largest average size on the high shore was at site 2. Austrolittorina antipodum had the smallest average size for all reproductive classes at site 3, except for the juveniles. Site 3 juveniles had the largest average size, which was larger than both the reproductively mature males and males. No one site among the $A$. cincta samples had the largest average size for all classifications or among reproductively mature snails. The high shore of site 2 had the largest average size for mature female and female $A$. cincta, with the smallest average size of mature males and males.

There were variations between these two species demographic distributions, transplant treatment effects, and in their abundance at different shore heights. These differences were further investigated by analyzing these same variables within the samples of each species.

\section{A. antipodum results}

Kruskal-Wallis tests comparing A. antipodum at each of the sites showed no significant differences in the reproductive classifications when tested against size class $(p=0.733)$, site $(p=0.126)$, transplant vs. control $(p=0.854)$, or transplant treatment (transplant or control for the low and high shore) $(p=0.249)$; however there was a significant difference in the abundance of each reproductive class along the pooled shore heights $(p=0.026$ complete results for all tests listed in appendix 6), which was primarily driven by the difference at site 2 . 
While there was no significant difference in the average size among the reproductive classes at each shore height, the average size of males on the low shore was larger than that on the high shore (Figure 29). The average size for each reproductive classification on the low and high shore shows a similar trend for each shore height with the exception of males. The average size of males on the low shore was larger than that of the high shore, however the male classification had the smallest sample size, and there was only one individual from the high shore.

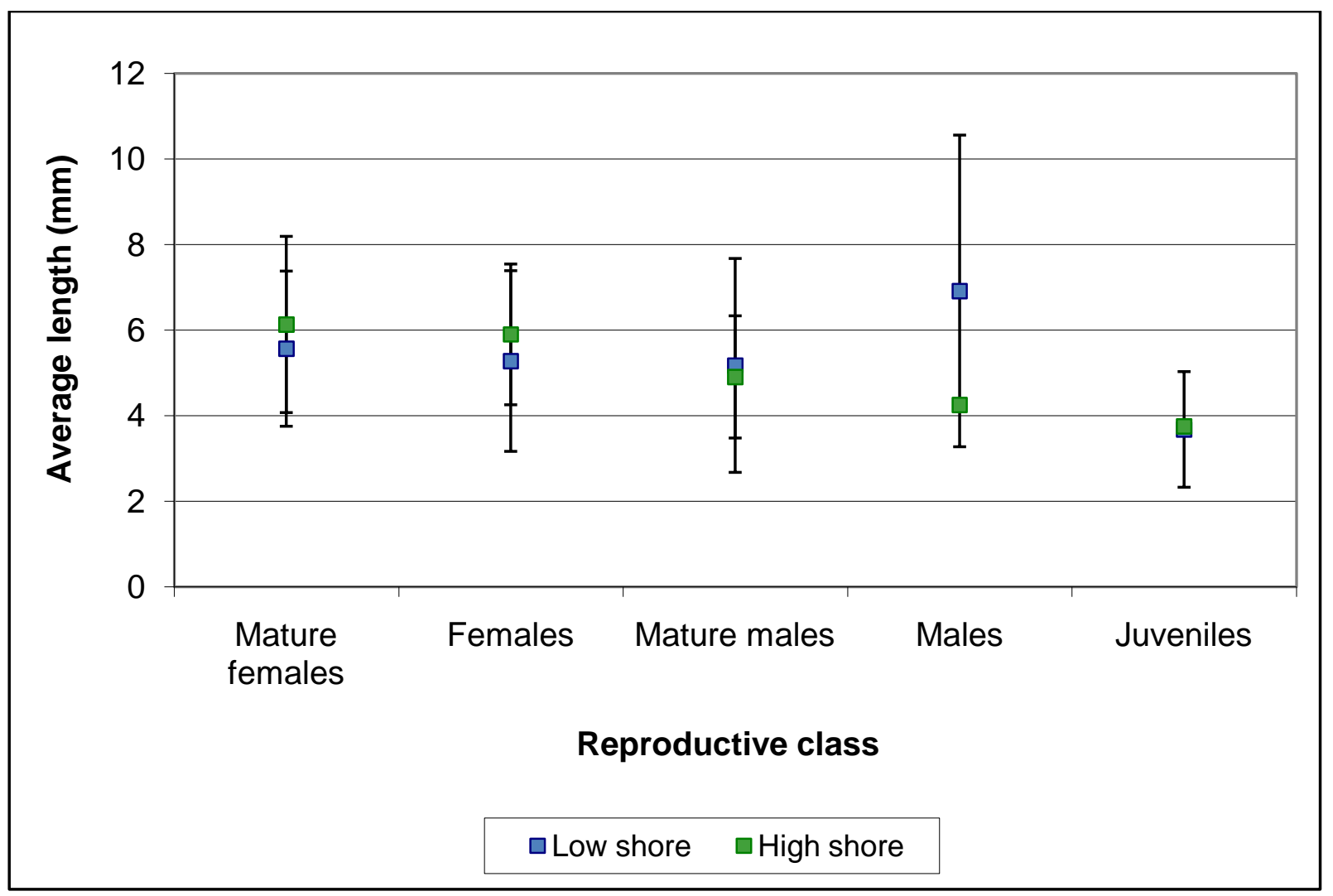

Figure 29. A. antipodum reproductive class average size on low and high shores across all sites. Boxes represent the mean size with bars indicating the standard deviation.

A Mann-Whitney test of mature female vs. mature male size, using the length measurement as a reference for the size, showed no significant difference in the size of mature males and the size of mature females $(p=0.058)$. The distribution of mature males and 
females among the three size classes shows a small proportion of mature females within the small size class and predominately falling within the medium and large size classes. The mature males are nearly evenly distributed within the three size classes with only $4 \%$ more in the medium size class.

Chi squared tests were conducted on the reproductive classifications verses shore level, with significant results $\left(p=0.020 ; \chi^{2}=7.846\right)$. Most of the snails were from the low shore, with more juveniles and females from the low shore, however there were more mature females and males from the higher shore. The average size for each reproductive class on each shore height at each site is represented in figure 30. The average size for each reproductive class along each shore height for all sites shows the largest average size for $A$. antipodum was among low shore males; however this reproductive class had the smallest sample size and one large individual (9mm in length) which was primarily responsible for this large average size. 


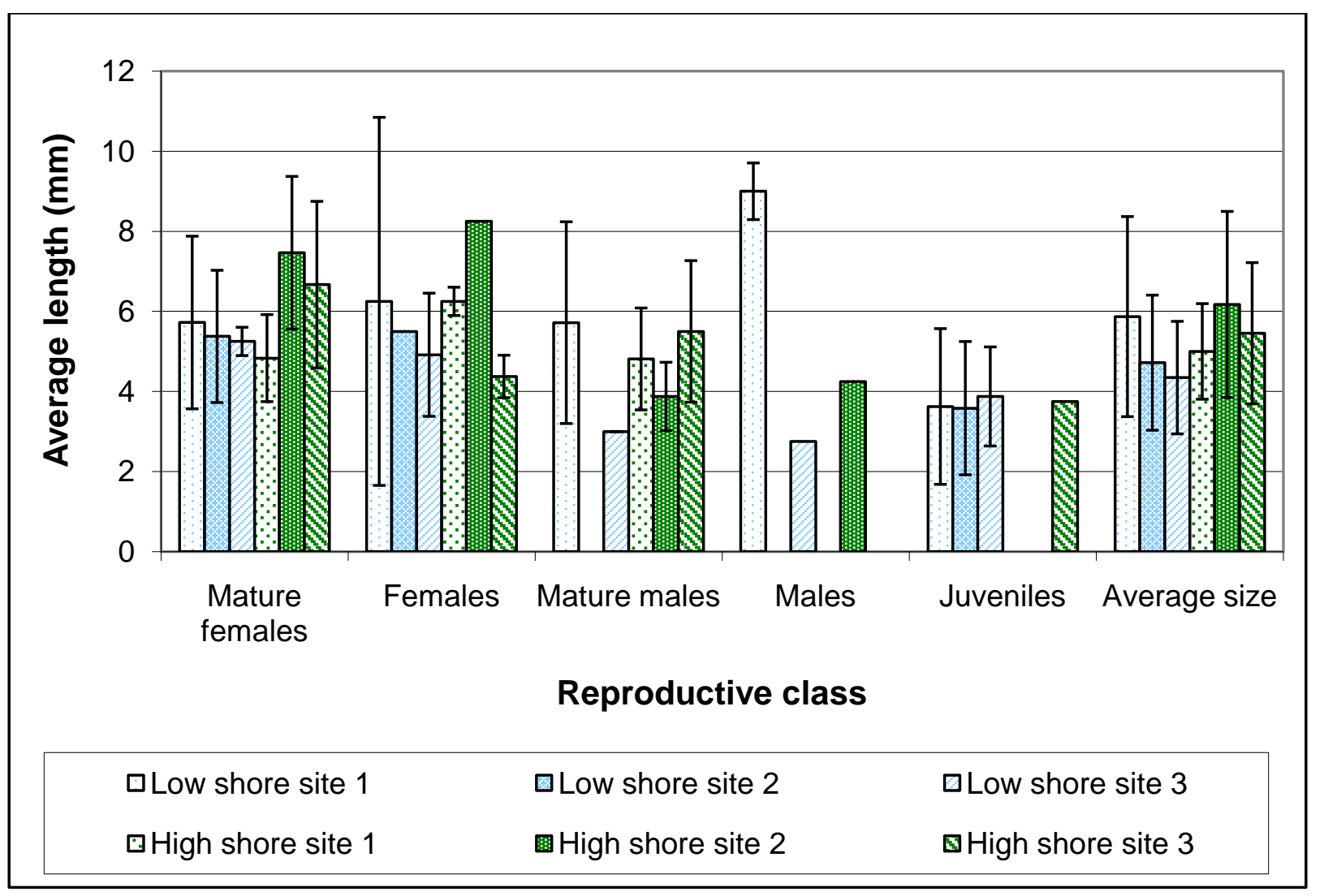

Figure 30. Size distribution of $A$. antipodum for all reproductive classes by site and shore height ( \pm standard deviation).

\section{$\underline{\text { A. cincta results }}$}

The same series of test ran on A. antipodum were run on A. cincta. Kruskal-Wallis tests of $A$. cincta at each of the sites showed no significant differences in the reproductive classifications when tested against size class $(p=0.139)$, site $(p=0.252)$, shore height ( $p=0.728)$, transplant vs. control $(p=0.474)$, and transplant treatment $(p=0.456)$. All juveniles fell into the small and medium size classes, adults within all size classes, and reproductively active adults within all sizes with the majority falling into the medium and large sizes. The average size for each reproductive classification on the low and high shore shows a similar trend for each shore height with the exception of juveniles (although there was significant 
overlap in the standard deviation) (Figure 31). The average size of juveniles was larger on the low shore was larger than that of the high shore.

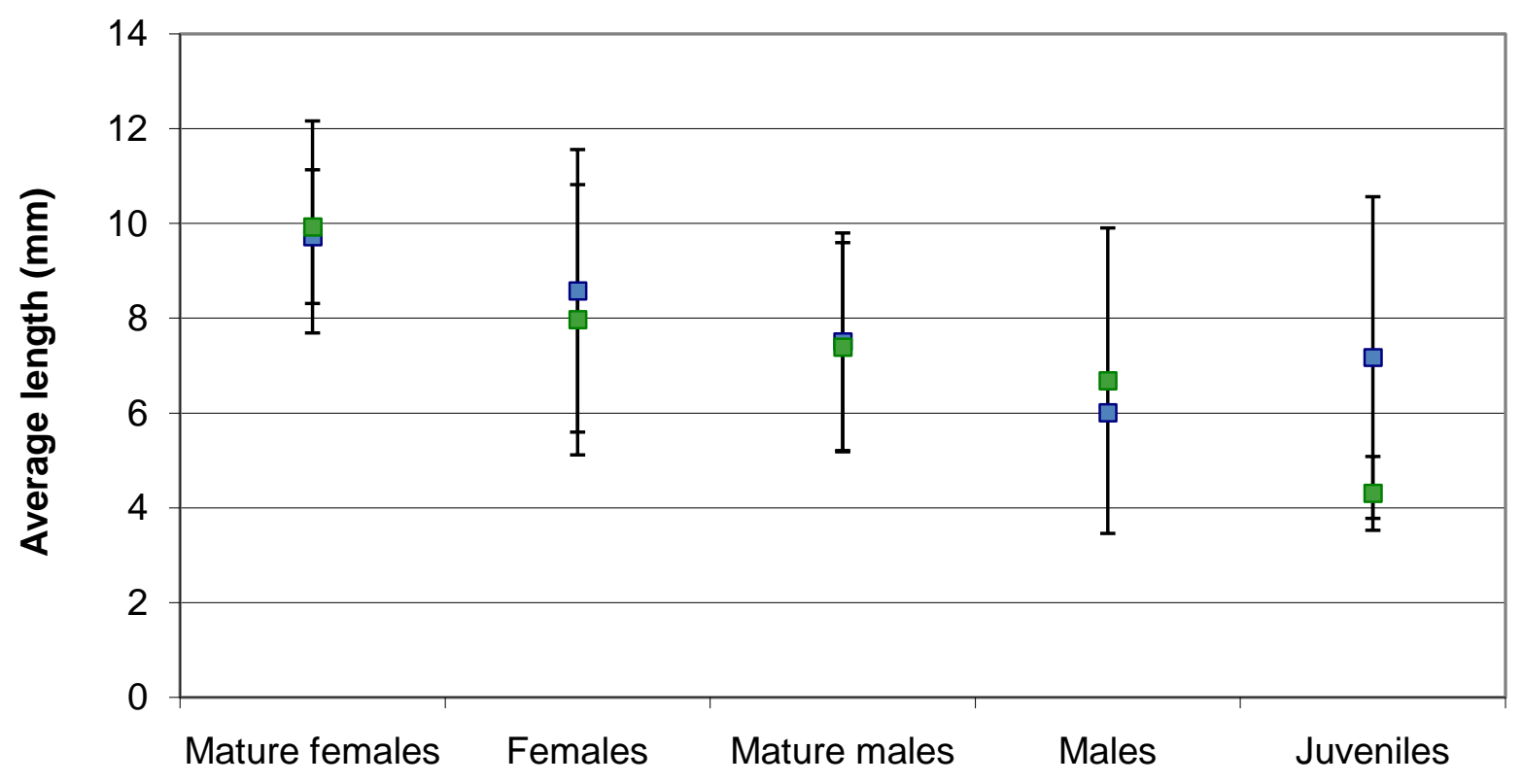

Reproductive class

口Low shore $\quad$ High shore

Figure 31. A. cincta reproductive class average size on low and high shores across all sites. Boxes represent the mean size with bars indicating the standard deviation.

A Mann-Whitney test of mature female vs. mature male length showed mature females were significantly larger than mature males $(p<0.001)$. The distribution of mature males and females among the three size classes shows a small proportion of mature females within the small size class and predominately falling within the large and medium size classes. The mature males are nearly evenly distributed within the small and large size classes, with a majority in the medium size class. 
Chi squared test were conducted on the reproductive classifications verses shore level, with no significant results $\left(\mathrm{p}=0.352 ; \chi^{2}=0.839\right)$. The average size for each reproductive class, along each shore height, for all sites, shows the largest average size for A. cincta was among mature females (Figure 32). Overall females, mature or not, were on average larger than males. Juveniles were significantly more abundant in the small size class.

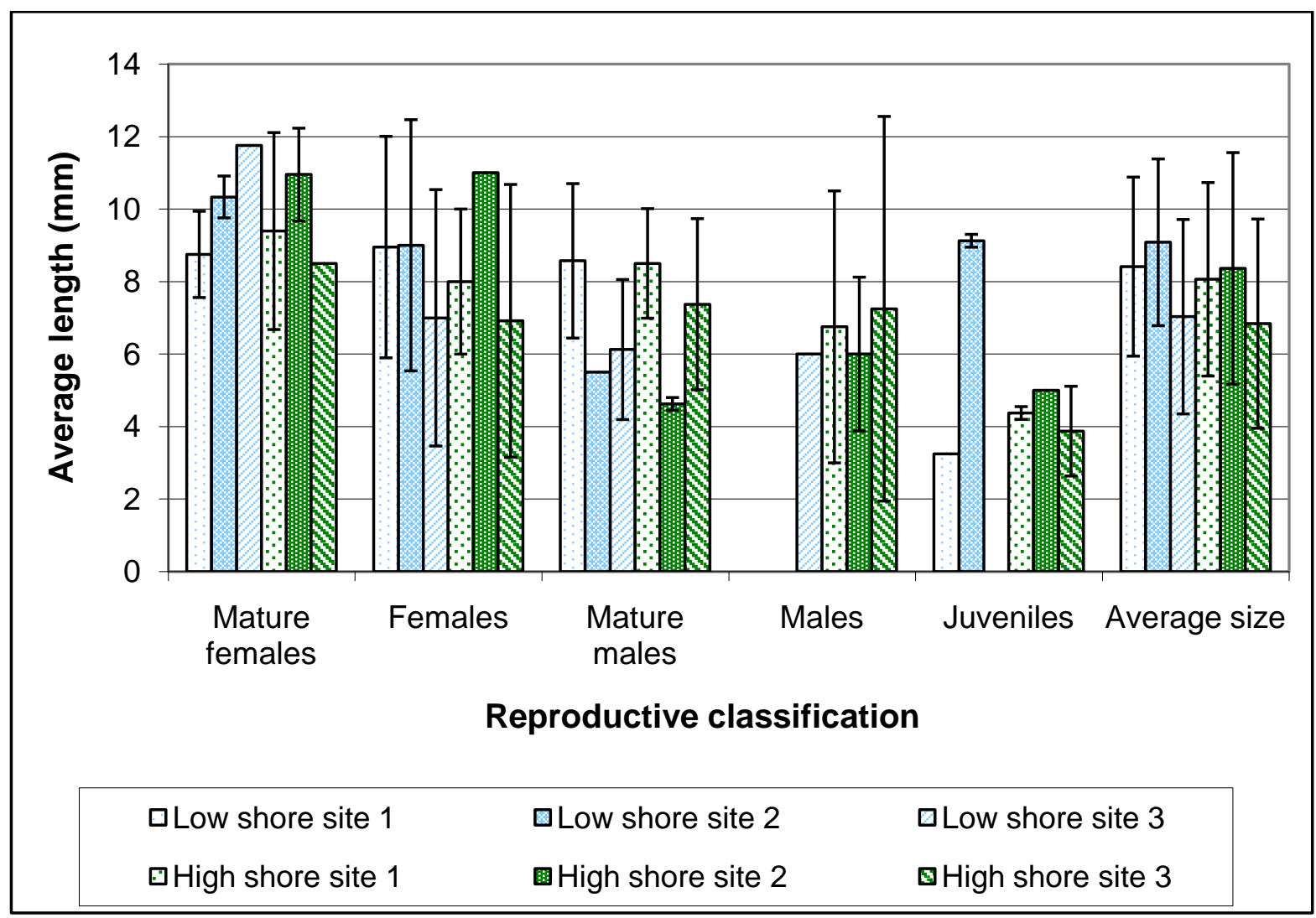

Figure 32. Size distribution of $A$. cincta for all reproductive classes by site and shore height.

\subsubsection{Effective population estimates}

The harmonic mean (average of all sampling rounds) for A. antipodum was found to be $~ 2559$ snails, while $A$. cincta had a harmonic mean of $~ 160$ snails. Effective population calculations, 
using the results of dissections and accounting for sex ratios, found the effective population of $A$. antipodum to be $87 \%$ of population, and $89 \%$ of the A. cincta population. Extrapolating these effective population estimates to the harmonic mean of each species reveals the effective population size estimates for the studied populations to be $\sim 2226$ snails for $A$. antipodum and $\sim 142$ snails for $A$. cincta along the Island Bay coast. 


\section{$\underline{3.4 \text { Movement results }}$}

The movement of 130 snails collected on the final sampling event was evaluated, of which 69 were $A$. antipodum and 61 A. cincta. The sample sizes at each of the three sites varied as only the movement of snails recaptured on the final sampling event and successfully dissected are presented here. Initially 120 snails of each species were released at each site (60 from the low shore and 60 from the high shore), and final recovery of A. antipodum from each site ranged from $13.3-30 \%$ recovery rate, and $12-24.2 \%$ for $A$. cincta. Site 1 had the highest recovery rate on the final sampling event for both species (A. antipodum -36, A. cincta-29), followed by site 2 (A. antipodum -17, A. cincta -16), and finally site 3 (A. antipodum -16, A. cincta -14). Snails were in the field from their release on April 28 until the final collection on December 20, 2008, for a total of 184 days.

To determine if there was a difference in the movement between the two species MannWhitney tests were used to compare the final distance that $A$. antipodum and $A$. cincta moved from the release site, the progress home, and the cumulative distance traveled. There was no significant difference in any of the movement rates between these species $(p=0.086$, $w=4480.0 ; p=0.184, w=4805.0$; and $p=0.255, w=4764.0$ respectively), although the maximum cumulative distance traveled was higher for A. antipodum, primarily due to one individual (Figure 33 *note- due to the scale of the x-axis bars indicating $0 \mathrm{~m}$ traveled actually indicate snails that traveled less than $1 \mathrm{~m}$ to $10 \mathrm{~m}$ ). This snail was a mature female low shore transplant, which crisscrossed a staggering $120 \mathrm{~m}$ around site 1. 


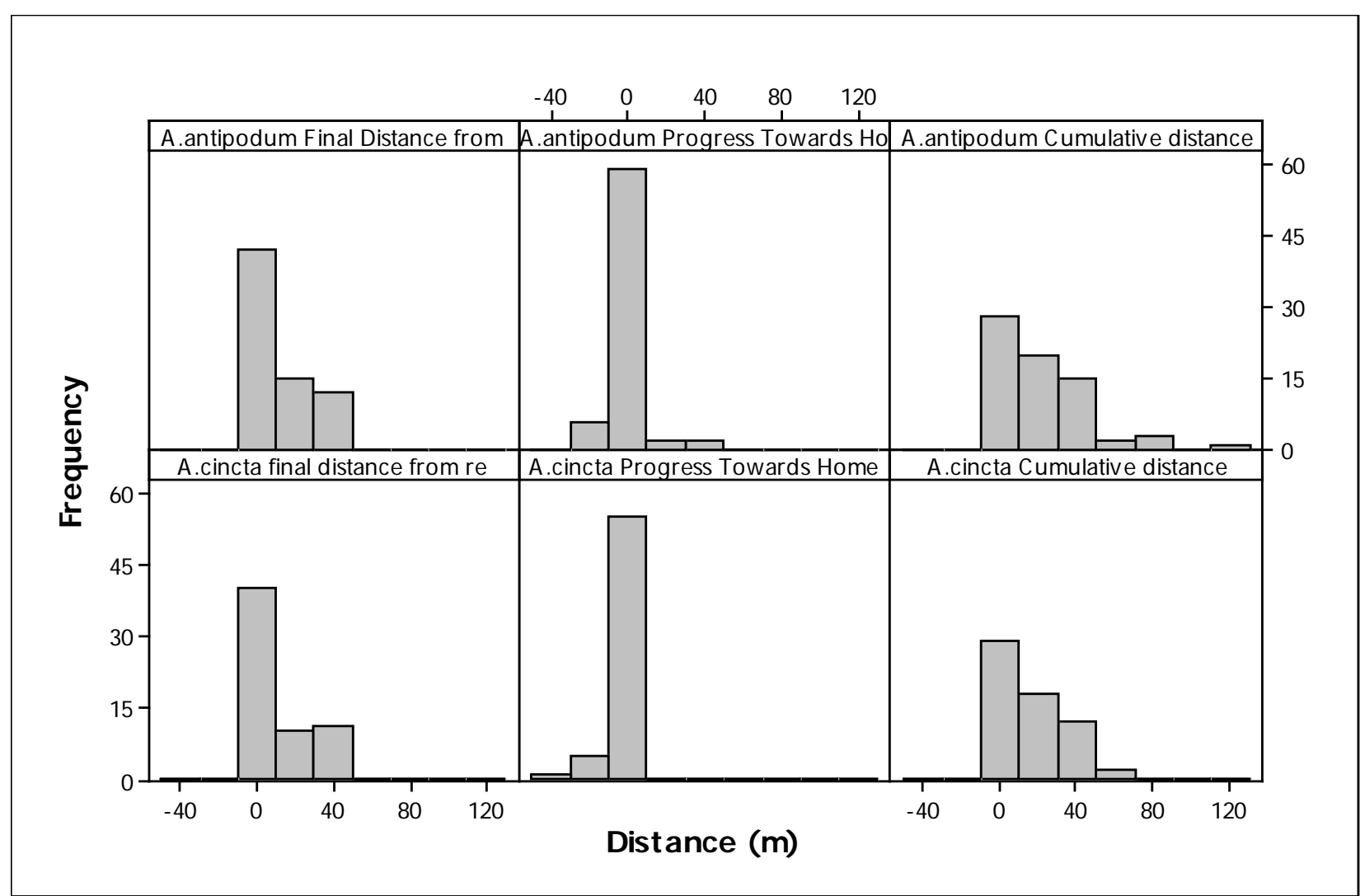

Figure 33. The final distance traveled from the release site, progress towards home made (shore level of origin), and cumulative distance traveled for each species from April- December 2008, for184 days. Due to the scale on the $\mathrm{x}$-axis bars indicating zero meters traveled represent snails that traveled less than $1 \mathrm{~m}$ to $10 \mathrm{~m}$.

Snail movements including the minimum, maximum and average distances traveled for each species at each shore height, transplant treatment, and reproductive classifications are presented in tables 8 and 9. Kruskal-Wallis tests were used for the remainder of the tests with complete results of statistical test presented in appendix 10. 
Table 8. Average distance for each of the three distance calculations traveled by A. antipodum, for each of reproductive class, within each transplant treatment, April- December 2008.

\begin{tabular}{|c|c|c|c|c|}
\hline A. antipodum & Sample size & $\begin{array}{l}\text { Final Distance From } \\
\text { Release Site Average }\end{array}$ & $\begin{array}{l}\text { Progress Towards Home } \\
\text { Average }\end{array}$ & $\begin{array}{l}\text { Cumulative Distance } \\
\text { Average }\end{array}$ \\
\hline Low shore & 37 & $13.92(+15.61)$ & $0.47( \pm 11.76)$ & $27.58( \pm 27.83)$ \\
\hline Control & 16 & $4.73( \pm 5.44)$ & $0.35( \pm 6.59)$ & $11.06( \pm 11.32)$ \\
\hline Mature females & 5 & $4.24( \pm 2.13)$ & $2.44( \pm 10.99)$ & $16.53( \pm 16.71)$ \\
\hline Females & 4 & $1.56( \pm 0.95)$ & $-0.21( \pm 1.17)$ & $5.01( \pm 2.51)$ \\
\hline Mature males & 4 & $3.71( \pm 1.16)$ & $0.03( \pm 2.96)$ & $9.98( \pm 3.79)$ \\
\hline Males & 1 & 3.52 & -0.78 & 3.55 \\
\hline Juveniles & 2 & $14.96(+9.61)$ & $-2.56(+2.07)$ & $15.40(+9.40)$ \\
\hline Transplants & 21 & $20.93( \pm 17.13)$ & $0.56( \pm 14.51)$ & $40.17( \pm 30.01)$ \\
\hline Mature females & 8 & $18.91( \pm 17.82)$ & $2.43( \pm 15.21)$ & $45.37( \pm 36.77)$ \\
\hline Females & 3 & $33.84( \pm 11.35)$ & $-6.07( \pm 8.19)$ & $34.62( \pm 11.61)$ \\
\hline Mature males & 5 & $32.66( \pm 10.52)$ & $-3.45( \pm 7.83)$ & $34.31( \pm 11.21)$ \\
\hline Males & 2 & $1.46( \pm 0.18)$ & $20.12( \pm 20.13)$ & $84.61( \pm 1.06)$ \\
\hline Juveniles & 3 & $6.83(+6.03)$ & $-4.33(+7.67)$ & $12.02(+9.32)$ \\
\hline High shore & 32 & $12.78( \pm 12.64)$ & $0.15(+6.18)$ & $20.16( \pm 16.18)$ \\
\hline Control & 19 & $17.67( \pm 13.66)$ & $-1.65( \pm 5.39)$ & $24.61( \pm 16.73)$ \\
\hline Mature females & 7 & $18.44( \pm 14.78)$ & $-2.19( \pm 5.19)$ & $27.77( \pm 16.24)$ \\
\hline Females & 3 & $13.68( \pm 8.59)$ & $-0.53( \pm 0.65)$ & $15.77( \pm 6.57)$ \\
\hline Juveniles & 9 & $18.41( \pm 13.89)$ & $-1.60( \pm 6.30)$ & $25.10( \pm 18.37)$ \\
\hline Transplants & 13 & $5.63( \pm 5.89)$ & $2.78(+6.32)$ & $13.65( \pm 12.81)$ \\
\hline Mature females & 5 & $4.81(+2.81)$ & $0.72( \pm 2.46)$ & $8.43( \pm 1.66)$ \\
\hline Females & 2 & $3.87( \pm 0.92)$ & $-0.27(+1.16)$ & $5.53( \pm 1.57)$ \\
\hline Mature males & 5 & $3.396( \pm 2.16)$ & $6.59( \pm 8.59)$ & $17.76( \pm 16.03)$ \\
\hline Males & 1 & 24.38 & 0.28 & 35.45 \\
\hline Grand Total & 69 & $13.39( \pm 14.32)$ & $0.32( \pm 9.59)$ & $24.14( \pm 23.46)$ \\
\hline
\end{tabular}


Table 9. Average distance for each of the three distance calculations traveled by A. cincta, for each of reproductive class, within each transplant treatment, April- December 2008.

\begin{tabular}{|c|c|c|c|c|}
\hline A. cincta & Sample size & $\begin{array}{l}\text { Final Distance From } \\
\text { Release Site } \\
\text { Average }\end{array}$ & $\begin{array}{l}\text { Progress Towards Home } \\
\text { Average }\end{array}$ & $\begin{array}{l}\text { Cumulative Distance } \\
\text { Average }\end{array}$ \\
\hline Low shore & 27 & $5.60( \pm 6.00)$ & $-2.49( \pm 6.78)$ & $11.63( \pm 10.47)$ \\
\hline Control & 15 & $5.51(+5.93)$ & $-2.54( \pm 6.48)$ & $12.43(+12.41)$ \\
\hline Mature females & 4 & $8.49( \pm 9.61)$ & $-5.57( \pm 10.77)$ & $23.00( \pm 18.36)$ \\
\hline Females & 5 & $4.31(+2.04)$ & $-0.26( \pm 0.70)$ & $9.83( \pm \overline{7} .27)$ \\
\hline Mature males & 5 & $4.78( \pm 3.74)$ & $-2.3(+4.49)$ & $8.33( \pm 3.35)$ \\
\hline Males & 1 & 3.20 & -3.01 & 3.66 \\
\hline Transplant & 12 & $5.72( \pm 6.19)$ & $-2.43( \pm 7.14)$ & $10.63( \pm 7.24)$ \\
\hline Mature females & 3 & $4.96( \pm 0.55)$ & $0.62( \pm 0.42)$ & $11.15( \pm 6.55)$ \\
\hline Females & 2 & $5.14(+0.07)$ & $-1.3(+1.82)$ & $9.27(+2.82)$ \\
\hline Mature males & 5 & $8.21( \pm 8.73)$ & $-5.47( \pm 10.21)$ & $13.55( \pm 8.33)$ \\
\hline Juveniles & 2 & $1.20(+1.2)$ & $-0.6(+0.60)$ & $3.93(+0.56)$ \\
\hline High shore & 34 & $18.98(+16.25)$ & $-2.23(+8.31)$ & $24.28( \pm 17.34)$ \\
\hline Control & 23 & $19.00(+15.79)$ & $-2.64(+9.22)$ & $23.5( \pm 17.53)$ \\
\hline Mature females & 8 & $19.44( \pm 16.83)$ & $-1.39( \pm 7.03)$ & $25.29( \pm 15.76)$ \\
\hline Females & 2 & $21.60(+19.95)$ & $-21.02(+19.76)$ & $23.4(+20.38)$ \\
\hline Mature males & 5 & $20.53( \pm 11.22)$ & $0.45( \pm 1.03)$ & $21.93( \pm 12.86)$ \\
\hline Males & 6 & $14.99(+14.38)$ & $-1.3(+1.63)$ & $22.23(+20.97)$ \\
\hline Juveniles & 2 & $22.82( \pm 18.10)$ & $-1.07( \pm 1.86)$ & $24.19( \pm 19.22)$ \\
\hline Transplant & 11 & $18.95( \pm 17.17)$ & $-1.37(+5.87)$ & $25.90( \pm 16.83)$ \\
\hline Mature females & 3 & $27.68(+19.57)$ & $-0.04(+0.51)$ & $43.46(+3.89)$ \\
\hline Females & 3 & $4.29(+1.42)$ & $-0.50( \pm 1.34)$ & $7.31( \pm 1.02)$ \\
\hline Mature males & 2 & $29.03(+9.52)$ & $-8.16(+10.93)$ & $32.41(+12.74)$ \\
\hline Juveniles & 3 & $18.16( \pm 16.60)$ & $0.95( \pm 2.47)$ & $22.6( \pm 14.84)$ \\
\hline Grand Total & 61 & $13.06( \pm 14.40)$ & $-2.35( \pm 7.67)$ & $18.68( \pm 15.99)$ \\
\hline
\end{tabular}




\subsubsection{A. antipodum}

The final distance traveled from the release site, progress towards home, and the cumulative distance traveled of each snail was calculated. These three movement measurements were compared for each species using the following factors: shore height across all sites, reproductive classification, size class, control vs. transplant, transplant treatment (controls and transplants assigned to each shore height), and transplant treatments for the different reproductive classes. Kruskal-Wallis tests were conducted to reveal if the movement of $A$. antipodum is influenced by spatial difference, demographics, size, or transplant treatment.

\section{Shore height}

Austrollitorina antipodum released the low and high shore showed significant differences in the final distance from the release site $(p=0.001)$ and the cumulative distance traveled $(p<0.001)$, but not in reference to the progress towards home made $(p=0.627)$. The final distance traveled by the low shore snails from the release site was significantly less than for snails on the high shore. The cumulative distance traveled was also significantly less for snails on the low shore than those on the high shore.

\section{$\underline{\text { Reproductive classification }}$}

The five reproductive classifications used were mature females, females, mature males, males, and juveniles. There were no significant differences for any of the distance calculations (final distance from the release site- FDFRS $(p=0.795)$, progress towards home- PTH $(p=0.434)$, or the cumulative distance traveled-CD $(p=0.204))$ among the different reproductive classifications. 
To ensure there were no differences for the reproductive classifications they were also tested for differences between the shore heights and transplant treatments. The FDFRS ( $p=0.640)$, PTH $(p=0.803)$, and CD traveled $(p=0.611)$ all showed no significant difference between movement and the reproductive classifications from the low and high shore. When the transplant treatments were tested among the different reproductive classifications, there was significant variation in the FDFRS $(p=0.017)$ and the CD traveled $(p=0.014)$ but not in the PTH $(p=0.790)$. Comparisons of low shore and high shore juveniles could not be made as there were no high shore juveniles found. Low shore transplant females, mature males, and high shore transplant males traveled significantly farther from the release site while low shore transplant males, low shore control females, and high shore transplant mature males traveled less from their release site (Figure 34). Austrolittorina antipodum low shore transplant males, mature males, and females along with high shore transplant males had higher cumulative distances traveled. Mature male and female low shore transplants and high shore controls moved on average at least $10 \mathrm{~m}$ more than the low shore controls and high shore transplants. Whereas, low shore control males and females, as well as high shore transplanted females had lower cumulative distances traveled (Figure 35). 


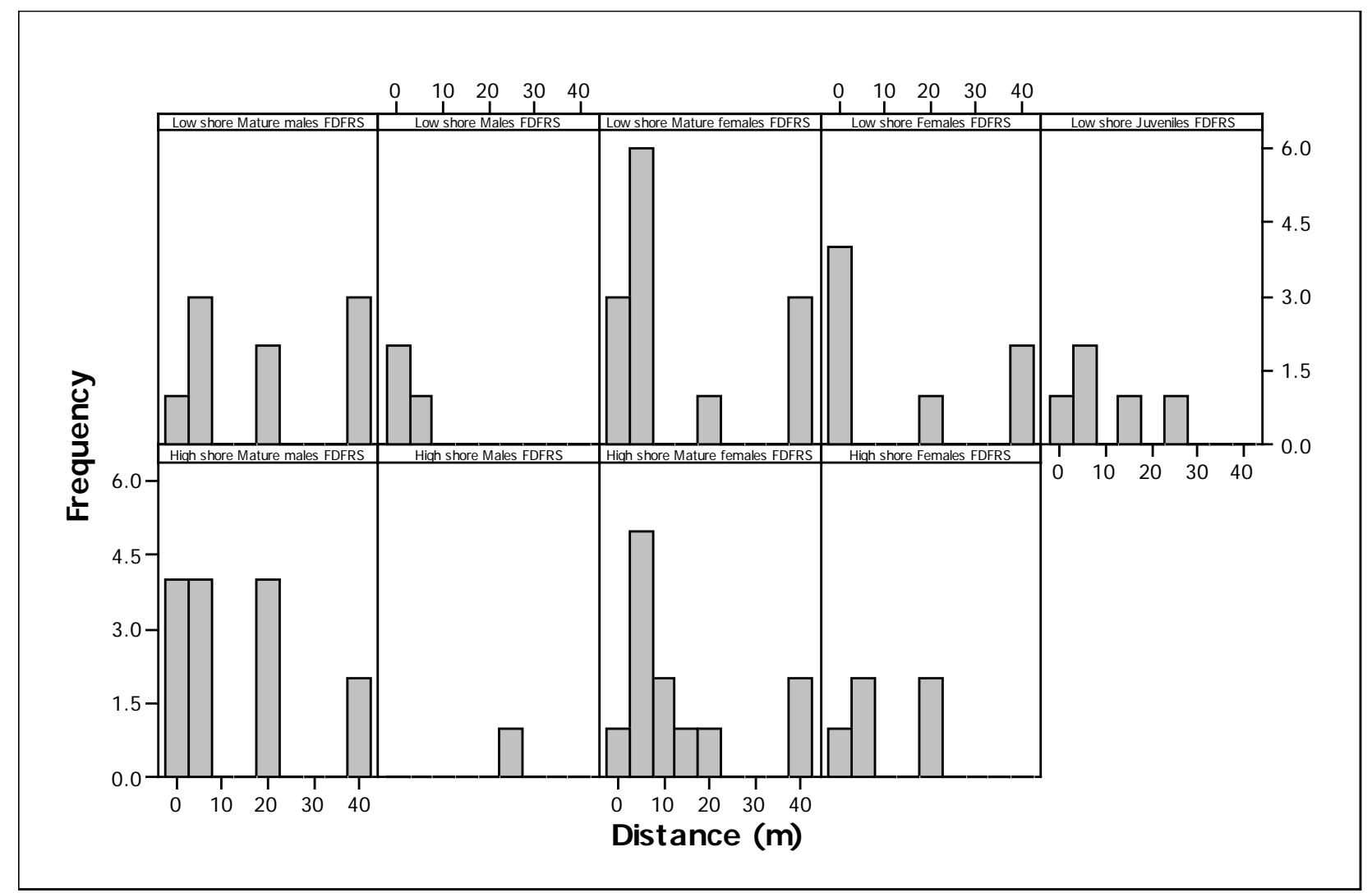

Figure 34. Austrolittorina antipodum final distance from release site for each of the reproductive classifications on the low and high shore. Bars indicating zero meters traveled represent snails that traveled less than $1 \mathrm{~m}$.

\section{$\underline{\text { Size }}$}

The movements for the three size classes (small, medium, and large) were compared to see if they varied among the different movement measurements. There was no significant difference in size classes for the FDFRS $(p=0.219)$, the PTH made $(p=0.705)$, or in the CD traveled $(p=0.622)$. These results indicate there was no significant influence of size class on the distance traveled by A. antipodum snails. 


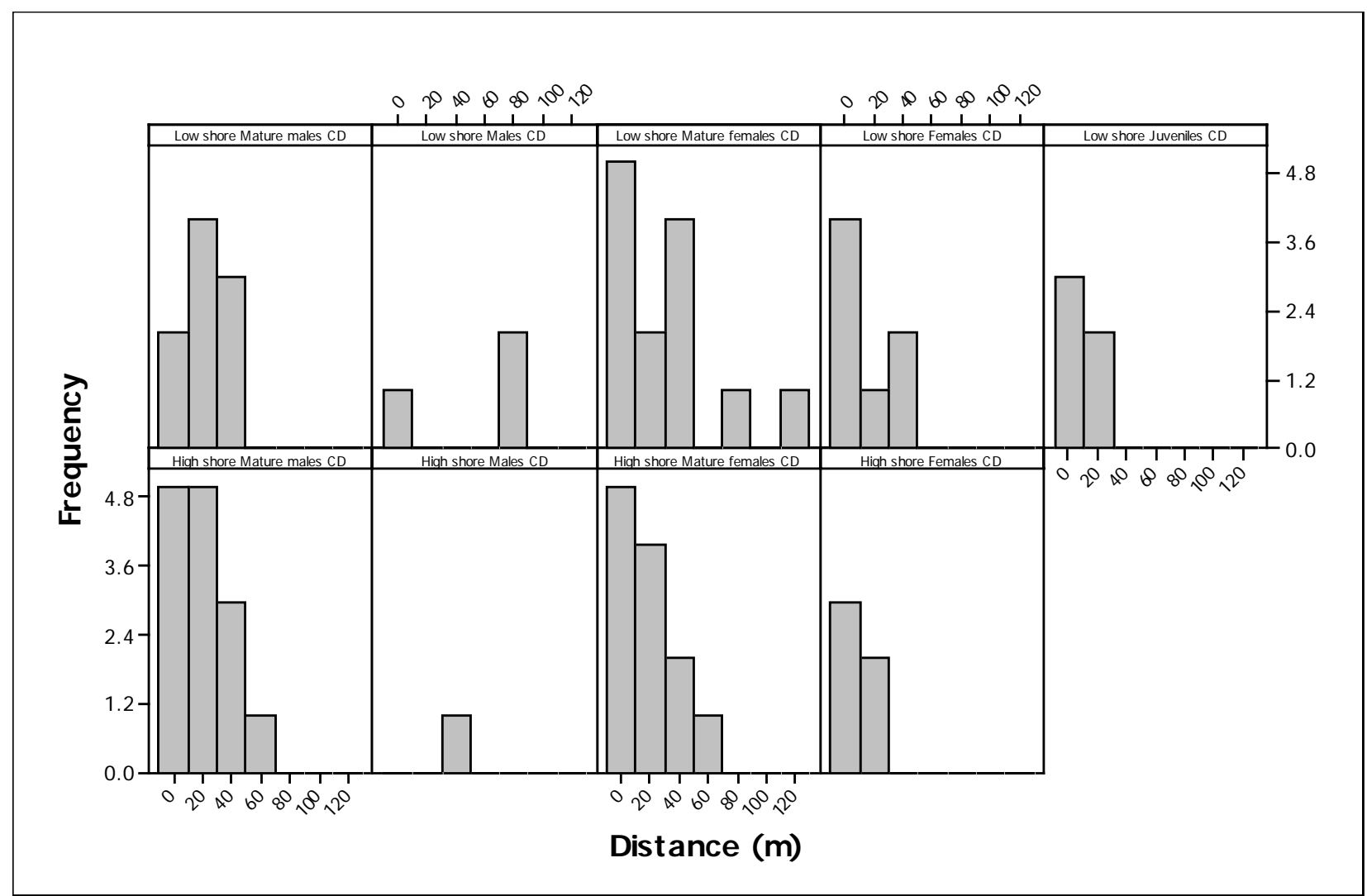

Figure 35. A. antipodum cumulative distance traveled for each reproductive classification along the low and high shore. Due to the scale on the x-axis bars indicating zero meters traveled represent snails that traveled less than $1 \mathrm{~m}$ to $10 \mathrm{~m}$.

\section{$\underline{\text { Transplant treatments }}$}

In order to determine if there was any difference in the movement of controls verse the transplants regardless of the shore height all controls were tested against all transplants. No significant differences were found between the controls and transplants FDFRS ( $p=0.593)$, PTH $(p=0.221)$, or the CD traveled $(p=0.137)$. However, when the transplant treatments were tested, specifying the shore height of the controls and transplants, there were significant differences in the FDFRS ( $p=0.014)$ and CD traveled $(p=0.001)$, but none in the PTH made $(p=0.351)$ (Figure 36). Austrolittorina antipodum low shore controls and high shore transplants moved significantly less from the release site than the other transplant treatments. 
The largest cumulative distance traveled was by the low shore transplants, with the low shore controls and high shore transplants showing the least movement.

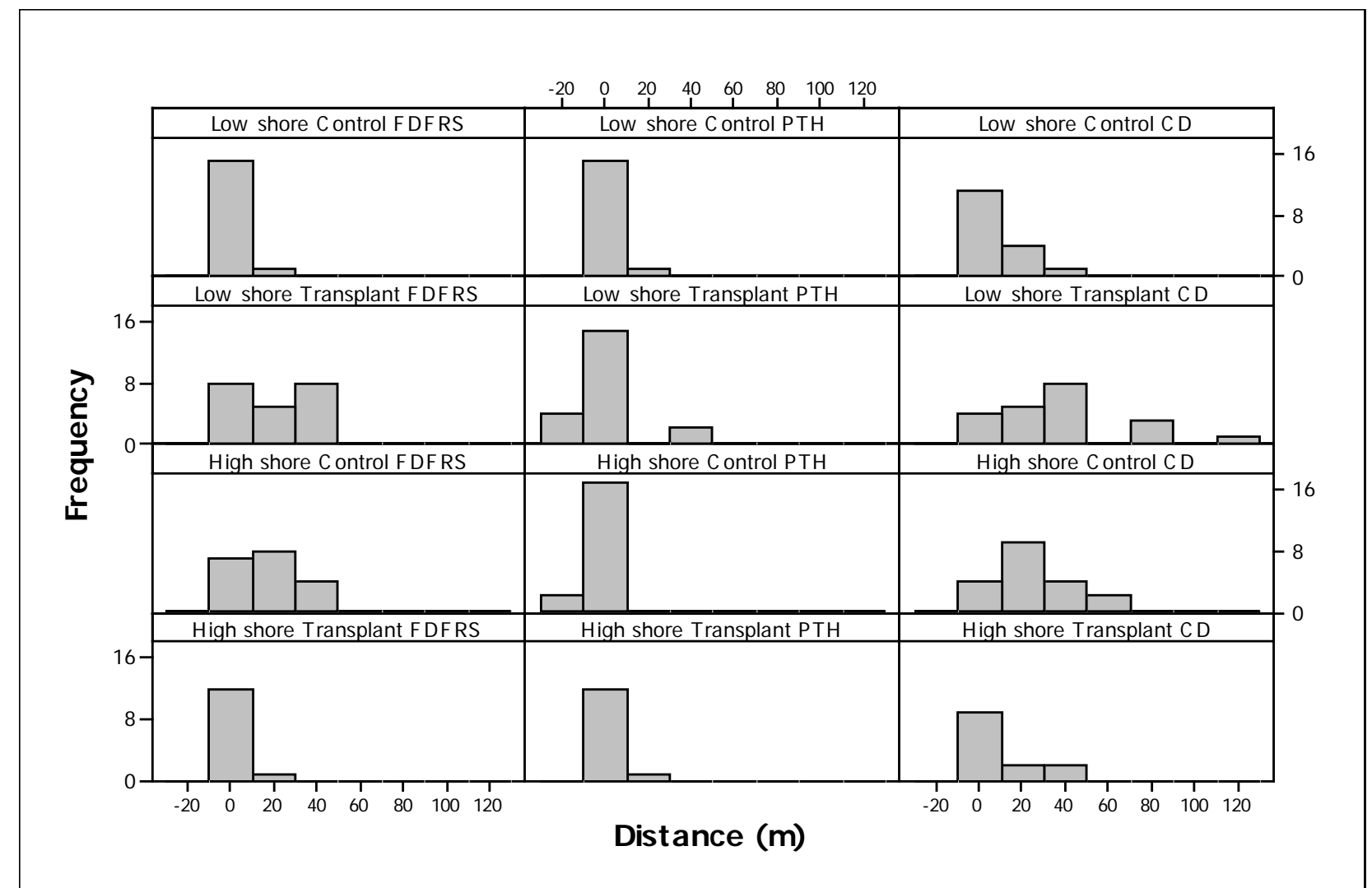

Figure 36. A. antipodum transplant treatment movements from April - December 2008 for the Final Distance From Release Site (FDFRS), Progress Towards Home (PTH), and Cumulative Distance (CD). Due to the scale on the $\mathrm{x}$-axis bars indicating zero meters traveled represent snails that traveled less than $1 \mathrm{~m}$ to $10 \mathrm{~m}$.

\subsubsection{A. cincta}

The final distance traveled from the release site, progress towards home, and the cumulative distance traveled of each A. cincta snail was calculated. These measurements were compared using the following factors: shore height across all sites, reproductive classification, size class, and transplant treatment. 


\section{$\underline{\text { Shore height }}$}

Austrolittorina cincta showed significant differences along the low and high shore in the FDFRS $(p=0.005)$ and the CD traveled $(p=0.011)$ but not in reference to the PTH snails made ( $p=0.679)$. As seen with A. antipodum, A. cincta low shore snails FDFRS was significantly less than snail on the high shore, and the CD traveled was also significantly less for low shore snails than high shore snails.

\section{$\underline{\text { Reproductive classification }}$}

The movements of $A$. cincta mature females, females, mature males, males and juveniles were compared. There were no significant differences for the FDFRS $(p=0.924)$, PTH $(p=0.198)$, or the CD traveled ( $p=0.185)$ among the different reproductive classifications.

As was done with $A$. antipodum tests for $A$. cincta were done to ensure there were no differences between the reproductive classifications. Austrolittorina cincta reproductive classifications were also tested for differences between the shore heights and transplant treatments. The FDFRS $(p=0.171)$ PTH $(p=0.431)$, and CD traveled $(p=0.059)$ all showed no variation between the reproductive classifications from the low and high shore. Reproductive classifications were also compared among the various transplant treatments and had no significant variation in the FDFRS ( $p=0.593)$, in the PTH $(p=0.793)$, or in the CD traveled $(p=0.214)$ (Figure 37 and 38). 


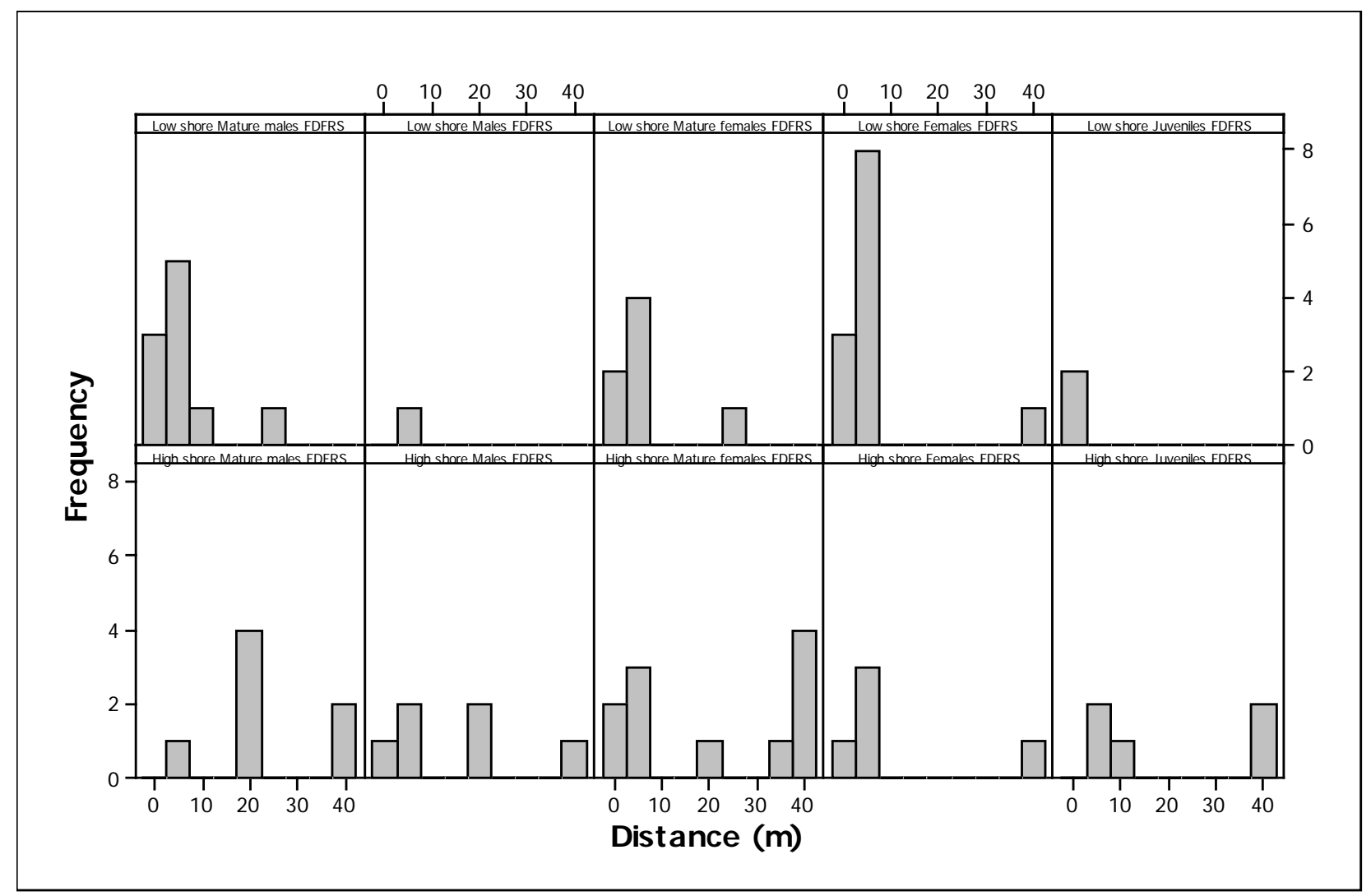

Figure 37. A. cincta final distance from release site for each of the reproductive classifications on the low and high shore. Bars indicating zero meters traveled represent snails that traveled less than 1 m.

\section{$\underline{\text { Size }}$}

The small, medium, and large size classes were compared to see if they varied among the three movement calculations. Size classes showed no variability in the FDFRS $(p=0.701)$, the PTH made $(p=0.666)$, or in the CD traveled $(p=0.600)$. These results indicate there was no significant influence of size class on the distance traveled by this sample of snails. 


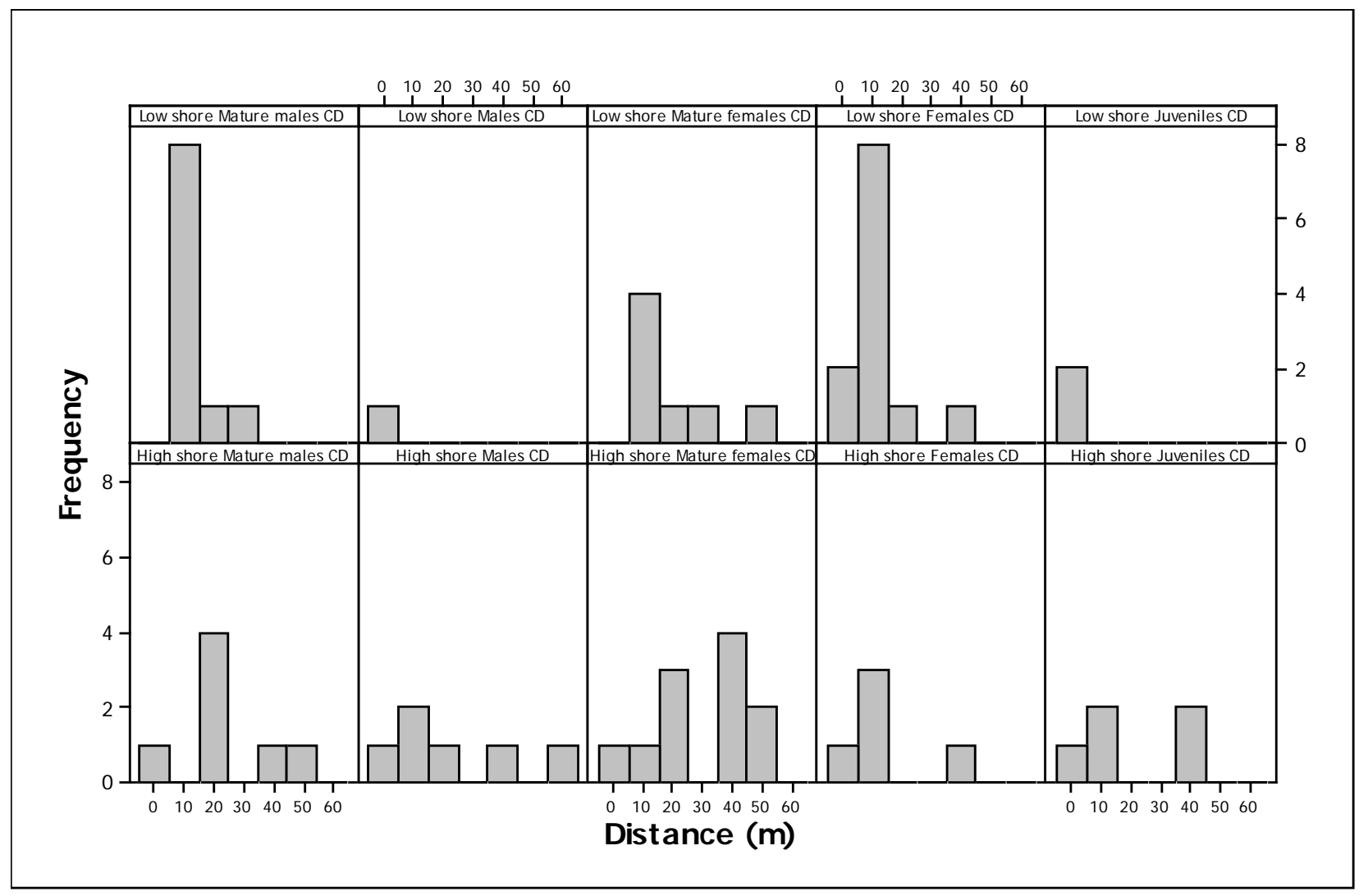

Figure 38. A. cincta cumulative distance traveled for each reproductive classification along the low and high shore. Bars indicating zero meters traveled represent snails that traveled less than $1 \mathrm{~m}$.

\section{$\underline{\text { Transplant treatments }}$}

To establish if there was any treatment affect the transplants verse the controls, the movement of controls verse the transplants across all shore heights were tested. No significant differences were found between the controls and transplants FDFRS ( $p=0.841)$ PTH $(p=0.639)$, or the CD traveled $(p=0.847)$. However, when the transplant treatments were tested, specifying the shore height of the controls and transplants, there was a significant difference in the FDFRS ( $p=0.045)$. No differences were found in the in the PTH made $(p=0.923)$ and the CD traveled $(p=0.070)$ (Figure 39). Austrolittorina cincta low shore 
controls and high shore transplants moved significantly less from the release site than the other transplant treatments, while the high shore controls moved significantly more.

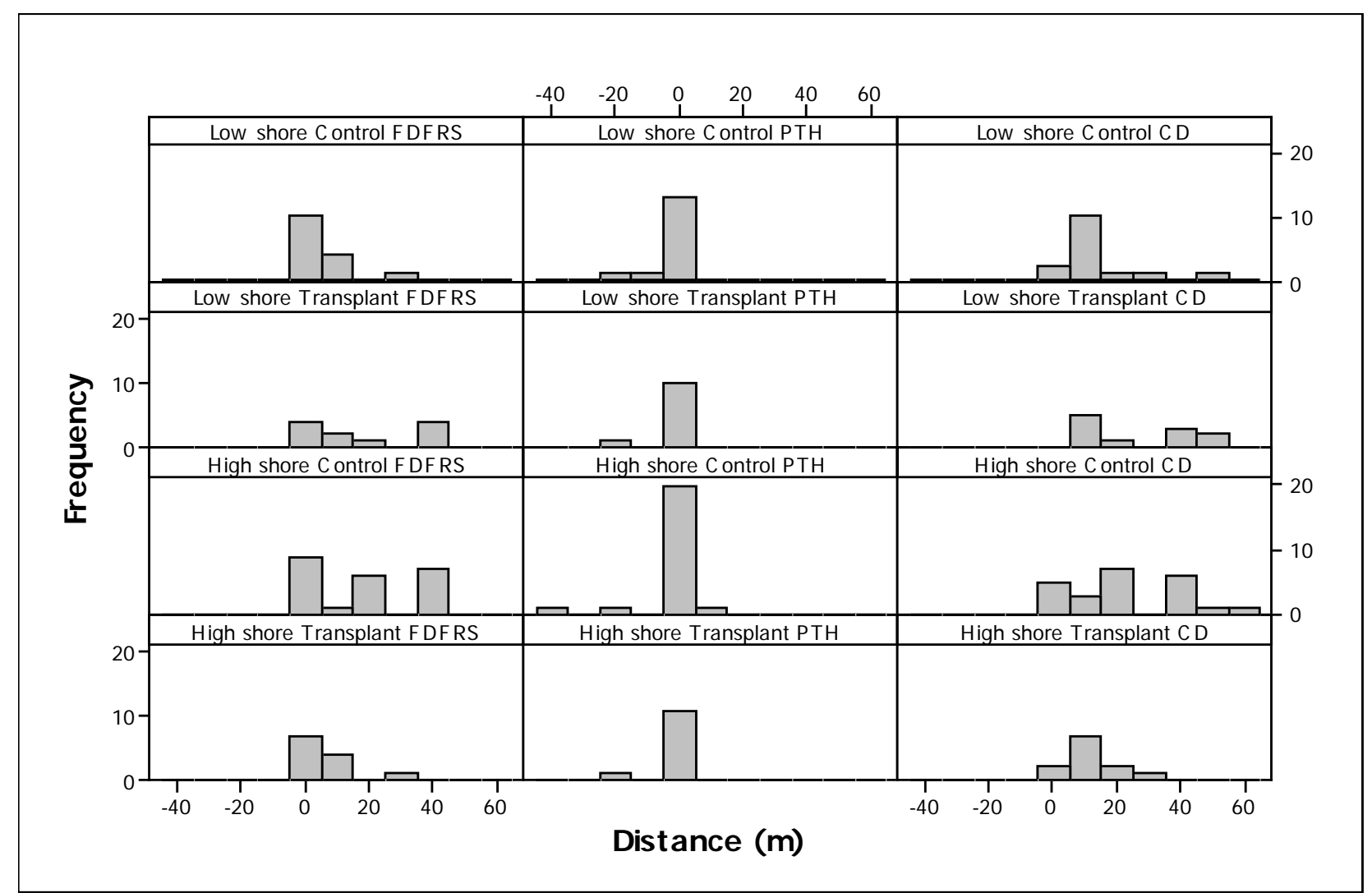

Figure 39. A. cincta transplant treatment movements from April - December 2008 for the Final Distance From Release Site (FDFRS), Progress Towards Home (PTH), and Cumulative Distance (CD). Bars indicating zero meters traveled represent snails that traveled less than $1 \mathrm{~m}$. 


\subsection{Discussion}

\subsection{Population size and structure}

The abundance, size, and behaviour of both A. antipodum and A. cincta were found to vary temporally and spatially for the Island Bay populations studied. Population surveys showed that the majority of Austrolittorina individuals along the Island Bay coastline to be A. antipodum (93.7\% of Austrolittorina snails collected). Species abundance can reflect and affect competitive interactions between species (Underwood, 1978). The higher abundance of A. antipodum may indicate that they are competitively superior to A. cincta in some way, or that the habitat found in the Island Bay area has a higher carrying capacity for this species.

The abundance of both species increased after December, with the highest abundance of A. antipodum found in February and A. cincta abundance peaked in March, followed by a steady decline in subsequent surveys. This data may reflect an increase in the abundance of snails during February and March due to snails emerging from shelter possibly in order to feed more during the summer months, although a longer sampling period is needed to determine if this is the case (Etter, 1989; Lauzon-Gauy and Scheilbling, 2009). These species are known to go without feeding for long periods of time and other species of Littorinids have been known to become inactive during the winter months or moving to areas which reduce exposure to freezing temperatures, emerging to feed when environmental conditions were more favorable (Grendon, 1977; Hamilton 1978; Lauzon-Gauy and Scheilbling, 2009). These results may also indicate large-scale seasonal migrations by Austrolittorina at Island Bay, which are known to occur among a number of other Littorinid species (Kojima, 1959; Hamilton, 1978). A portion 
of the increases seen in February and March are presumably reflecting the addition of new recruits into the adult population during these surveys, which is supported by size distribution and settlement data.

While there was not a significant difference in the abundance of A. antipodum due to temporal variation, there were significantly more $A$. cincta in March and less in July. Austrolittorina cincta may be affected more by the change in weather patterns during these times than A. antipodum is. Previous research has shown a higher rate of dislodgement due to waves for larger intertidal gastropods (Petraitis, 1982). Austrolittorina cincta is a larger snail and has a potentially higher probability of being dislodged by wave activity than the smaller A. antipodum. Due to this A. cincta may be more active during the calmer summer months and less active during the frequently severe weather conditions of the winter months. On the other hand, individuals may continue to move around the shore even in conditions that increase the probability of dislodgement. Pilkington (1972) found A. cincta made a slight downward migration in Portobello during the breeding season from November to the middle or end of March. This incomplete journey toward the ocean was not sufficient to release eggs into the ocean unless spawning is timed with high tides and rough weather. Onshore-offshore seasonal movements have been observed in other intertidal gastropods and further investigation is needed to determine if A. antipodum or A. cincta undergo such migrations (Kojima, 1959; Williams, 1975; Hamilton, 1978).

The abundance of both species varied spatially among the three sites. Site differences were seen with $A$. antipodum being more abundant at site 1 and less abundant at site 3 , where A. cincta was most abundant. Abundance comparisons across all sites replicates showed both species to be less abundant at site $1 \mathrm{~b}$, with $A$. cincta more abundant than $A$. antipodum at 
site 3c and less abundant at site 2a. Looking even closer at the spatial variation, all shore heights between all sites replicates were compared to determine if there were specific areas where the species showed variation in their abundance for either species. Austrolittoria antipodum was most abundant on the low shore at site 1c and least abundant on the high shore at site 1b. Austrolittorina cincta was also least abundant on the high shore of site $1 \mathrm{~b}$, and most abundant at site 3c low and mid shores. At site $1 \mathrm{~b}$ the mid and high shore was composed mainly of a large flat area that had little structural complexity with the lowest rugosity of all sites and shore heights. This large flat area had little macroalgae present, but lichen was abundant, and the raised area of the high shore was rarely covered by waves. This combination of environmental factors proved unfavorable for both species. In these conditions snails are more exposed and more vulnerable to the potential threats of desiccation and predation than at other sites surveyed, with little shelter from the elements or predation available. Although rugosity was not a significantly important factor in this study that may be due to methodologies used. Batham (1956) noted the scarcity of $A$. cincta at sites with flatter surfaces, and Knox (1953) also found $A$. cincta to be more abundant on irregular rock with numerous crevices. Site 3c had the highest rugosity of all sites, which may account for the higher abundance of $A$. cincta. In Doubtful Sound, New Zealand Boyle et al. (2001) found a decline in the density of both species with increasing freshwater input, and while not monitored in the current study, could be affecting their distributions in Island Bay populations near the Owhiro Bay site (site 3). This site is near a small freshwater stream, this and other sites may have areas periodically inundated with freshwater after large storms.

The size distribution of both species showed a Vermeij (1972) ‘type 1 distribution’ with snail's mean shell size increasing, moving from the low shore to the high shore. This shell 
length size gradient was found during all sampling rounds suggesting snails maintain this gradient. While this type 1 distribution was seen throughout the course of this study, there was temporal variability in the mean size on individuals along each shore height. The type 1 distribution seen here may be driven by: biotic factors such as food resources, ontogenic migrations, physiological adaptations, behavioural responses, predation, and abiotic factors such as available refuge and exposure. Undoubtedly, a number of these factors working together in a dynamic matter, that varies both temporally and spatially to shape the distribution of these species along the shore.

Temporal variance in the size distribution resulted in a decline in the mean size of $A$. antipodum on the low shore during March and on all shore heights in May. A similar pattern was seen in A. cincta with a reduction in the mean size on the low and mid shore in March, and again along all shore heights in May. This type of shoreward shift in distribution with the upward displacement of the population as young periwinkles settle to the population has been seen in populations of Littorina littorea (Linnaeus, 1758) (Smith and Newell, 1955). The increased density due to settlers entering the adult habitat may be a driving force in the upward migration of individuals (Hobday, 1995). This shift presumably reflects the growth of cohorts entering the new areas of the shore, as the changes in the average size of individuals within a cohort can be tracked in the shifting size structure of the population (Creese, 1981). William (1990) found that in populations of Littorina obtusata (Linnaeus, 1758) the emergence of hatchlings triggered a ontogenetic migration of the previous year's hatchlings to move up shore and join the adult population, which may be occurring in the populations studied here as new settlers begin to appear on the shore. The highest settlement rates were found in February (see settlement section 3.2), followed by the decrease in the mean size found in population surveys. 
This is, in all probability, due to the successful recruitment of some these individuals, which moved into the adult population. The appearance of more individuals within the smallest size class during May and June, at the site with the highest settlement rates supports this hypothesis.

The subsequent reduction in the mean size along all shore heights in May could be reflecting a movement among older cohorts due to ontogenic migrations, or an increase in competition on the low shore attributed to the influxes of settlers. Research on limpets has shown that smaller individuals with smaller radulae are more effective grazers, as the smaller radulae allow them to scrape off algae closer to the rock (Stimson, 1970; Reid, 2002). If this is the case with these Austrolittorina species, recruits and smaller individuals maybe outcompeting the larger ones at lower shore heights. As more settlers establish themselves into these populations their potentially superior grazing ability may be driving the other size classes up the shore, resulting in a domino effect of smaller, more effective grazers, moving into an area and driving out other less effective larger size classes. Larger and older individuals would then move into high shore areas where small individuals would have difficulty surviving (Hobday, 1995). Thus, food resources are potentially shaping the size distribution of both of these species.

While both of these species are generalist herbivores, the distribution of these species may reflect snails foraging on preferred food items. Some species of prosobranchs are known to have distribution patterns which mirror or are highly correlated with their preferred food items (Walter, 1980). Norton et al. (1990) suggested that Littorinids are able to use chemical cues from a distance to detect preferred items, moving towards those they favor and away from those they dislike without having to ingest the algae. The preferences of each species may also change with age or availability, and the food preferences of these species have yet to be 
determined. Food resources are likely to influence the distribution of these species but the extent of that influence and how it interacts with other factors requires further investigation.

The change in the mean sizes on the low shore may reflect ontogenetic migrations resulting from motivating forces other than food resources. Other species in the family Littorina are known to preferentially mate with individuals of a certain size, in general males preferring to mate with larger females (Gibson, 1964; Saur, 1990). Ontogenetic migrations of larger individuals to the high shore could be occurring once winkles reach sexual maturity. Moving away from the low shore, where juveniles are more abundant would be an advantageous behaviour if size assortative mating is occurring within these Austrolittorina (Edwards, 1969; Hobday, 1995). If more desirable, larger individuals are more abundant in a certain area, moving into this area would increase the probability of finding a mate than if different sized individuals were randomly distributed along the shore (Hobday, 1995). The highest abundance of pairing, for both species, was found on the mid shore, which may suggests that individuals with different shore height preferences meet in the middle. On the other hand, this may illustrate an increase in the probability of encountering another individual as snails move down the shore, where snail densities are higher, in search of mates. Concurrent movement studies did find females that were not reproductively active and mature male $A$. antipodum moved more than other reproductive classifications (see Movement section 3.4), suggesting that to some extent the population structure is fluidly maintained by the movement of different demographics.

There were significant temporal and spatial variability in the four behaviour parameters measured (solo snails, snails in pairs, aggregations, and mixed aggregations containing both species) for both species. The number of solo individuals was similar for both species; 
however, A. cincta was found in pairs less often but in aggregations, in particular mixed aggregations, more often. The number of solo winkles encountered for each species increased in each survey until July, when there was a dramatic decline. The amount of pairing observed in A. antipodum was low in February, peaked in March and began to decline thereafter. A similar pattern was seen in A. cincta although the highest pairing rate was found a bit later in May. Both species showed the highest amount of aggregation in March. Behaviour variability by site showed similar patterns for each species, yet shore height comparisons, across and between all sites, showed the unique behavioural responses of each species.

The temporal variance seen in the number of solo snails may be explained by snails seeking out shelter during the winter months, which could have resulted in the decline in solo snails found in July. There is a potential link to thermal regulation and the amount of solo and aggregated snails. Muñuz et al. (2008) found a correlation between Echinolittorina peruviana's (Lamark, 1822) operative temperature (stored body heat) and density along the mid and high shore. Echonolittorina peruviana was found to aggregate more when its operative temperature was low at night, and was found at lower densities when its operative temperature was high during mid-day. Austrolittorina in the populations studied here may be using similar behaviours in the regulation of their operative temperature, as the number of solo snails of each species decreased during the cooler winter months, when aggregating would help maintain a high operative temperature. Future studies incorporating measurements of operative temperatures may reveal that this is an important factor influencing the behaviours of these species.

The coincidence of A. antipodum having high rates of pairing and aggregating in March may be an indication of mating occurring. If these periwinkles are changing their behaviour 
and aggregating more during mating, the potential to find a mate increases and there may be other advantages such as maintaining or increasing the gene pool variability. Snails in aggregations have an increased chance to mate multiple times and females can potentially fertilize their eggs with sperm from a variety of males increasing the probability that some of her offspring will survive. Mäkinen et al. (2007) found Littorina saxatilis (Olivi, 1792) to have the second highest rate of multiple paternity found in invertebrates after social insects, and suggest this indiscriminate mating is an example of genetic bet hedging. The amount of mating occurring within each group was not able to be determined as A. antipodum and A. cincta were often found in dense aggregations with snails stacked on top of each other. The sex of individuals within pairs, and if copulation was currently occurring, was not determined. Thus these pairs cannot be considered to be mating pairs, yet there is a strong probability that a high portion of them were due to the position snails were found in. Genetic test may also reveal high levels of multiple paternity for these species. If aggregating behaviour is primarily driven by mating, one would expect higher aggregation rates in February when reproduction is still occurring based on the presences of settlers found into June. However, there was a decline in Austrolittorina settlement during the end of March and the low numbers of pairs and groups during this time may explain the decline seen during the middle of the settlement season.

An increased chance of mating is one of many potential explanations for the aggregating behaviours seen here. Numerous explanations for aggregating behaviour in intertidal gastropods have been suggested including: size, reduction of physiological stress, availability of refuge, microhabitat preference, tide and weather conditions, and as anti-predator behaviour (Vermeij, 1972; Fotheringham, 1974; Levings and Garrity, 1983; Chapman and Underwood, 1996; Erlandsson et al., 1999; Muñoz, 2008). It was not feasible to review all of 
these factors and the aggregation patterns of these species; however differences between the sites and shore heights were reviewed as well as some environmental parameters. These parameters include the slope of each quadrat and qualitative measurements of rugosity, algal and lichen abundance. A basic review of these parameters uncovers a potential link between rugosity and aggregation patterns for these species, while no significant correlation was found here other studies have shown a correlation (Batham, 1958; Morton, 1975; Hayward, 1987). The average amount of aggregations was highest in A. antipodum where the average rugosity was lowest, while $A$. cincta's average number of aggregations was highest where the average rugosity was also highest. This indicates a potential mechanism of partitioning of these species along a shore is due to rugosity, with $A$. cincta occupying areas of higher rugosity.

It is often difficult to determine the dominant factor influencing the distribution of species and often there are a number of abiotic and biotic factors that influence the distribution of organisms (Walter, 1980). The density of conspecifics, other species in the community and predators have been shown to effect the abundance, distribution, and size of some intertidal gastropods and no effect on others (Vermeij, 1972; Chapman, 1994; Chapman, 1994; Muñoz et al., 2007). No predators were personally observed feeding on these species during this study, although generally birds, crabs, and fish feed on littorinids (Reid, 1996; Cotton et al., 2004). Foster (1966) studied populations of A. antipodum at two locations on the Auckland Peninsula, and also noted the apparent lack of predators and suggested the main cause of mortality to be dislodgement. It is also possible that these species have few predators and that their main causes of death are from waves, temperature extremes, and trematode infections (Foster, 1966; Vermeij, 1972; Emson et al., 2002). If dislodgement and temperature extremes are the main factors restricting population growth for these species one would expect smaller populations of 
A. cincta as they are larger and more susceptible to dislodgement, and are relatively more abundant than A. antipodum in areas with extreme temperatures. While A. cincta may generally occupy areas that could be life threatening they are also capable of moving out of these areas as seen in the results of the movement chapter.

Austrolittorina populations studied here appear to be structured by size, food availability, and potentially reproductive classification showing temporal variability. Settlement may also help shape these species distribution shifting spatial abundance from year to year (Underwood, 1978; Walter, 1980). A combination of these factors, among others, appears to be interacting and shaping population structures of these species in unique ways. Future research will help determine the weight of the various factors and facilitate the understanding of intertidal ecology. 


\section{$\underline{4.2 \text { Settlement }}$}

New Zealand Austrolittorinids show marked seasonality in their reproductive cycles, with peak periods of recruitment in February and March for Island Bay populations. On the southern island of New Zealand (roughly 800km south of the Island Bay populations studied here) Pilkington (1971) conducted studies on Portobello populations of Austrolittorinids, which showed some similarities with the results of this study. Pilkington's observed of spawning and egg production in both species from Nov-January and predicted larval durations which correspond to when young snails were found to be settling in the present study. The highest abundance of egg capsules in tide pools in Portobello was in the beginning of January, which is sync with highest rates of settlement. The decline in settlement seen here also aligned with when Pilkington saw declines in pairing, and the following time lapse when the lower production of eggs would lead to lower settlement. Pilkington found highest densities of egg capsules in November and December, but they were present from November until March. This aligns with the results presented here, indicating presences of settlers from late December-June. The similarities between these two studies suggest Austrolittorina may be using the same spawning and settlement cues across their range. Pilkington suggests that these species spawn irregularly based on the environmental stimuli of high salinities and rough seas. Other species of Littorinids have also been found to time spawning events during stormy conditions, and future work should not only account for weather but also tidal and lunar cycles (Fish, 1979; Cronin et al., 2000).

Snails from the Portobello population spawned multiple times and Pilkington suggests that $A$. antipodum may be able to rapidly form eggs when they detect the optimum 
environmental conditions. The two peaks of settlement seen in the current study may indicate individual females are releasing eggs in intervals, with some females having mature eggs one month after previously spawning. This process may be occurring on a population scale as seen in other species of littorinids (Hughes, 1995; McGrath, 1997). In the Portobello populations of these species pairing and spawning showed no correlation to spring tides. While spawning was not correlated with tides, there may be more of a tidal and/or lunar influence on settlement. The two peak periods of settlement observed in the current study both occurred during the twoweek sampling events when the moon was full, and the possible correlations between tidal and lunar cycles and Austrolittorina settlement warrants further investigation. Other species of Littorinids have shown peak periods of spawning during the full moon, indicating the spawning was not only correlated with tides but potentially the lunar cycle as well (Struthsaker, 1966; Fish, 1979). Another possibility is that some individuals are reproducing later in the season due to some other factor, such as the availability of food, with snails from less quality habitat spawning later in the season, resulting in the later settlement of their offspring (Spight and Emlen, 1976).

Long planktonic larval durations are beneficial in large areas of inconsistent habitat quality (Strathmann, 1985). In these circumstances an extended period within the plankton would provide more time to find suitable habitat. Although, longer planktonic periods can result in larvae being transported farther distances away from suitable habitat, resulting in larvae settling on a diverse variety of substratum and potentially less preferred habitat, or higher mortality (Pechenik, 1999). Thorson (1946) suggests some individuals remain in the plankton for a longer period of time and continue to grow. Evidence of this has been found with Littorina littorea as individuals are able to settle at shell lengths of $0.25 \mathrm{~mm}$; however 
individuals as large as $0.5 \mathrm{~mm}$ have been found in plankton tows (Smith and Newell, 1955). The presence of recruits in June also supports a possible longer larval duration of two months with the potential of some larvae having more reserves then others. If for example, larger females of these species are providing their offspring with more reserves they may remain in the plankton longer than the offspring of less fecund individuals (Spight and Emlen, 1976; Strathmann, 1985; Cheung and Lam, 1999). This is supported by the appearance of a larger cohort of individuals, with one to two more whorls, seen later on in the settlement season. These larvae could have remained in the plankton longer providing the opportunity to grow to larger sizes before settlement, potentially enhancing survival by reduced mortality or enhanced competitive skills as seen in other species (Hughes and Roberts, 1980).

The larger individuals found on settlement pads may have come from more fecund females, providing them with larger yoke reserves, allowing for extended time within the plankton, and increasing the time available to seek out suitable habitat . However, these may have simply been larger individuals that had previously settled in the surrounding area and crawled onto the settlement plate, or individuals that recruited to the settlement plate once the plate was deployed and grew while on the plate for the remainder of its deployment. The possibility of more fecund females producing young with larger reserves capable of longer planktonic periods remains to be determined, however it is clear there was a temporal effect on settlement. Another possibility is that some individuals are reproducing later than others, which may have been creating the second peak in settlement. This possibility is discussed in more detail in the fecundity discussion (section 4.3). Settlement did show significant variability from site to site during this study indicating snails are selecting settlement sites based on some specific criterion or due to differences in larval supply between the sites. 
It was not possible to determine if the spatial variation was due to reproductive output of snails from the individual sites, habitat quality of the sites, or the density of adults at the settlement sites. Determining the specific number and relative importance of factors involved in the settlement site selection of these species was beyond the scope of this study; however, a basic review of ecological and environmental parameters, as well as adult density was undertaken and revealed no specific associations with ecological and environmental parameters and that snails preferred to settle into adult habitat.

\section{Ecological and environmental parameters}

Timing and seasonality are not the only factors determining settlement of Austrolittorinids. Other factors such as habitat quality, competition between species, and the presence of adults may also play important roles in governing settlement of Austrolittorina. Tests on abundance of settlers (using the subset of the data) showed sites with settlement pads placed within adult populations had more Austrolittorina settlers than those within the barnacle zone. While similar species of prosobranchs with planktonic egg stage show high larval recruitment within barnacle zone, and migrate into supralittoral zone where adults are, this does not appear to be the case for the Island Bay populations of Austrolittorina (DeMagalhães, 1998). Snails in these populations settle directly into the adult population more than within the barnacle zone, therefore the presence of a dense barnacle zone would not indicate high settlement and may indeed indicate an area of lower Austrolittorina settlement. Ecological and environmental parameters tested also showed variation between the sites; however there were no correlations between these parameters and the number of settlers. Site 2a had the overall 
highest settlement, lowest ranking of crustaceans present, and lowest ranking for abundance of algae and sand.

The lower abundance of crustaceans may have allowed for higher settlement rates of Austrolittorinids at site 2a due to reduced competitive interactions or due to direct predation. Higher abundances' of crustaceans at other sites may inhibit the settlement of Austrolittorinids at those sites. A species of New Zealand Cellena was found to prevent Siphonaria from establishing in its preferred habitat, and this may be the case with crustaceans and Austrolittorinids (Cresse, 1988). Research has shown that competitive interactions between gastropods at high densities can alter the community structure by reducing the abundance of other species present on the shore (Underwood, 1978). Further investigation of the results of this study suggest that it may not be the lower abundance of crustaceans allowing Austrolittorinids to settle at site 2a, but rather the high abundance of Austrolittorinids preventing the crustaceans from settling into this area. Site 3a had the highest amount of crustaceans, barnacles, and bivalves and was among the lowest in Austrolittorina settlement. Austrolittorinids may have superior competitive skills that enable them to be a competitive dominates within these subtidal communities, cage studies and other laboratory experiments are needed to determine the interspecific interactions occurring in these areas. Competition between Austrolittorina and other species is an important factor to consider yet it may not be as important as other factors.

The abundance of algae was initially believed to be an important factor the dictating settlement of A. antipodum and A. cincta as other gastropod species have shown enhanced colonization of surfaces covered with microalgae and detritus (Struthsaker and Costlow, 1968); however, here I found higher abundance of macroalgae was not correlated with 
more Austrolittorina settlers. Indeed there appears to be the opposite trend as the site with the highest settlement had the lowest amount of algae and the site with the second lowest settlement had the highest abundance of algae. It may not necessarily be the abundance of algae that young snails are looking for when selecting a settlement site, but rather the species of algae present, although this is probably not the main factor dictating settlement as these species are believed to have a generalist/opportunistic diet (Reid, 2004). High abundances of algae may limit the snails' ability to find suitable substrate to attach to, this along with other influences such as suspended debris may inhibit snails ability to settle into a site.

Sand is frequently suspended within the intertidal zone and can be an irritant for some species, scouring individuals. While the presence of sand is not the main factor dictating where young snails settle, it may be a contributing factor to newly settled individuals ability to recruit as these young snails may not be able to tolerate persistent sand scouring from suspended sand (Batham, 1956). Less suspended sand may indicate calmer sea conditions which would be more beneficial for snails searching for a settlement site, due to less scouring and irritation due sand.

While the current study does provide a timeframe of when Austrolittorina settlement is occurring and when the peak periods within the settlement season occur, the direct factors influencing their site selection remain undetermined. Vermeij (1972) suggested that juveniles will occupy areas of the shore known as 'zones of minimal mortality', which tend to be areas where individuals are sheltered and are least susceptible to physiological stress. For the Austrolittorinids at Island Bay these sites are potentially in hard to survey areas such as cracks and crevices along the low shore. The ecological and environmental parameters tested by this study may not be the most influential factors in Austrolittorina settlement, the presence of 
adults is potentially more important as there were significantly more settlers at sites within the adult population than those within below adults in the barnacle zone.

\section{Density manipulations and settlement plate placement}

Adult densities have been shown to affect settlement due to the strength of conspecific cues, the availability of habitat and resources, and their influence on the abundance of other species (Gadgil, 1971; Hadfield and Koehl, 2004; Botello and Krug, 2006). Although the density manipulations attempted in this study did not find a significant effect of adult density on settlement of snails, this is probably due to an underestimation of the mobility of the species. The sites were cleared regularly to maintain density treatments; however there was still an influx of snails altering the intended density treatment for each of the pads. Movement studies conducted on these species (see movement section 4.4) show both species moving around larger areas (with both species capable of moving over $20 \mathrm{~m}$ in one month) than anticipated, and much larger density manipulations would have been needed to truly detect any impact the density of adults might have on settlement. Further studies are need as species can be self-regulating at high densities (i.e. available space for settlers is limited due to the number of adults in the area), and this may play an important role in the settlement of $A$.

antipodum and A. cincta (Underwood, 1978). The use of cages is recommended to maintain the desired density treatment as the mobility of the snails was major limiting factor in this studies effectiveness. However, cage studies must use the correct eye size of cage wiring, to reduce the potential of the cage inhibiting settlement.

While density manipulations showed no detectable effects on settlement the placement of settlement pads within or below the adult population did. More settlers were found on pads 
placed within the adult population than below the adults within the barnacle zone. These results illustrate that the presence and density of adults does have some effect on Austrolittorina settlement. These settling snails are probably responding to cues from conspecifics rather than other species such as barnacles. High abundances' of adults potentially indicate quality habitat with the presence of food resources, refuge, and a limited number of predators (Foster, 1966; Chapman, 1996). The presences of adults appears to be a key factor in site selection for these species and further investigation should help uncover if the presences of adults is a critical cue for settlement limiting the colonization of new areas and other cues involved in the settlement process.

In conclusion, during this 7 month study from Dec. 2007- June 2008 Island Bay Austrolittorina settled from December to June with the highest settlement rates occurring in February and March. In addition to temporal differences in settlement rates there were also spatial differences in settlement although the cause of this variation could not be determined. The influence of adult density on settlement was inconclusive but the potential impacts of density on settlement should be studied. More in depth studies of larval behaviour are needed and although larvae are hard to rear in lab, these studies would provide important clues to the factors influencing settlement and dispersal. As well as helping determine the subtle differences between these species when they are settlement size, such as unique shell surface ornamentation (Fish and Fish, 1981). Samples of A. antipodum and A. cincta may have unique hatchling lines and future work will help determine if this could be used as an identifying characteristic for these species (per comm. Bruce Marshall; Fish and Fish, 1981). 


\section{$\underline{4.3 \text { Fecundity }}$}

Population demographics and fecundity are important considerations when investigating the parameters shaping populations. These two species of New Zealand Austrolittorina showed some similarities in the distribution of certain demographics (i.e. the high abundance of reproductively active adults on the high shore), but showed variation in the others (i.e. the distribution of juveniles) (Table 10).

Table 10. Summary of the similarities and disparities between A. antipodum and A. cincta, both significant and non-significant.

Similarities between species Disparities between species

* More reproductive adults on the high $*$ More A. antipodum were from the low shore shore and more of the $A$. cincta were from

* More total females on the low shore the high shore

* Skewed sex ratios on all low shore sites

* Males reached sexual maturity sooner than females * More A. antipodum juveniles were from the low shore and more of the $A$. cincta juveniles were from the high shore

* Females attain larger sizes before they sexually mature * A. antipodum had more reproductive adults that were transplants and more of the * No juveniles were found in the large size class

* Site 2 had the most variability between the reproductive classes (both species showed an effect of shore height and reproductive $A$. cincta were controls * A. antipodum had more mature females from the low shore and A. cincta had more from the high shore treatment on reproductive class although the effects varied)

* A. antipodum had even sex ratios on 2 of the 3 high shore sites, while $A$. cincta showed divergence from the 1:1 sex ratio at all site and all shore levels

The type of variation seen between these species in the distribution of certain demographics, such as juveniles, suggests there may be physiological and behavioural 
differences driving these results. Austrolittorina antipodum had a higher proportion of mature adults than $A$. cincta, with mature females and mature males being the two most abundant reproductive classes. This high abundance of mature adults and a skewed sex ratio with more females present may be among the primary factors enabling the larger populations of $A$. antipodum. If males are mating with more than one female the lower number of males would not become a limiting factor in reproduction until the population reach some critical level where Allee effects limit reproductive success (Stoner and Ray-Culp, 2000). While A. cincta also had more females than males (both mature females and females) overall, the most abundant reproductive class was mature males. The higher number of mature males compared mature females may also contribute to the lower population sizes of $A$. cincta. The high abundance of males compared females may have lead to less successful fertilization (i.e. males mating with other males) and more time spent looking for a mate could have reduced the length of the breeding season for A. cincta (Ito and Wada, 2006). If A. antipodum has a longer spawning season, this may increase gene flow which would lead to more stable and the ultimately larger populations of A. antipodum. Large populations are less likely to experience a crippling loss of individuals due to stochastic events and environmental changes (Hohenlohe, 2004). The successful settlement of juveniles appears to be about the same for each species, as approximately $10 \%$ of the snails sampled for each species were juveniles.

Sex ratio comparisons confirmed that A. antipodum had a larger proportion of females than males, compared to $A$. cincta, which again may be linked to the higher abundance of $A$. antipodum. The majority of $A$. antipodum females were mature, and although there were more mature female $A$. cincta, the proportion of mature females was closer to that of females among the different reproductive classes. The proportion of males that were mature was high for both 
species. The higher proportion of mature individuals among the males compared to females for both species is more than likely due to the faster maturation rates of males than females. Other Littorinid studies have found a prevalence of females over males was generally restricted to certain size classes, and the authors suggests the differences in growth rates between females and males account for this (Moore, 1937; Lenderking, 1951;; Rochette, 2003). This may also be true for these New Zealand Austrolittorina, as there were more females in the larger size classes although further investigation into the growth rates would be needed to confirm this.

Although there was some variation in the sex ratios of both species, in general the high shore was closer to a more balanced sex ratio and the low shore tended to have more females. This divergence from a balanced sex ratio became more exaggerated with smaller sample sizes. At site 1, which had the highest sample sizes the sex ratio was more balanced, indicating these skewed sex ratios are potentially an artifact of small sample sizes at the other sites. Site 2 which had the most skewed sex ratio along the low shore for both species (with more females present and very few if any males) also had the highest recruitment; this higher abundance of females may indicate higher larval production. This site also had the largest average size of mature females on the high shore for both species, and previous research has shown some littorinid males select mates based on size with larger females being the preferred mates (Johannesson et al., 1995).

The divergence from the 1:1 sex ratio along the low shore may be due to females actively moving to the low shore during the spawning season, which has been observed in other Littorinids (Cronin et al., 2000; Tokada, 2003; Ito and Wada, 2006). Edwards (1969) argues the probability of sexually mature individuals encountering one another increases if a population has size class segregation. If males due seek out larger females as suggested by 
Rochette (2003) the absences of males from the low shore at site 2 could be a result of males migrating to the high shore where larger females are generally found. The overall abundance of reproductively active adults was larger on the high shore, although there were more females on the low shore. The higher abundances of females on the low shore appears to be correlated to spawning, as these species have planktonic larvae and the success of offspring depends on reaching pelagic waters (Edwards, 1969). The large number of mature female A. antipodum on the low shore suggests that these behaviours are potentially enhancing the rate of successfully broadcasting fertilized eggs. The active migration or behavioural aggregation of mature females on the low shore increases the proximity of reproducing females to the ocean, thereby directly increasing the probability that eggs will be taken out to sea, where the planktotrophic larvae can develop. These larvae feed and grow within the plankton before metamorphosing and settling along the shoreline.

The higher abundance of $A$. cincta juveniles on the high shore indicates the possibility of this species having a more robust physiology than A. antipodum or juveniles experiencing higher mortality. Smaller size classes and juveniles are predominately present on the low shore where there is less physiological stress due to desiccation, heat, and restricted feeding times (Vermeij, 1972; Spight and Emlen, 1976; Muñoz, 2008). Austrolittorina cincta attains an overall larger adult size than A. antipodum and due to this has less body surface area and may cope more easily with the environmental stresses of desiccation and heat than the smaller $A$. antipodum. The larger average size of A. cincta may account for the larger number of juveniles found on the high shore as they are potentially physiologically more capable of moving up shore before reaching maturity. Although this may help juveniles escape predation, the overall higher abundance of $A$. antipodum found in concurrent population studies suggests 
that the behavioural difference of $A$. antipodum juveniles to reside primarily on the low shore may have contributed to this species larger population. The combined effects of lower physiological stress experienced by juveniles remaining on the low shore for longer periods of time and the effects of resource partitioning presumably are among the key factors increasing the survivorship and population numbers of $A$. antipodum over the larger, but less abundant, $A$. cincta.

Although it was not possible to assess individual fecundity, there was some evidence for higher fecundity among the larger sized A. antipodum and A. cincta females at site two. Larger size is commonly associated with higher fecundity with larger females producing more young (Spight and Emlen, 1976; Strathmann, 1985). Hawaiian species of Littorinids, also with a planktotrophic larval stage, spawn less frequently at smaller sizes with larger females producing more eggs, although exceptions to these general trends could be found. This may be the case with these New Zealand Austrolittorinids at some study sites (i.e. site 3c) where there is the potential to experience rougher sea conditions in the winter resulting in dwarfism along lower shores sites and individuals reaching sexual maturity at smaller sizes. This has been documented in British Littorina living within the barnacle zone, due to the environmental conditions small size is advantageous when seeking shelter within these environments (Reid, 1993). Within other species of Littorinids individuals in the same population have shown differences in the size of sexual maturity due to shore height, with snails along the low shore attaining sexual maturity at smaller sizes (Spight and Emlen, 1976; Rochette, 2003). This may indeed be occurring for both A. antipodum and A. cincta as the average sizes of maturity varied not only between the sites but also shore heights. 
While a species reproductive strategy is important, it is not always the most influential factor in predicting population connectivity. Kyle and Boulding (2000) compared the population genetic structure of Littorina species with and without pelagic larval dispersal and found one of the species with pelagic larvae had surprisingly high population structure, illustrating it is inappropriate to unilaterally link reproductive strategy with the degree of genetic structure among populations. Other factors such as the effective population size can play an integral dynamic in the genetic structure of a population. Information on population demographics including; population size, sex ratios, and minimum size of reproductive maturity can be used to estimate the effective population size which is important for monitoring the health of a population. These three aspects of a populations demographics were used to calculate the effective population of both species. The effective population for $A$. antipodum was $87 \%$ of the population and $89 \%$ of the $A$. cincta population. While the proportion of each species within the effective population was similar, the calculated sizes of effective populations varied with $A$. antipodum having 2226 snails in the effective population, while $A$. cincta had $~ 142$ snails. The smaller number of individuals in the effective population of $A$. cincta compared to that of $A$. antipodum coupled with the skewed sex ratios may limit the gene flow within $A$. cincta's population. If there are small populations with sex ratios skewed towards more males with small females producing less eggs, there may be more genetic structure than in larger populations with even sex ratios, illustrating the importance population demographics can have on populations' genetic structure. These same demographic characteristics of a population can have implications on the rate of settlement among populations. However, this was only a snapshot of these species reproductive classes distributions taken during the spawning season, and the distribution of demographics may 
change throughout the year. Further research is needed to if this a relatively consistent or temporary demographic distribution.

Future work should be attempt to rear the eggs of both species through the larval phases in the lab, identifying key characteristic that can be used to differentiate between the recruits of these species. Lab work will also be necessary to provide evidence for or against the hypothesis that $A$. antipodum has a larger population due to higher production and survivorship of larvae, higher settlement and higher juvenile survivorship. 


\subsection{Movement}

Austrolittorina antipodum and A. cincta both had similar movements with no significant differences found between the final distance from the release site, the progress towards home, or the cumulative distances traveled. Sympatric Littorinids with similar food requirements have been shown to have different rates of movement within the same environment (Chapman and Underwood, 1994), and although the direct comparisons between A. antipodum and A. cincta showed no significant difference, movement patterns of these Austrolittorina species do appear to vary.

Shore height had some influence on movement for both A. antipodum and A. cincta, with A. antipodum moving more on the low shore and A. cincta moving more on the high shore. These results coincide with the findings from other studies on the Littorina family in which shore height is a factor effecting the distribution and movement of periwinkles (Grendon, 1977; Byers and Mitton, 1981; McQuaid, 1981; Petraitis, 1982; Williams, 1995; Chapman, 1999; Lee and Lim, 2009). Snails along the low shore traveled less from the release site and a lower cumulative distance. The abundance of macroalgae on the low shore may account for snails on the low shore traveling less. Although there was food available on the

high shore the prevalent potential food source for these species is lichen, and less macroalgae is available on the high shore. However, food preference may not be the primary motivating factor driving the movements of A. antipodum, as Morton (1975) states they are very intermittent feeders remaining inactive for long periods of time. Previous research has shown marine organism experience less physiological stress in low shore environments compared to the high shore and this reduced stress combined with the availability of food may explain the 
movements of these snails (Vermeij, 1972; Grendon, 1977; Underwood, 1979). While the low shore offers its own unique challenges such as increased wave exposure, Littorinids have developed physical and behavioural adaptations to survive in these dynamic environments (Emerson et al., 2002; Lee and Lim, 2009). These adaptations include: a sealable operculum, enhanced enzyme function, resistance to desiccation, geotaxis, reheotaxis, phototaxis, orientation to on coming surf, reduced movements during dry conditions, aggregation, and seeking out crevices, over hangs and shaded areas (Newell, 1958; Grendon, 1977; Emerson et al., 2002; Lauzon-Guay and Scheibling, 2009; Lee and Lim, 2009 ).

\section{$\underline{\text { Movement of reproductive classes }}$}

Movements were compared among the different reproductive classifications to examine any behavioural differences in the movements of mature females, females, mature males, males, and juveniles. For A. antipodum there were no significant differences when the reproductive classifications were compared across shore heights; however, when both the snails reproductive class and transplant treatment were examine, there was significant variation in the final distance from the release site and the cumulative distance traveled. No differences in the movements of $A$. cincta were associated with reproductive classification.

The movement away from the release site by A. antipodum mature females did not show significant variation among the transplant treatments. On average mature females moved less, however, while not significant mature females transplanted to the high shore had the highest average distance from the release site and cumulative distances traveled. These mature females appeared to be attempting to return to the low shore, possibly in preparation for spawning. Nodilittorina radiata (Eydoux \& Souleyet, 1852) have been show to seasonally 
migrate moving down to the low shore in summer, where they will actively move around, with females releasing their planktonic eggs into the ocean (Habe 1955; Ito et al, 1998). Transplanted mature females that did not move back down to the low shore may have been waiting for a specific set of environmental conditions to make a down shore migration. Hampered mobility due to pregnancy and heightened anti-predator behaviours may account for why mature female A. antipodum moved less than other females (Koch et al., 2007). Another possibility is that mature females may not breed every year and hence do not need to migrate down shore to spawn (Emson et al., 2002). While mature females did not show any significant differences in their movement females did.

Austrolittorina antipodum females appear to prefer to be on the low shore and will orientate themselves and move to this preferred shore height if removed from it. Females transplanted from the low shore to the high shore moved relatively large distances to get back to the low shore. High shore females transplanted to the low shore generally made no such efforts to return to the high shore, and seemed to adjust to their new location showing movement similar to the female low shore controls. This type of acclimation and behavioural adaptation to new conditions has been documented in an intertidal limpet by Hobday (1995). High shore controls also moved considerable distances from the release site and these females may have already been conditioned to traveling far distances either in search of food, mates, or both. Female Buccinum undatum (a subtidal gastropod), especially those with underdeveloped reproductive organs, were found to work harder and take increased risks in the face of predators in order to feed (Koch et al., 2007). Austrolittorina antipodum females movements may indicate these females are seeking out rich food supplies to build up the energy requirements needed for reproduction. The low shore has a higher abundance and more diverse array of food 
items for Austrolittorinids, providing females preparing to reproduce a bounty of potential energy reserves. This abundance of food may explain why the majority of high shore females transplanted to the low shore remained there. Female A. antipodum may also undergo seasonal migrations, for example moving temporarily from the high shore to the low shore during the mating and spawning season. If this is occurring transplantation could have been advantageous to high shore females by potentially reducing the energy they would have had to expend to reach the low shore in search of food and mates, or to release their eggs once fertilized.

Examining the average final distance traveled from the release site, the female's traveled farthest initially, with movement declining over time until the final recapture when there was an increase in movement. The final increase in movement was presumably an artifact of the large time lag of 6 months between this and the previous sampling event allowing more time to travel. However, the movement of a related species has been shown to decline over the course of a study, as Hamilton (1978) also found the movements of Littorina irroarata declined over time. These movements seem to be more indicative of snails searching out preferred habitat or food rich in energy, and not movements due to reproduction, as spawning begins in November and the large initial movements were seen in April and May. On the other hand, females may need only to get to the low shore and the majority of the work in seeking out a mate could fall to the males (Ito and Wada, 2006; Koch et al., 2007).

Mature male transplants also showed significant differences in their movements compared to the other reproductive classifications and transplant treatments. Low shore transplanted mature males, like low shore transplant females, traveled far distances from the release site. These snails moved large cumulative distances to get back to the low shore. The movement of these males may be driven by the search for a mate. Mature males are potentially 
following the trails of females leading them to the low shore as trail following is a common trait among Littorinids (Erlandsson et al., 1999; Edwards and Davies, 2002; Muñoz et al., 2008). Mature male high shore transplants moved significantly less from the release site than other snails. Mature male A. antipodum, like females, may also prefer the low shore due to the higher abundance of food, mates, or both.

Transplanted male A. antipodum movements varied from mature males as well as other reproductive classifications. Unlike the mature males, low shore transplanted males did not move far from the release site, presumably because they are not searching for mates. The difference in the mature males and males movements up and down the shore indicate that mature males prefer to be on the low shore presumably due to the presence of mates and a higher abundance of females.

There were no significant differences found between juveniles from the different transplant treatments and the other reproductive classifications in any of the movements analyzed. However, the dispersal differences of these species are highlighted by the presence of juvenile $A$. cincta along the high shore of all sites, while a single juvenile $A$. antipodum was found on the high shore of site 3 . Thus there was no replication for A. antipodum, and only the movements of $A$. cincta juveniles were able to be analyzed. The physiology of $A$. cincta allows it to withstand a wider range of environmental conditions as seen by its wider geographic and shoreline distributions (Reid, 1996). These adaptations may allow juvenile A. cincta to move through a wider range of microhabitats, while juvenile A. antipodum are constrained to more precise environmental conditions, such as those found along the low shore. Previous research has shown smaller individuals are more affected by solar radiation and desiccation than larger individuals and in general that these environmental conditions are more prominent along the 
high shore than other shore heights (Lee and Lim, 2009; Muñoz et al., 2008; Koch et al., 2007; Cleland and McMahon, 1989). The limited movement of A. antipodum juveniles transplanted to the high shore suggests that the physiology of these individuals has not developed to the point where they can tolerate the more stressful conditions found there, while $A$. cincta juveniles are able to, and further tests of juvenile movements are needed to determine if this occurring.

The lower movement rates of juvenile A. antipodum appear to be linked more to its developmental stage than its size, as the size of individual snails appears to have no influence on the movements of either species. Edwards (1968) noted that the vertical position on the shore for the intertidal gastropod Olivella biplicata (Sowerby, 1829) was more a function of age than size, and results in the separation of reproductively mature and immature individuals. Size class comparisons for each of the aspects of movement examined (final distance from release site, progress towards home, and cumulative distance traveled) showed no significant differences. The reproductive status and transplant treatment seem to be more important factors than size in predicting the movements of A. antipodum, and for A. cincta the transplant treatment.

Snail transplant treatments had a significant effect on the movement of both species. No indication of behavioural isolation was found and results indicate that the extent of adult mobility can maintain connectivity between reproductively activity adults on the low and high shores. Austrolittorina antipodum low shore controls and high shore transplants moved significantly less from the release site, traveling the smallest cumulative distances. Austrolittorina cincta low shore controls and high shore transplants also traveled significantly less from the release site, with high shore controls moving far from the release 
site. Other research on the Littorinidae family has shown that transplanted snails returned to their shore level of origin (Grendon, 1977; McQuaid, 1981; Chapman, 1999; Lee and Lim, 2009). These results suggest that low shore snails prefer to, or are acclimated to live within the environmental conditions present at the low shore and will seek to return to this environment if removed from it. This may go beyond acclimation and species may have physiological restraints that inhibit them from residing and even moving through certain environmental conditions.

Some species found on the high shore have been found to have more stable enzymes when subjected to heat, allowing these species to maintain activity at higher temperatures (Hull et al., 1999; Lee and Lim 2009). This has yet to be tested for A. antipodum and A. cincta and enzyme stability may be found to be different between these species or the low and high shore individuals of these species. When snails conditioned to the more physiologically stressful environment of the high shore were moved to the low shore they seemed to prefer these conditions as they made little effort to move back to their original shore height. As Petraitis (1982) notes it is possible that the lack of consistent directionality in the movements of snails may be due to the different, yet consistent, preferences of individual snails. Another possibility is that these snails residing on the high shore only become active during certain conditions, such as high humidity and after rainfall, as this has been documented in Littorinid species (Emson et al., 2002). The same results were seen with the different reproductive classifications of A. antipodum and it appears that females and mature males are particularly sensitive to being at a certain shore level as they will attempt to return to the preferred shore level if moved. 
Individuals along the high shore appear to be conditioned to moving far distances. Results from concurrent population surveys show a general trend of lower algal abundance and lower snail densities along the high shore. Periwinkles on the high shore may be conditioned to move farther through this patchy environment to find resources such as food and mates. These individuals appear to expend more energy moving around than those on the low shore and one explanation for this is less predation on the high shore. Predators have been shown to affect movement and behaviours of Littorinids by reducing the movement rates, snails altering their direction of travel, seeking out shelter, and snails ending copulating when they sense predators (Koch et al., 2007; Cotton et al., 2004). If there are lower predation rates along the high shore living in this more physically demanding and potentially more physiologically stressful environment could still be more advantageous.

Lichen was present on all high shore sites providing ample food for high shore Austrolittorina, yet these snails had high movement rates. Vermeij (1972) points out that some resources along the high shore may become limiting and in order to have sufficient energy to allocate to reproduction migrations to more energy rich areas may be necessary. Lichen may not provide the necessary nutrients and snails may need to seek out other food sources to meet their nutritional needs. Food preference tests would help determine if these animals are moving in search of food. Lauzon-Guay and Scheibling (2009) found that high tides bringing in food to the high shore can lead to a reduction in Littorina littorea movement down shore and their movements to be consistent with food-dependent dispersal. Austrolittorina along the high shore were observed aggregating around bull kelp that had washed up to the high shore during storms and one tagged A. antipodum was recaptured grazing on bull kelp that had washed up near the high shore release site of site 1. Additional 
research is needed to determine if these species are moving along the high shore in search of different foods to meet their nutritional requirements, or if as generalist they can sustain themselves on lichen opportunistically feeding on any food resources that become available, or if other factors such as reproduction are motivating these movements.

Island Bay Austrolittorina demonstrated variation in movements due to shore height, reproductive classification, and transplant treatment. Snails appear to move less along the low shore, although in general this shore height is more populated. The low shore appears to be a more favorable habitat as snails transplanted from this shore height seek to return to it and those transplanted to it appear to do little to move out of it. Neither species showed variation in movement due solely to their reproductive status or any indication of behavioural isolation between adults reproducing on the low and high shores. When the reproductive classifications were compared among the transplant treatments only A. antipodum had significant differences found. Females and mature males transplanted from the low shore to the high shore moved towards the low shore, and juveniles were not found on the high shore.

These results indicate snail movement is not random and supports the results of the population study showing a definite population structure with certain demographics of the population preferring and positioning themselves along certain areas of the shore. If displaced from these areas some snails will move back to their preferred shore height. It is still undetermined if physiological factors are dictating this movement or if behavioural triggers such as seeking out food or mating are responsible. However, it is clear that adult mobility does not limit reproduction between low and high shore adults, as both species are capable of maintaining connectivity between reproductive populations along each shore height via adult movement. 
This movement study has illustrated that knowing the reproductive classification of individuals assigned to the various transplant treatments aids in our understanding of the behaviour of these species, the organization of the social structure, and in understanding the potential factors influencing movements. While supported by other studies conducted on similar species the plausible explanations presented here are limited by the duration of this study and the forces driving the observed differences between snail movement patterns could not be determined. Future work should be conducted for longer periods of time, ideally one year or longer, to detect any difference between seasonal migrations and those which are driven by foraging, mating, or spawning. Comparisons of movement during different tidal cycles, between night and day, and the effects of weather have yet to be determined and studies addressing these factors should be conducted as they have been shown to affect other Littorinids movements (Hobday, 1995; Emson et al., 2002; Muñoz et al., 2008). 


\section{$\underline{5.0 \text { Conclusion }}$}

This study has revealed aspects of A. antipodum and A. cincta's behaviour and ecology that were previously unknown such as: population size estimates and distributions for Island Bay populations, peak times of settlement, demographic distributions and sex ratios, and the movements of these species. Austrolittorina antipodum was found to be more abundant than A. cincta during all surveys at all sites with a harmonic mean (average of all surveys' total abundance) of 25,590 individuals $/ \mathrm{m}^{2}$, while $A$. cincta was 1,600 individuals $/ \mathrm{m}^{2}$ for the Island Bay population. Overall both species were more abundant on the low shore and had a Vermeij type 1 distribution (an increase in shell size moving from the low to high shore) (Vermeij, 1972). Peak recruitment occurred during February and March, although identification to the species level could not be determined for the recently settled snails. Mature snails of both species were more abundant on the high shore and both species had skewed sex ratios. Low and high shores had different sex ratios and A. antipodum females were more abundant on the low shore at all sites, whereas A. cincta had more males on the low shore of site 3 . Juveniles were restricted to the smaller size classes, with more A. antipodum juveniles collected from the low shore and more $A$. cincta juveniles from the high shore. The distances traveled were similar for both species and on average A. antipodum traveled $24.1 \mathrm{~m}( \pm 23.5 \mathrm{~m})$ and A. cincta traveled $18.7 \mathrm{~m}( \pm 16 \mathrm{~m})$. Both species did show an effect of transplant treatment on movement indicating individual snails may have preferred shore heights, while no indication of behavioural isolation was detected. Austrolittorina antipodum showed a significant effect of transplant treatment on the movements of the different reproductive classes, while $A$. cincta showed no effect of reproductive class on the movement of snails. 
The larger population of A. antipodum compared to A. cincta may have important implications on population persistence, dispersal potential (i.e. both larval dispersal and adult dispersal), connectivity and genetic diversity, as well as indicating the relative carrying capacities of each species (Gadgil, 1971; Newman and Pilson, 1997). On evolutionary time scales the factors which would lead to the higher abundance of $A$. antipodum compared to $A$. cincta would be: life history, natural selection, opportunities for population growth, carrying capacities, habitat associations, physiological requirements and limitations, local stabilizing mechanisms (i.e. predation, immigration, competition), and metapopulation dynamics among other factors (Gadgil, 1971; Murdoch, 1994; Johnson et al., 2001; Reznich and Ghalambor, 2001). The factors examined in this study suggest the prevalence of $A$. antipodum over $A$. cincta is presumably due to a number of factors including: their spatial distribution along the shore line and habitat associations, increased pairing and potential mating opportunities, sex ratios skewed towards more females feasibly resulting in higher larval production, behaviours which possibly increases the potential of gametes reaching the ocean and potentially increasing juvenile survivorship, and slightly higher mobility increasing the potential of finding resources.

The distribution of these species has been shown to change with the direction and exposure (Batham, 1958; Pilkington, 1972). In some populations, such as those studied here, A. antipodum was found to be more abundant on the low shore while $A$. cincta was found to be more abundant on the high shore with a wider vertical range. The abiotic and biotic characteristics of the high shore may also contribute to the smaller population sizes of $A$. cincta. Foraging time and resources are generally limited within high intertidal zones, potentially leading to less reproductive success as animals have fewer resources available for 
reproduction and limit time to search for mates (Vermeij, 1972; Chelazzi et al., 1988; Etter, 1989; Hughes, 1995; Emson et al., 2002). Austrolittorina cincta populations may also be limited by the incomplete down-shore movement of adults during the reproductive season and juveniles moving up the shore. Juveniles moving into the patchy high shore environment while they are young and have limited energy reserves to sustain themselves and may suffer higher mortality. These behaviours are potentially resulting in less gametes successfully reaching the ocean and less juveniles surviving to adulthood, with this loss of gametes and juveniles possibly reducing connectivity between populations (Edwards, 1969). The differences in these species population sizes and sex ratios may have important implications on the reproductive success of individuals and on the entire population's effective population size. These differences can alter dispersal and connectivity, feasibly altering the population and community structure of an area (Nunney, 1993; Johnson et al., 2001).

While A. antipodum had a much larger population than A. cincta, the proportion of reproductively active adults within each species populations were similar. These species also shared the same type of shell size gradient with larger (generally mature) individuals concentrated in one area (the high shore), potentially increasing mating opportunities. Yet $A$. cincta were found in pairs (pairs are defined as on snail on top of the other in a position that indicate potential mating) less often than A. antipodum, suggesting there may be less mating occurring among $A$. cincta. In Otago populations of $A$. cincta were also found to pair less than A. antipodum, showing no correlation between copulations and the environmental parameters measured, and spawned less than A. antipodum under laboratory conditions (Pilkington, 1971). If there are indeed less successful copulations occurring among A. cincta, connectivity between populations is potentially limited due to issues of larval supply leading to poor settlement and 
juvenile survivorship. Another possibility is behavioural differences between their larvae influence settlement, with $A$. antipodum potentially showing more flexibility in settlement behaviours or less precise habitat requirements. If A. antipodum larvae are found to have more flexible behaviours than A. cincta, they may show more fluctuation in the amount of settlement, but overall have more persistent local populations than A. cincta (Persson and De Roos, 2003). Austrolittorina cincta larvae may also be seeking out more defined microhabitats and their populations may experience slightly different selective pressures which limit the carrying capacity of certain areas (Gadgil, 1971).

Two spikes in settlement were seen for these species in February and March. Multiple spikes in settlement have been documented in other Littorina species, with rhythmic spawning being linked to tides and lunar phases (Smith and Newell, 1955; Cronin et al., 2000). Peak settlement found in the present study was during settlement plate deployments around the full moon, indicating lunar and tidal cycles may influence the settlement and potentially the spawning of these species. Spawning of these species was assessed by Pilkington (1971); however this assessment was by the presences of eggs in plankton tows and from animals observed in the lab. Both species spawned under laboratory conditions, although spawning was erratic, A. cincta spawned less than A. antipodum and sometimes not at all. While this may reflect normal spawning for these species, the sporadic spawning of individuals suggests it may have been due to stress and may not represent true spawning cycles. The two peaks in settlement may have evolved to enhance dispersal by helping to ensure stochastic events do not limit settlement and dispersal opportunities. An annual study of the reproductive status of these species is needed to determine if there are individuals reproducing out of sync with the others (creating the multiple spikes in settlement) or if individuals are spawning multiple times, and to 
establish a more precise approximation of the duration of their spawning seasons (Henninger and Hodgson, 2001).

A species population size can be depressed over its entire range due to variation in adult density and crowding as a result of dispersal, and variation in the carrying capacity with time (Gadgil, 1971). While manipulations used to assess the effects of variable adult density on settlement were not successful, the number of conspecifics may prove to influence settlement and potentially connectivity. More settling Austrolittorina were collected from settlement pads within the adult population than below it, indicating the presences of adults is a factor influencing settlers. If larvae are using cues from conspecific adults, the density of individuals should affect the strength of these cues, and areas of low density may not provide strong enough cues for the young settlers to return to their natal site or settle into new areas, thereby reducing dispersal and connectivity potential (Atema et al., 2002; Pasternak et al., 2004; Botello and Krug, 2006). The presences of adults indicates good habitat and the benefits of settling into an area high quality habitat appears to out weight the potential effects of competition and crowding. The impacts of adult density on the strength of settlement cues and the degree of crowding may not be as important as the ability of the local oceanography and hydrology in facilitating or hampering larval exchange, and these factors warrant further investigation.

Larval behavioural experiments are needed to determine if behavioural differences between these species result in one species having higher settlement rates than the other. Austrolittorina cincta larvae may experience higher predation than A. antipodum, be less efficient at perceiving settlement cues, or have a more defined type of microhabitat which they settle onto (Gebauer et al, 2002; Hadfield and Koehl, 2004; Santagata, 2004). Less settlement 
can lead to less dispersal which can in turn hamper connectivity between populations.

However, larval behaviours and lower settlement may not be the primary factors limiting A. cincta populations; it may be more tied to elements of larval production such as spawning success.

Pilkington’s (1971) spawning study notes that the vertical migration of A. cincta to the low shore was not sufficient to release eggs into the ocean, which may impede spawning success in $A$. cincta populations. The timing of spawning may be of critical importance not only to ensure gametes successfully reach the open ocean, but also to ensure the timing of larval development and metamorphosis coincides with tide and lunar cycles as well as a high abundance of food (Emson et al., 2002). Results of the present study showed a delay in pairing between $A$. cincta compared to A. antipodum. If high shore snails are spawning at later times (i.e. when storms are becoming more frequent) than low shore snails, the higher abundance of A. cincta females on the high shore may result in them spawning slightly later than $A$. antipodum (Cronin et al., 2000). This is supported by population survey data and the delayed shift to a smaller mean size of individuals on the low shore apparently due to settlement, indicating $A$. cincta settles onto the shore slightly later than $A$. antipodum. There was also a delay in the shift to a smaller mean size along all shore heights for $A$. cincta compared to $A$. antipodum. Again this may be due to a delay in A. cincta settlement as the presences of settlers appears to trigger ontogenetic migrations of other cohorts, as seen in other species of Littorinids (Williams, 1990).

Based on findings from the fecundity chapter, locating a mate at the right time and the right place is presumably among the key factors that would be limiting the reproductive success of $A$. cincta, the supply of settlers, and potentially their connectivity. Austrolittorina cincta had 
a higher proportion of males in their populations than A. antipodum did, with one low shore site where sex ratios were skewed towards more males, showed a less distinct demographic distribution, and less pairing. Successful copulation and spawning are crucial to maintaining population connectivity via larval dispersal, and lower larval production and dispersal may limit the connectivity between $A$. cincta populations. While the assessment of individual fecundity was unsuccessful, and larval production and mortality estimates could not be made, it would be worthwhile collecting this data in the future. This is likely to resolve whether or not the smaller abundance of $A$. cincta is due to poor production of larvae, if they have higher larval mortality rates, or a limited carrying capacity. This information will also help determine the affects of larval production and mortality on dispersal and connectivity.

The growth rates of periwinkles have been shown to affect individual fecundity and reproduction rates, and A. cincta may have growth rates that result in slower/reduced reproduction compared to A. antipodum (Spight and Emlen, 1976; Hughes and Roberts, 1980). Rochette et al. (2003) found snail size (shell length) to be a strong predictor of maturity status, suggesting larger females are more fecund, and therefore more advantageous to mate with. They also found a variable relationship between shore level and size at sexual maturity with evidence of this being partially due to genetics. Site 2 had the largest average size mature females and largest average size for females for both species. Site 2 also had the highest settlement. If settlement at each site reflects the amount of local larval production, the larger females of this site may be producing more offspring, resulting in the higher settlement at this site (Stoner and Ray-Culp, 2000; Strathmann et al., 2002; Warner and Cowen, 2002). Male littorinids have been show to preferentially mate with large females, making primary assessments of mates by their size followed by determining sex or ecotype (Erlandsson et al., 
1999; Hollander et al., 2005). The preference to mate with larger females may be due to a positive heterozygosity-sexual fitness relationship related to size, as was found in populations of Littorina mariae (Turton, 1825) (Rolán- Alvarez et al., 1995). Faster growth could not only enable female snails to reach maturity sooner, but also aid in copulation as males may prefer to mate with larger females. In populations of $L$. saxatilis ontogenic growth was found to be influenced by habitat-associated selection, gender and age-specific selection, factors that may also be affecting A. antipodum and A. cincta in different ways (Hollander et al., 2006). The lifelong growth patterns, longevity, and causes of mortality for these species and how that varies among different demographics still need to be assessed.

There were no significant differences detected in the mobility or distances traveled by these two species, indicating adults of each species are equally capable of traveling relatively far distances. It is feasible that individuals traveling parallel to the shore could travel kilometers within their lifetime, indicating the potential importance of adult dispersal on population connectivity. While populations in close proximity may experience similar selective pressures, there is still the possibility of adult behavioural differences impacting distribution patterns and connectivity (Frank, 1965; Hellberg, 1996). Littorinids are known to maintain separate breeding populations even in the absences of geographic barriers (Wilding and Grahame, 2001). While no such behaviours were detected in this study there was some extent of demographic partitioning along the shore for both species, with transplantation revealing preferences of some A. antipodum demographics. Williams (1995) found transplants moved towards home while controls (individuals translocated within their home range or shore level or origin) moved randomly. This directionality in movement due to transplant treatment may be why A. cincta did not show the directionality in movements that $A$. antipodum did, as 
more A. cincta in the final recapture were controls. Chapman (2000a) found that Littorina unifasciata $(G r e y, 1826)$ responded to factors associated with the area they placed not where they were from. The movement of individuals may also be more characteristic of its demographic and their associated behaviours, than an individual's preferred habitat.

The slight differences in these species preferred habitat and potential dietary differences may have lead to the divergence of these species from a common ancestor, ultimately shaping their population structure (Reznick and Ghalambor, 2001). As abundant primary grazers the two species examined in this study have the ability to shape intertidal communities and alterations in their behaviour have the potential to influence many species (Petraitis, 1983; Lauzon-Guay and Schiebling, 2009). Phillips and Hutchison (2008), found A. antipodum and A. cincta to be among a group of New Zealand molluscan grazers that had a strong effect on the algal assemblages of the mid intertidal zone. Their study was conducted in the same area as my study, illustrating that these species are shaping the communities in numerous ways. These two Austrolittorina species are prospective candidates for Behaviourally Mediated Indirect Interactions (BMII) in both their planktonic and benthic stages (Dill et al., 2003).

Behaviourally mediated indirect interactions are processes where the change of some property of one species, the 'initiator', changes the behaviour of the 'transmitter' species, which in turn has an effect on another community member, the 'receiver' (Dill et al., 2003). These Austrolittorina species have the potential to play anyone of these roles (initiator, transmitter, or receiver) through: predation/prey interaction, direct and indirect competition (for both space and resources), actions of settlers, among other interactions. These species may take on anyone of these rolls in BMIIs, or play different rolls throughout their different life stages. Further investigations into the behaviour and ecology of these species will help define the role they 
play in their community, in BMIIs, how they help structure their community, and uncover other factors affecting their dispersal and population connectivity.

This study has shown that $A$. antipodum and $A$. cincta have unique behaviours which shape their populations. Austrolittorina antipodum has a much larger population, primarily occupying the low shore, with female behaviours which may enhance reproduction. The peak settlement of these species is during February and March, and these settlement events appear to be shaping the distribution of conspecifics. Skewed sex ratios and the movements of different demographics may be among the primary factors affecting the success of these species, as well as the number of fecund individuals in a population. Movements did not indicate any behavioural isolation occurring between the low and high shores, and demonstrated the mobility of different demographics. These results have reinforced how differences in the behaviour of these species influence a population structure, and highlighted the potential of adult movement to affect dispersal and population connectivity. 
$\underline{\text { Appendix }}$ 



\section{$\underline{\text { References }}$}

Agardy, T., 1994. Advances in marine conservation: The role of marine protected areas. Trends in Ecology and Evolution. 9 (7): 267-270

Allendorf, F., 2006. Conservation and the genetics of populations: units of conservation. Chapter 16, pp. 380-420

Atema, J., Kingsford, M.J., and G. Gerlach, 2002. Larval reef fish could use odour for detection, retention and orientation to reefs. Marine Ecology Progress Series. 241: 152- 160.

Batham, E.J., 1956. Ecology of southern New Zealand sheltered rocky shore. Transactions of the Royal Society of New Zealand

84: 447-465.

Batham, E.J., 1958. Ecology of southern New Zealand exposed rocky shore at Little Papanui, Otago Peninsula. Transactions of the Royal Society of New Zealand 85: 647-658.

Bell, J.J., 2008. Similarity in connectivity patterns for two gastropod species lacking pelagic larvae. Marine Ecology Progress Series. 357: 185-194

Bohonak, A.J., 1999. Dispersal, gene flow, and population structure. The Quarterly Review of Biology. 74:21-45

Botello, G., and P.J. Krug, 2006. 'Desperate larvae’ revisited: age, energy and experience affect sensitivity to settlement cues in larvae of the gastropod Alderia sp. Marine Ecology Progress Series. 312: 149- 159.

Boulding, E.G. and F.M. Harper, 1998. Increasing precision in randomised field experiments: barnacle microtopography as a predictor of Littorina abundance. Hydrobiologia. 378:105-114

Boyle, M.C., Jillett, J.B., and P.V. Miladenov, 2001. Intertidal communities in Doubtful Sound, New Zealand: changes over time. New Zealand Journal of Marine and Freshwater Research. 35: 663-673

Chapman, M.G., 1986. Assesment of some controls in experimental transplants of intertidal gastropods. Journal of Experimental Marine Biology and Ecology. 103: 181- 201

Chapman, M.G., 1994a. Small- and broad-scale patterns of distribution of the upper-shore littorinid Nodilittorina pyramdalis in New South Wales. Australian journal of ecology. 19(1):8395

Chapman, M.G., 1994b. Small-scale patterns of distribution and size structure of the itertidal littorinid Littorina unifasciata (Gastropoda: Littorinidae) in New South Wales. Australian Journal of Marine and Freshwater Research. 45(4): 635-652 
Chapman, M.G. and A.J. Underwood, 1996. Influences of tidal conditions, temperature and desiccation on patterns of aggregation of the high-shore periwinkle, Littorina unifasciata, in New South Wales, Australia. Journal of Experimental Marine Biology and Ecology. 196: 213-237

Chapman, M.G., 1999. Assessment of variability in responses of intertidal periwinkles to experimental transplantations. Journal of Experimental Marine Biology and Ecology. 236: 171190

Chapman, M.G., 2000a. A comparative study of differences among species and patches of habitat on movements of three species of intertidal gastropods. J. Exp. Mar. Biol. Ecol. 244:181201

Chapman, M.G., 2000b. Poor design of behavioural experiments get poor results: examples from intertidal habitats. J. Exp. Mar. Biol. Ecol. 250:77-95

Chelazzi, G., Focardi, S., and J. Deneubourg, 1988. Analysis of movement patterns and orientation mechanisms in intertidal chitons and gastropods. In: Chelassi G, Vannini M (eds) Behavioural adaptation to intertidal life. NATO ASI Series, Vol 151. Plenum Press, New York, p 173-184

Cheung, S.G., and S. Lam, 1999. Effect of food availability on egg production and packaging in the intertidal scavenging gastropod Nassarius festivus. Marine Biology. 135: 281- 287

Cotton, P.A., Rundle, S.D., and K.E. Smith, 2004. Trait compensation in marine gastropods: shell shape, avoidance behaviour, and susceptibility to predation. Ecology. 85(6): 1581- 1584

Cowen, R.K., Lwiza K.M.M., Sponaugle, S., Paris, C.B., and D.B. Olson, 2000. Connectivity of marine populations: open or closed? Science. 287: 857-859

Creese, R.G., 1981. Patterns of growth, longevity, and recruitment of intertidal limpets in new South Wales. Journal of experimental marine biology and ecology. 51: 145- 171

Cronin, M.A., Myers, A.A., and R.M. O’Riordan, 2000. The reproductive cycle of the intertidal gastropod Melarhaphe neritiodes on the west and south coasts of Ireland. Proceddings of the Royal Irish Academy. 100B(2): 97-106

Crowe, T.P. and A.J. Underwood, 1999. Differences in dispersal of an intertidal gastropod in two habitats: the need for and design of repeated experimental transplantation. Journal of Experimental Marine Biology and Ecology. 237: 31-60

Cruz, R., Vilas, C., Mosquera, J., and C. García, 2004. Relative contribuiotn of dispersal and natural selection to the maintenance of a hybrid zone in Littorina. Evolution. 58(12): 2734- 2746

Dellow, V., 1950. Inter-tidal ecology of Narrow Neck Reef, New Zealand. (Studies in inter-tidal zonation 3). Pacific Science 4:355-374. 
De Magalhães, C.A., 1998. Density and shell-sized variation of Nodilittorina lineolata (Orbigny, 1840) in the intertidal region in southeastern Brazil. Hydrobiologia. 378:143-148

Dill, L.M., Heithaus, M.R., and C.J. Walters, 2003. Behaviorally Mediated Indirect Interactions in Marine Communities and their Conservation Implications. Ecology. 84 (5):1151- 1157.

Edgar, G.J., Bustamante, R.H., Fariña, Calvopiña, M., Martínez, C., and M.V. Toral-Granda, 2004. Bias in evaluating the effects of marine protected areas: the importance of baseline data for the Galapagos Marine Reserve. Environmental Conservation. 31(3): 1-7

Edwards, D. C., 1968. Reproduction in Olivella biplicata. Veliger. 10: 297-304

Edwards, D. C., 1969. Zonation by size as an adaptation for intertidal life in Olivella biplicata. American Zoologist. 9:399-417

Emson, R.H., Morritt, D., Andrews, E.B., and C.M. Young, 2002. Life on a hot dry beach: behavioural, physiological, and ultrastructural adaptations of the littorinid gastropod Cenchritis (Tectarius) muricatus. Marine Biology. 140: 723- 732

Endler, J.A., 1977. Gene flow and population differentiation. Science. 179: 243- 250.

Erlandersson, J., Kostylev, V., and E. Rolán-Alvarez, 1999. Mate search and aggregation behaviour in the Galician hybrid zone of Littorina saxatilis. Journal of Evolutionary Biology. 12: 891-896

Etter, R.J., 1989. Life history variation in the intertidal snail Nucella Lapillus across a waveexposure gradient. Ecology. 70(6): 1857- 1876

Fernándex, J., Galindo, J., Fernándex, B., Pérez-Figueroa, A., Caballero, A., and E. RolánAlvarez, 2005. Genetic Differentiation and Estimation of Effective Population Size and Migration Rates in Two Sympatric Ecotypes of the Marine Snail Littorina saxatilis. Journal of Heredity. 96(4): 460- 464

Fish, J.D., 1979. The Rhythmic spawning behaviour of Littorina littorea. J. Moll. Stud. 45:172177

Foster, B.A., 1966. The effects of wave exposure and aspect on the vertical shore distribution and population composition of Melarhapha oliveri. Tane 12: 37-44.

Fotheringham, N., 1974. Trophic Complexity in a Littoral Boulderfield. Limnology and Oceanography. 19(1): 84-91

Frank, P.W., 1965. The biodemography of an intertidal snail population. Ecology. 46(6): 831844 
Fretter, V, and A. Graham, 1994. British prosobranch Molluscs, their functional anatomy and ecology, revised and updated edition. The Ray Society, London

Gebauer, P., Paschke, K., and K. Anger, 2002. Metamorphosis in a semiterrestrial crab, Sesarma curacaoense: intra- and interspecific settlement cues from adult odors. Journal of Experimental Marine Biology and Ecology. 268: 1- 12

Gillander, B.M., Able, K.W., Brown, J.A., Eggleston, D.B., and P.F. Sheridan, 2003. Evidence of connectivity between juvenile and habitat for mobile marine fauna: an important component of nurseries. Maine Ecology Progress Series. 247: 281- 295

Glazer, R., 2005. A model for decoupling emigration from mortality in recapture surveys of slow-moving benthic marine gastropods. Journal of Shellfish Research. 24(2):387-392

Grech, M., 1989. A laboratory study on the behavioural responses of Littorina neritoides in relation to its zonation on Maltese shores. Marine Behaviour and Physiology. 15: 123- 135

Grendon, R.P., 1977. Habitat selection and migratory behaviour of the intertidal gastropod Littorina littorea. The Journal of Animal Ecology. 46(1):79-92

Gutierrez, P.C., 1988. The Ecology and Behavior of the Mangrove Periwinkle, Littorina angulifera. Biotropica. 20(4): 352-356

Hadfield, M. G., and M.A.R. Koehl, 2004. Rapid Behavorial Responses of an Invertebrate Larva to Dissolved Settlement Cue. The Biological Bulletin. 207: 28- 43.

Hamilton, P.V., 1978. Intertidal Distribution and Long-Term Movements of Littorina irrorata (Mollusca: Gastropoda). Marine Biology. 46: 49- 58

Hayward, B., 1987. Kawerua mollusc. Tane. 32: 1-10

Henninger, T.O., and A.N. Hodgson, 2001. The reproductive cycle of Helcion pruinosus (Patellogastropoda) on two South African boulder shores. The Journal of Molluscan Studies. 67:385- 394

Hobday, A., 1995. Body-size variation exhibited by an intertidal limpet: Influence of wave exposure, tidal height and migratory behaviour. Journal of Experimental Marine Biology and Ecology. 189:29- 45

Hohenlohe, P.A., 2004. Limits to gene flow in marine animals with planktonic larvae: models of Littorina species around Point Conception, California. Biological Journal of the Linnean Society. 82:169-187

Hollander, J., Lindegarth, M., K. Johannesson, 2005. Local adaptation but not geographical separation promotes assortative mating in a snail. Animal Behaviour. 70: 1209-1219 
Hollander, J., Adams, D.C., and K. Johannesson, 2006. Evolution of adaptation through allometric shifts in a marine snail. Evolution. 60(12): 2490-2497

Hughes, R.N., and D.J. Roberts, 1980. Reproductive effort of winkles (Littorina spp.) with contrasted methods of reproduction. Oecologia. 47: 130- 136

Hughes, R.N., 1995. Resource allocation, demography and the radiation of life histories in rough periwinkles (Gastropoda). Hydrobiologia. 309: 1-14

Ito, A., and S. Wada, 2006. Intrasexual copulation and mate discrimination in a population of Nodilittorina radiate (Gastropoda: Littorinidae). Japan Ethological Society. 24: 45-49

Johannesson, K., Rolán-Alvarez, E., and A. Ekendahl, 1995. Incipient reproductive isolation between two sympatric morphs of the intertidal snail. Evolution. 49: 1180-1190

Jones, P.J.S., and A. Carpenter, 2009. Crossing the divide: the challenges of designing an ecologically coherent and representative network of MPAs for the UK. Marine Policy. 33(5):737- 743

Knox, G.A., 1953. The intertidal ecology of Taylor's Mistake, Banks Peninsula. Transactions of the Royal Society of New Zealand 81: 189-220.

Koch, N., Lynch, B., and R. Rochette. 2007. Trade-off between mating and predation rish in the marine snail, Littorina plena. Invertebrate Biology. 126(3): 257-267

Kojima, Y., 1959. The relation between seasonal migrations and spawning of a periwinkle, Littorina brevicula (Phillipi). Bulletin of Marine Biology. Stn Asamushi 9:183- 186

Korff, W.L. and P.C. Wainwright, 2004. Motor pattern control for increasing crushing force in the striped burrfish (Chilomycterus schoepfi). Zoology. 107: 335-346

Kyle, C.J. and Boulding E.G., 2000. Comparative population genetic structure of marine gastropods (Littorina spp.) with and without pelagic larval dispersal. Marine Biology. 137:835845

Lee, S. and S.S.L. Lim, 2009. Vertical zonation and heat tolerance of three Littorinid gastropods on a rocky shore at Tanjung Chek Jawa, Singapore. The Raffles Bulletin of Zoology. 57(2): 551560

Levings, S.C. and S.D. Garrity, 1983. Diel and tidal movement of two co-occurring neritid snails: differences in grazing patterns on a tropical rocky shore. Journal of Experimental Marine Biology and Ecology. 67: 261-278

Lauzon-Guay, J. And R.E. Scheibling, 2009. Food dependent movement of periwinkles (Littorina littorea) associated with feeding fronts. 28(3): 581- 587 
Mäkinen, T., Panova, M., and C. André, 2007. High Levels of Multiple Paternity in Littorina saxatilis: Hedging the Bets? Journalof Heredity. 98: 705-711

McGrath, D., 1997. Population structure and recruitment of the intertidal gastropod Melarhaphe neritoides (L.) on an exposed rocky shore on the south coast of Ireland. Proceedingof the Royal Irish Academy. 97B: 75-79

Mitton, J.B., Berg, C.J., and K.S. Orr, 1989. Population Structure, Larval Dispersal, and Gene Flow in the Queen Conch, Strombus gigas, of the Caribbean. Biological Bulletin. 177: 356- 362.

Morton, J.E., 1975. Form and habit in some small gastropods of New Zealand boulder beaches. Veliger 18: 1-15.

Morton, J.E. and M.C. Miller, 1968. The New Zealand Sea-shore. Collins, London, pp. 638

Muñoz, J.L.P., Camus, P.A., Labra, P.A., Finke, G.R., and F. Bozinovic, 2008. Thermal constraints on daily patterns of aggregation and density along an intertidal gradient in the periwinkle Echinolittorinaperuviana. Journal of Thermal Biology. 33: 149-156

Newell, G.E., 1958. An experimental analysis of the behaviour of Littorina littorea (L.) under natural conditions and under natural conditions. J. Mar. Biol. Assoc. U.K. 37: 241-266

Newman, D., and D. Pilson, 1997. Increased probability of extinction due to decreased genetic effective population size: experimental populations of Clarkia pulchella. Evolution. 51(2): 354362

Norton, T.A., Hawkins, S.J., Manley, N.L, William, G.A., and D.C. Watson, 1990. Scraping a living: a review of Littorinid grazing. Hydrobiologia. 193: 117-138

Nunney, L., 1993. The influence of mating system and overlapping generations on effective population size. Evolution. 47(5): 1329-1341

Nunney, L., and D.R. Elam, 1994. Estimating the Effective Population Size of Conserved Populaitons. Conservation Biology. 8(1):175- 184

Palumbi, S.R. (2001). The ecology of marine protected areas, in: Bertness, M.D.; Gaines, S.D. et al. (Ed.) (2001). Marine community ecology. pp. 509-530

Panova, M., Hollander, J., and K. Johannesson, 2006. Site-specific genetic divergence in parallel hybrid zones suggests nonallopatric evolution of reproductive barriers. Molecular Ecology. 15(13): 4021- 4031

Pasternak, Z., Blasius, B., and A. Abelson, 2004. Host location by larvae of a parasitic barnacle: larval chemotaxis plume tracking in flow. Journal of plankton research. 26: 487- 493. 
Paulay, G. and C. Meyer, 2006. Dispersal and divergence across the greatest ocean region: Do larvae matter? Integrative and Comparative Biology. 46:269- 281

Pechenik, J.A., 1999. On the Advantages and disadvantages of larval stages in benthic marine invertebrate life cycles. Marine Ecology Progress Series. 177: 269- 297.

Persson, L., and A.M. De Roos, 2003. Adaptive habitat use in size-structured populations: Linking individual behaviour to population processes. Ecology. 84(5): 1129- 1139

Petraitis, P.S., 1982. Occurrence of random and directional movements in the periwinkle, Littorina littorea (L.). Journal of Experimental Marine Biology and Ecology. 59: 207- 217

Petraitis, P.S., 1983. Grazing patterns of the periwinkle and their effect on sessile intertidal organisms. Ecology. 64: 522- 533

Pilkington, M. C., 1971. Eggs, larvae, and spawning in Melarapha cincta (Quoy \& Gaimard) and M. oliveri Finlay (Littorinidae, Gastropoda). Aust. J. mar. Freshwat. Res. 22:79-90

Phillips, N.E. and E. Hutchison., 2008. Grazer effects on algal assemblages and mussel recruitment in two different mid-intertidal communities in the Cook Strait, New Zealand. New Zealand Journal of Marine and Freshwater Research. 42: 297- 306

Powell, A.W.B., 1933a. The high-tidal Mollusca of Rangitoto Island, Auckland; with descriptions of a new genus and two new species. Transactions and Proceedings of the New Zealand Institute 63: $144-152$.

Ried, D.G., 1996. Systematics and evolution of Littorina. The Ray Society, London. No 164.

Reid, D.G., 2004. Morphological Review and Phylogenetic Analysis of Nodilittorina (Gastropoda: Littorinidae). The Journal of Molluscan Studies. 68(3): 259-281

Reid, D.G. and S.T. Williams, 2004. The Subfamily Littorininae (Gastropoda: Littorinidae) in the Temperate Southern Hemisphere: The Genera Nodilittorina, Austrolittorina and Afrolittorina. Records of the Australian Museum. 56:75-122

Reznick, D.N. and C.T. Ghalambor, 2001. The population ecology of contemporary adaptations: what empirical studies reveal about the conditions that promote adaptive evolution. Genetica. 112-113: 183-198

Rochette, R, Tétreault, F., and J. Himmelmann, 2001. Aggregation of whelks, Buccinum undatum, near feeding predators: the role of reproductive requirements. Animal Behaviour. 61: 31-41.

Rochette, R., Dummall, K., and L. M. Dill, 2003. The effect of life-history variation on the population size structure of a rocky intertidal snail (Littorina sitkana). J. Sea Research. 49:119132. 
Rolán- Alvarez, E., Zapata, C., and G. Alvarez, 1995. Multilocus heterozygosity and sexual selection in a natural population of the marine snail Littorina mariae (Gastropoda:

Prosobranchia). Heredity. 75: 17-25

Santagata, S., 2004. A Waterborne Cue for the Actinotroch larva of Phoronis pallid (Phoronida) Produced by Upogebia pugettensis (Decapoda: Thalassinidea). The Biological Bulletin. 207: 103- 115.

Saur, M., 1990. Mate discrimination in Littorina littorea (L.) and L. Saxatilis (Olivi) (Mollusca: Prosobranchia). Hydrobiologia 193:261- 270

Scheltema, R.S., 1971. Larval dispersal as a means of genetic exchange between geographically separated populations of shallow-water benthic marine gastropods. 140: 284-322

Schmeller, D.S., and J. Merilä, 2007. Demographic and Genetic Estimates of Effective Population and Breeding Size in the Amphibian Rana temporaria. Conservation Biology

Schmidt, A.L., and R.E. Scheibling, 2007. Effects of native and invasive macroalgal canopies on composition and abundance of mobile benthic macrofauna and turf-forming algae. Journal of Experimental Marine Biology and Ecology. 341: 110- 130

Sebastian, C.R., Steffani, C.N., and G.M. Branch, 2002. Homing and movement patterns of a South African limpet Scutellastra argenvillei in an area invaded by an alien mussel Mytilus galloprovincialis. Marine Ecology Progress Series 243:111-122.

Spight, T.M., and J. Emlen, 1976. Clutch sizes of two marine snails with a changing food supply. Ecology. 57 (6):1162- 1178

Steneck, R.S. and L. Watling, 1982. Feeding Capabilities and Limitation of Herbivorous Molluscs: A Functional Group Approach. Marine Biology. 68: 299-319

Steyermark, A., 2002. A high standard metabolic rate constrains juvenile growth. Zoology. 105: 147-151

Stoner, A.W., and M. Ray-Culp, 2000. Evidence for Allee effects in an over-harvested marine gastropod: density-dependent mating and egg production. Marine Ecology Progress Series. 202: 297-302

Strathmann, R.R., 1985. Feeding and Nonfeeding Larval Development and Life-History Evolution in Marie Invertebrates. Annual Review of Ecology and Systematics. 16: 339- 361

Strathmann, R.R., Hughes, T.P., Kuris, A. M., Linderman, K.C., Morgan, S.G., Pandolfi, J.M., and R.R. Warner, 2002. Evolution of local recruitment and its consequences for marine populations. Bulletin of Marine Science. 70 (1): 377- 396. 
Struthsaker, J.W. and J.D. Costlow, 1968. Larval development of Littorina picta (Prosobranchia, Mesogastropoda), reared in the laboratory. Proceedings of the Malacological Society. 38: 153160

Takada, Y., 2003. Dimorphic migration, growth, and fecundity in a seasonally split population of Littorina brevicula (Mollusca: Gastropoda) on a boulder shore. Popul. Ecol. 45:141-148

Tinkle, D.W., and N.F. Hadley, 1975. Lizard reproductive effort: caloric estimates and comments on its evolution. Ecology. 56: 427- 434.

Thorson, G., 1950. Reproductive and larval ecology of marine bottom invertebrates. Biological Review. 25(1):1- 45

Underwood, A.J., 1978. An Eperimental Evaluation of Competition between Three Species of Intertidal Prosobranch Gastropods. Oecologia. 33 (2): 185-202

Underwood, A.J., 1979. The ecology of intertidal gastropods. Advances in marine biology. 16: $111-201$

Underwood, A.J., and M.G. Chapman, 1989. Experimental analyses of the influences of topography of the substratum on movements and density of an intertidal snail, Littorina unifasciata. J. Exp. Mar. Biol. Ecol. 134:175-196

Underwood, A.J., Chapman, M.G., Cole, V.J. and M.G. Palomo, 2008. Numbers and density of species as measures of biodiversity on rocky shores along the coast of New South Wales. Journal of Experimental Marine Biology and Ecology. 366: 175- 183

Warner, R.R., and R.K. Cowen, 2002. Local retention of production in marine populations: evidence, mechanisms, and consequences. Bulletin of Marine Science. 70(1): 245- 249

Wilding, C.S., Butlin, R.K., and J. Grahame, 2001. Differential gene exchange between parapatric mophs of Littorina saxatilis detected using AFLP markers. Journal of Evolutionary Biology. 14: 611- 619

Williams, G.A., 1990. The comparative ecology of the flat periwinkles, Littorina obtusata (L.) and L. Mariae Sacchi et Rastelli. Field Studies. 7: 469-482

Williams, G.A., 1995. Maintenance of zonation patterns in two species of flat periwinkle, Littorina obtusata and L. Mariae. Hydrobiologia. 309: 143-150

Wright, S., 1938. Size of population and breeding structure in relation to evolution. Science. 87:430- 431.

Vermeij, G.J. 1972. Intraspecific shore-level size gradients in intertidal mollusks. Ecology. 53(4):693-700 
Appendix 1. List of movement calculations used.

1. Reference angle calculation ${ }_{\mathrm{i}}=$

$$
\operatorname{Degrees}\left(\operatorname{ACOS}\left(\frac{\text { Distance }_{\mathrm{i}}^{2}+\text { distance between reference bolts-Distance }_{\mathrm{ii}}^{2}}{2 * \text { Distance }_{\mathrm{i}} * \text { distance between reference bolts }}\right)\right)
$$

2. $\mathrm{X}_{\mathrm{i}}=$

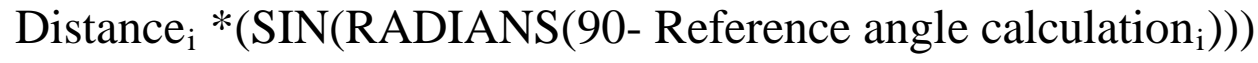

3. $\mathrm{Y}_{\mathrm{i}}=$

If (up/down ${ }_{\mathrm{i}}=$ "up”, Distance $_{\mathrm{i}}{ }^{*}$ (SIN(RADIANS(Reference angle calculation $\left._{\mathrm{i}}\right)$ )), Distance ${ }_{\mathrm{i}}^{*}(\mathrm{SIN}(\mathrm{RADIANS}$ (Reference angle calculation $\left.\left.\left.\left._{\mathrm{i}}\right)\right)\right)^{*}(-1)\right)$

4. Reference angle calculation ${ }_{\mathrm{ii}}=$

$\operatorname{IF}\left(\right.$ Distance $_{\mathrm{ii}}=$ “”, Reference angle calculation ${ }_{\mathrm{i}}$,

Degrees $\left(\operatorname{ACOS}\left(\frac{\text { Distance }_{\mathrm{i}}^{2}+\text { distance between reference bolts-Distance }_{\mathrm{ii}}^{2}}{2 * \text { Distance }_{\mathrm{i}} * \text { distance between reference bolts }_{\text {ista }}}\right)\right)$

5. $\mathrm{X}_{\mathrm{ii}}=$

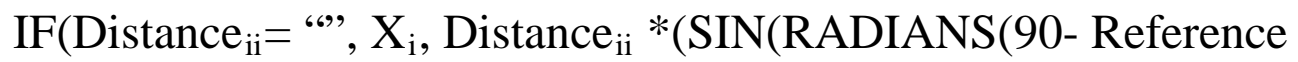
angle calculation $\left._{\mathrm{ii}}\right)$ ))

6. $\mathrm{Y}_{\mathrm{ii}}=$

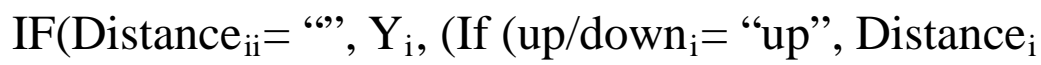
*(SIN(RADIANS(Reference angle calculation $\left.\left.{ }_{\text {ii }}\right)\right)$ ),

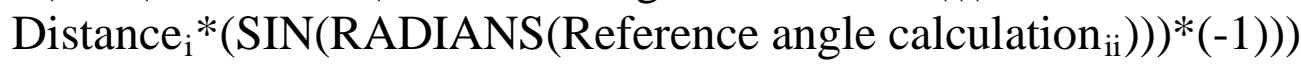

7. Distance traveled between recapture events $\mathrm{s}_{\mathrm{i}}=$

$$
\sqrt{(((X i i-X i) 2)+(Y i i-Y i) 2))}
$$

8. Final Distance From Release Site $=$

$$
\sqrt{\left(x_{\text {final }}-x_{\text {initial }}\right)^{2}+\left(y_{\text {final }}-y_{\text {initial }}\right)^{2}}
$$




\section{Progress Toward Home $=$}

$$
\sqrt{\left(x_{\text {transplant/translocate }}-x_{\text {home }}\right)^{2}+\left(y_{\text {transplant/translocate }}-y_{\text {home }}\right)^{2}}-\sqrt{\left(x_{\text {final }}-x_{\text {initial }}\right)^{2}+\left(y_{\text {final }}-y_{\text {initial }}\right)^{2}}
$$

\section{Cumulative Distance $=$}

Distance traveled between recapture events ${ }_{i}+$ Distance traveled between recapture events $_{\mathrm{ii}}+$ Distance traveled between recapture events $_{\mathrm{iii}} \ldots \ldots \ldots \ldots$. 
Appendix 2. Population size and structure statistical results.

\begin{tabular}{lcccccc} 
Kruskal- Wallis test & \multicolumn{2}{c}{ A.antipodum } & \multicolumn{2}{c}{ A.cincta } & & DF \\
Factors tested & P & H & DF & P & H & D \\
\hline \hline Abundance vs shore height & 0.236 & 2.88 & 2 & 0.219 & 2.83 & 2 \\
Shore height abundance vs sampling round & $<0.001^{*}$ & 36.34 & 11 & $<0.001^{*}$ & 50.81 & 11 \\
Shore height abundance vs site & $<0.001^{*}$ & 604.48 & 8 & $<0.001^{*}$ & 22.14 & 8 \\
Abundance vs site & 0.024 & 7.47 & 2 & 0.219 & 3.04 & 2 \\
Size vs round & $<0.001^{*}$ & 110.95 & 3 & $<0.001^{*}$ & 18.28 & 3 \\
Size vs site & $<0.001^{*}$ & 1574 & 8 & $<0.001^{*}$ & 61.55 & 8 \\
Size vs shore height & $<0.001^{*}$ & 1951.8 & 2 & $<0.001^{*}$ & 63.28 & 2 \\
Size vs site and shore height & $<0.001^{*}$ & 2115.5 & 11 & $<0.001^{*}$ & 80.3 & 8 \\
Number of solo snails vs round & $<0.001^{*}$ & 1003.3 & 3 & $<0.001^{*}$ & 93.16 & 3 \\
Number of pairs vs round & $<0.001^{*}$ & 950.16 & 3 & $<0.001^{*}$ & 74.61 & 3 \\
Number of groups vs round & $<0.001^{*}$ & 361.15 & 3 & $<0.001^{*}$ & 135.85 & 3 \\
Number of mixed groups vs round & $<0.001^{*}$ & 869.44 & 3 & $<0.001^{*}$ & 133.83 & 3 \\
Number of solo snails vs site & $<0.001^{*}$ & 1389.1 & 8 & $<0.001^{*}$ & 122.61 & 8 \\
Number of pairs vs site & $<0.001^{*}$ & 1105 & 8 & $<0.001^{*}$ & 145.2 & 8 \\
Number of groups vs site & $<0.001^{*}$ & 912.37 & 8 & $<0.001^{*}$ & 148.09 & 8 \\
Number of mixed groups vs site & $<0.001^{*}$ & 1043.7 & 8 & $<0.001^{*}$ & 176.3 & 8 \\
Number of solo snails vs shore height & $<0.001^{*}$ & 399.96 & 2 & 0.067 & 5.39 & 2 \\
Number of pairs vs shore height & $<0.001^{*}$ & 138.81 & 2 & $<0.001^{*}$ & 9.82 & 2 \\
Number of groups vs shore height & $<0.001^{*}$ & 448.32 & 2 & $<0.001^{*}$ & 59.55 & 2 \\
Number of mixed groups vs shore height & $<0.001^{*}$ & 374.51 & 2 & $<0.001^{*}$ & 82.51 & 2
\end{tabular}

\section{Kruskal- Wallis tests results}

\section{Species comparisons}

Abundance of A.antipodum vs A.cincta

Comparison of A.antipodum and A.cincta abundance vs site

Comparison of A.antipodum and A.cincta abundance vs \# solo snails

Comparison of A.antipodum and A.cincta abundance vs \# pairs

Comparison of A.antipodum and A.cincta abundance vs \# groups

Comparison of A.antipodum and A.cincta abundance vs \# mixed groups

\begin{tabular}{ccc}
$\mathrm{P}$ & $\mathrm{H}$ & $\mathrm{DF}$ \\
\hline$<0.001^{*}$ & 299.17 & 1 \\
$0.002^{*}$ & 24.59 & 8 \\
0.07 & 3.28 & 1 \\
$0.003^{*}$ & 9.09 & 1 \\
$<0.001^{*}$ & 64.89 & 1 \\
$<0.001^{*}$ & 243.63 & 1
\end{tabular}


Kruskal- Wallis tests results

Habitat comparisons

Slope angle vs site

$\begin{array}{ccc}<0.001^{*} & 136.12 & 2 \\ <0.001^{*} & 1324.73 & 2 \\ <0.001^{*} & 368.28 & 2 \\ <0.001^{*} & 19.27 & 2 \\ <0.001^{*} & 369.65 & 2 \\ <0.001^{*} & 179.86 & 2 \\ <0.001^{*} & 500.95 & 2 \\ <0.001^{*} & 22.41 & 2 \\ <0.001^{*} & 684.08 & 8 \\ <0.001^{*} & 1724.16 & 8 \\ <0.001^{*} & 858.38 & 8 \\ <0.001^{*} & 437.88 & 8\end{array}$

Rugosity vs site

Macroalgae percent cover vs site

Lichen percent cover vs site

Slope angle vs shore height

Rugosity vs shore height

Macroalgae percent cover vs shore height

Lichen percent cover vs shore height

Slope angle vs all sites replicates

Rugosity vs all sites replicates

Macroalgae percent cover vs all sites replicates

Lichen percent cover vs all sites replicates

$<0.001^{*}$

437.88

DF 
Appendix 3. Table of average size of each species, at each shore height, for all replicate sites.

A. antipodum average length ( $\mathrm{mm})$

\begin{tabular}{|c|c|c|c|c|c|c|c|c|}
\hline \multirow[b]{2}{*}{ Site } & \multicolumn{2}{|c|}{ A. antipodum average length (mm) } & \multicolumn{6}{|c|}{ A. cincta average length $(\mathrm{mm})$} \\
\hline & Low shore & Mid shore & High shore & Site average & Low shore & Mid shore & High shore & Site average \\
\hline $1 a$ & $3.37( \pm 0.79)$ & $3.62( \pm 1.00)$ & $4.35( \pm 1.34)$ & $3.78( \pm 1.15)$ & $2.48( \pm 1.54)$ & $3.58( \pm 2.69)$ & $4.53( \pm 3.60)$ & $3.36( \pm 2.73)$ \\
\hline $1 b$ & $3.48( \pm 0.81)$ & $4.17( \pm 1.00)$ & $4.91( \pm 1.21)$ & $3.83( \pm 0.99)$ & $3.90( \pm 2.90)$ & $2.47( \pm 2.13)$ & & $3.68( \pm 2.84)$ \\
\hline $1 c$ & $2.36( \pm 0.60)$ & $3.38( \pm 0.73)$ & $4.08( \pm 1.34)$ & $3.09( \pm 1.05)$ & $1.66( \pm 0.55)$ & $4.46( \pm 2.41)$ & $4.91( \pm 3.92)$ & $2.83( \pm 2.33)$ \\
\hline $2 a$ & $2.90( \pm 0.68)$ & $3.48( \pm 0.55)$ & $5.46( \pm 1.34)$ & $3.73( \pm 1.34)$ & $3.63( \pm 2.63)$ & $4.15( \pm 1.22)$ & $7.60( \pm 1.44)$ & $4.50( \pm 2.63)$ \\
\hline $2 b$ & $2.48( \pm 0.43)$ & $4.19( \pm 1.05)$ & $3.69( \pm 1.13)$ & $3.20( \pm 1.12)$ & $1.86( \pm 0.84)$ & $4.00( \pm 2.06)$ & $4.35( \pm 2.45)$ & $3.19( \pm 2.11)$ \\
\hline $2 c$ & $2.54( \pm 0.60)$ & $2.88( \pm 0.60)$ & $3.51( \pm 0.78)$ & $2.90( \pm 0.73)$ & $2.37( \pm 1.72)$ & $2.98( \pm 2.90)$ & & $2.65( \pm 2.36)$ \\
\hline $3 a$ & $3.60( \pm 0.76)$ & $4.31( \pm 0.82)$ & $4.33( \pm 0.93)$ & $4.00( \pm 0.90)$ & $4.30( \pm 3.03)$ & $6.33( \pm 2.35)$ & $7.37( \pm 2.31)$ & $6.43( \pm 2.69)$ \\
\hline $3 b$ & $3.24( \pm 0.62)$ & $3.79( \pm 0.90)$ & $3.73( \pm 0.61)$ & $3.58( \pm 0.76)$ & $3.48( \pm 2.20)$ & $1.72( \pm 1.13)$ & $5.87( \pm 2.54)$ & $3.65( \pm 2.48)$ \\
\hline $3 c$ & $2.87( \pm 0.64)$ & $3.14( \pm 1.04)$ & $3.20( \pm 1.14)$ & $3.03( \pm 0.91)$ & $2.99( \pm 1.80)$ & $4.66( \pm 2.86)$ & $3.69( \pm 2.03)$ & $3.29( \pm 2.01)$ \\
\hline All sites & $2.89( \pm 0.79)$ & $3.56( \pm 0.96)$ & $4.03( \pm 1.26)$ & $3.39( \pm 1.07)$ & $2.92( \pm 2.15)$ & $3.83( \pm 2.66)$ & $4.73( \pm 2.96)$ & $3.45( \pm 2.54)$ \\
\hline
\end{tabular}


Appendix 4. Settlement complete statistical results.

\begin{tabular}{lcccccc} 
Kruskal- Wallis tests results & \multicolumn{3}{c}{ Main data set } & \multicolumn{3}{c}{ Subset of data } \\
Factors tested & P & H & DF & P & H & DF \\
\hline \hline Abundance of settlers vs sampling round & $<0.001^{*}$ & 60.15 & 7 & $<0.001^{*}$ & 32.91 & 4 \\
Abundance of settlers vs site 1 and sampling round & $0.003^{*}$ & 21.28 & 7 & $0.021^{*}$ & 11.53 & 4 \\
Abundance of settlers vs site 2 and sampling round & $<0.001^{*}$ & 41.6 & 7 & $<0.001^{*}$ & 31.98 & 4 \\
Abundance of settlers vs site 3 and sampling round & $0.004^{*}$ & 21.12 & 7 & 0.091 & 8.02 & 4 \\
Abundance of settlers vs site & $0.014^{*}$ & 19.15 & 8 & 0.032 & 16.83 & 8 \\
Abundance of settlers vs distance to adults & 0.472 & 53.04 & 53 & 0.404 & 57.93 & 56 \\
Aundance of unidentified prosobranch vs site & $<0.001^{*}$ & 52.13 & 8 & $0.010^{*}$ & 20.16 & 8 \\
Aundance of Entonella sp vs site & $<0.001^{*}$ & 182.18 & 8 & $<0.001^{*}$ & 120 & 8 \\
Aundance of cyprid barnacle larvae vs site & $<0.001^{*}$ & 89.6 & 8 & $<0.001^{*}$ & 65.92 & 8 \\
Aundance of all other snails vs site & $<0.001^{*}$ & 37.21 & 8 & $<0.001^{*}$ & 31.47 & 8 \\
Aundance of bivalves vs site & $<0.001^{*}$ & 39.2 & 8 & $0.006^{*}$ & 21.38 & 8 \\
Aundance of worms vs site & 0.055 & 15.2 & 8 & $0.012^{*}$ & 19.58 & 8 \\
Aundance of crustaceans vs site & 0.094 & 13.34 & 8 & 0.237 & 10.42 & 8 \\
Aundance of macroalgae vs site & $<0.001^{*}$ & 86.09 & 8 & $<0.001^{*}$ & 81.48 & 8 \\
Aundance of sand vs site & $<0.001^{*}$ & 48.51 & 8 & $0.002^{*}$ & 24.65 & 8 \\
Abundance of settlers vs density manipulation & 0.803 & 0.44 & 2 & 0.350 & 2.1 & 2 \\
Site comparisons of the abundance of & 0.175 & 32.56 & 26 & 0.323 & 28.74 & 26 \\
settlers vs density manipulation & & & & & &
\end{tabular}

\section{Main data set correlation tests}

\begin{tabular}{lcc} 
Factors tested & $\mathrm{P}$ & Pearson correlation \\
\hline \hline Abundance of settlers vs distance to adults & 0.833 & 0.017 \\
Abundance of settlers vs unidentified prosobranch settler & $0.013^{*}$ & -0.004 \\
Abundance of settlers vs Entonella sp. & $0.037^{*}$ & 0.063 \\
Abundance of settlers vs cyprid barnacle larvae & 0.767 & 0.399 \\
Abundance of settlers vs all other snails & 0.323 & 0.731 \\
Abundance of settlers vs bivalves & 0.191 & 0.354 \\
Abundance of settlers vs worms & 0.589 & 0.651 \\
Abundance of settlers vs crustaceans & 0.119 & 0.202 \\
Abundance of settlers vs macroalgae & 0.201 & 0.126 \\
Abundance of settlers vs sand & 0.512 & 0.084
\end{tabular}


Appendix 5. Table of sex ratios and demographic comparisons for each species, at each site, in each size class.

\begin{tabular}{|c|c|c|c|c|c|c|}
\hline Site & Species & Size & MF :MM & MF:F & MM:M & $q::^{\Uparrow}: \mathbf{J}$ \\
\hline \multirow[t]{4}{*}{1} & A. antipodum & $\mathrm{L}$ & $31: 38$ & $63: 37$ & $75: 25$ & $50: 50: 0$ \\
\hline & & M & $53: 40$ & $100: 0$ & $100: 0$ & $57: 43: 0$ \\
\hline & & $\mathrm{S}$ & $25: 50$ & $67: 33$ & 100:0 & $38: 50: 12$ \\
\hline & & $\Sigma$ & $13: 40$ & 79:21 & 89:11 & $49: 46: 5$ \\
\hline \multirow[t]{4}{*}{1} & A. cincta & $\mathrm{L}$ & 29:36 & $50: 50$ & $83: 17$ & $57: 43: 0$ \\
\hline & & M & 38:38 & $67: 33$ & $85: 15$ & $56: 44: 0$ \\
\hline & & $\mathrm{S}$ & $14: 14$ & $50: 50$ & $50: 50$ & $28.5: 28.5: 43$ \\
\hline & & $\Sigma$ & $30: 32$ & $58: 42$ & $80: 20$ & $51: 41: 8$ \\
\hline \multirow[t]{4}{*}{2} & A. antipodum & $\mathrm{L}$ & 83:0 & $83: 17$ & 0 & 0:100:0 \\
\hline & & M & $50: 20$ & $83: 17$ & $67: 33$ & $60: 30: 10$ \\
\hline & & $\mathrm{S}$ & $20: 40$ & $100: 0$ & $100: 0$ & $20: 40: 40$ \\
\hline & & $\Sigma$ & $52: 19$ & $85: 15$ & $80: 20$ & $62: 24: 14$ \\
\hline \multirow[t]{4}{*}{2} & A. cincta & $\mathrm{L}$ & 70:0 & $70: 30$ & $50: 50$ & 0:100:0 \\
\hline & & M & $20: 20$ & $100: 0$ & $50: 50$ & $20: 40: 40$ \\
\hline & & $\mathrm{S}$ & $0: 40$ & $0: 100$ & $67: 33$ & $20: 60: 20$ \\
\hline & & $\Sigma$ & $40: 15$ & $67: 33$ & $60: 40$ & $60: 25: 15$ \\
\hline \multirow[t]{4}{*}{3} & A. antipodum & $\mathrm{L}$ & $40: 40$ & $67: 33$ & $100: 0$ & $60: 40: 0$ \\
\hline & & M & $25: 17$ & 33:67 & $100: 0$ & $75: 17: 8$ \\
\hline & & $\mathrm{S}$ & $0: 43$ & $0: 100$ & $75: 25$ & $14: 57: 29$ \\
\hline & & $\Sigma$ & $21: 29$ & $38: 62$ & $88: 22$ & 54:33:13 \\
\hline \multirow[t]{4}{*}{3} & A. cincta & $\mathrm{L}$ & $20: 20$ & 33:67 & $50: 50$ & $60: 40: 0$ \\
\hline & & M & $14: 71$ & $100: 0$ & 83:17 & $15: 85: 0$ \\
\hline & & $\mathrm{S}$ & $0: 40$ & $0: 100$ & $80: 20$ & $30: 50: 20$ \\
\hline & & $\Sigma$ & $9: 45$ & 29:17 & $67: 33$ & 32:59:9 \\
\hline
\end{tabular}


Appendix 6. Fecundity complete statistical results.

Austrolittorina antipodum only

Variables tested

Kruskal- Wallis test Correlation test

All sites pooled

$\begin{array}{llll}P & H & \text { DF } & \text { correlation } P\end{array}$

Reproductive class vs size class

0.733

$\begin{array}{lll}0.62 & 2 & -0.047\end{array}$

0.67

Reproductive class vs site

0.126

$\begin{array}{lll}4.14 & 2 & 0.196\end{array}$

0.075

Reproductive class vs shore height

$0.026 *$

$\begin{array}{lll}4.95 & 1 & -0.246\end{array}$

$0.024^{*}$

Reproductive class vs transplant or control

0.854

$\begin{array}{lll}0.32 & 2 & -0.05\end{array}$

0.651

Reproductive class vs transplant treatment

0.249

$\begin{array}{lll}5.4 & 4 & -0.05\end{array}$

0.651

\section{Austrolittorina cincta only}

Variables tested

Kruskal- Wallis test Correlation test

\section{All sites pooled}

Reproductive class vs size class

\begin{tabular}{ccccc} 
& & \multicolumn{3}{c}{ Pearson } \\
P & $H$ & DF & correlation & $P$ \\
0.139 & 3.94 & 2 & 0.007 & 0.95 \\
0.252 & 2.76 & 2 & -0.063 & 0.582 \\
0.728 & 0.12 & 1 & -0.033 & 0.775 \\
0.474 & 0.51 & 1 & 0.088 & 0.439 \\
0.456 & 2.61 & 3 & -0.024 & 0.832
\end{tabular}


Appendix 7. Table of each reproductive classifications distribution among the small, medium, and large size classes for site 1 .

Site 1 Austrolittorina antipodum

Site 1 Austrolittorina cincta

\begin{tabular}{|c|c|c|c|c|c|c|c|}
\hline $\begin{array}{l}\text { Reproductive } \\
\text { status }\end{array}$ & $\begin{array}{l}\text { Size } \\
\text { class }\end{array}$ & $\begin{array}{l}\text { Size } \\
\text { range }\end{array}$ & $\begin{array}{l}\text { Average } \\
\text { size }\end{array}$ & $\begin{array}{l}\text { Sample } \\
\text { size }\end{array}$ & $\begin{array}{l}\text { Size } \\
\text { range }\end{array}$ & $\begin{array}{l}\text { Averag } \\
\text { e size }\end{array}$ & $\begin{array}{l}\text { Sample } \\
\text { size }\end{array}$ \\
\hline \multirow[t]{4}{*}{ Mature female } & $S$ & 3.5 & 3.5 & 2 & 5 & 5 & 1 \\
\hline & $M$ & 4- 5.25 & 4.6 & 8 & 8- 8.5 & 8.21 & 6 \\
\hline & $\mathrm{L}$ & 6- 9.25 & 7.4 & 5 & $10.5-12.5$ & 11.63 & 4 \\
\hline & $\Sigma$ & $3.5-9.25$ & 5.2 & 15 & 5- 12.5 & 9.2 & 11 \\
\hline \multirow[t]{4}{*}{ Female } & $\mathrm{S}$ & 3 & 3 & 1 & 4.5 & 4.5 & 1 \\
\hline & M & - & - & - & 6- 8 & 7.2 & 3 \\
\hline & $\mathrm{L}$ & 6- 9.5 & 7.33 & 3 & 10- 12.5 & 10.69 & 4 \\
\hline & $\Sigma$ & 3- 9.5 & 6.3 & 4 & $4.5-12.5$ & 8.6 & 8 \\
\hline \multirow[t]{4}{*}{ Mature Male } & $S$ & 3- 3.5 & 3.25 & 4 & 4.5 & 4.5 & 1 \\
\hline & $M$ & 4- 5 & 4.4 & 6 & $6.75-8.5$ & 7.83 & 6 \\
\hline & $L$ & 4- 9 & 7.5 & 6 & 10- 11 & 10.2 & 5 \\
\hline & $\Sigma$ & 3- 9 & 5.4 & 16 & $4.5-11$ & 8.5 & 12 \\
\hline \multirow[t]{4}{*}{ Male } & $\mathrm{S}$ & - & - & - & 3 & 3 & 1 \\
\hline & $M$ & - & - & - & 6.75 & 6.75 & 1 \\
\hline & $L$ & 8.5- 9.5 & 9 & 2 & 10.5 & 10.5 & 1 \\
\hline & $\Sigma$ & 8.5- 9.5 & 9 & 2 & 3- 10.5 & 6.8 & 3 \\
\hline \multirow[t]{4}{*}{ Juvenile } & $\mathrm{S}$ & 2.25 & 2.25 & 1 & $3.25-4.5$ & 4 & 3 \\
\hline & M & 5 & 5 & 1 & - & - & - \\
\hline & $L$ & - & - & - & - & - & - \\
\hline & $\Sigma$ & 2.25- 5 & 3.6 & 2 & $3.25-4.5$ & 4 & 3 \\
\hline
\end{tabular}


Appendix 8. Table of each reproductive classifications distribution among the small, medium, and large size classes for site 2 .

Site 2 Austrolittorina antipodum

Site 2 Austrolittorina cincta

\begin{tabular}{|c|c|c|c|c|c|c|c|}
\hline $\begin{array}{c}\text { Reproductive } \\
\text { status }\end{array}$ & Size class & Size range & $\begin{array}{c}\text { Average } \\
\text { size }\end{array}$ & $\begin{array}{l}\text { Sample } \\
\text { size }\end{array}$ & Size range & $\begin{array}{c}\text { Average } \\
\text { size }\end{array}$ & $\begin{array}{l}\text { Sample } \\
\text { size }\end{array}$ \\
\hline \multirow{4}{*}{ Mature female } & $\mathrm{S}$ & 3.5 & 3.5 & 1 & - & - & - \\
\hline & $M$ & 5- 5.5 & 5.25 & 4 & 9 & 9 & 1 \\
\hline & $\mathrm{L}$ & 7.5- 10.75 & 8.2 & 6 & 10- 12.5 & 11 & 7 \\
\hline & $\Sigma$ & 3.5- 10.75 & 6.7 & 11 & 9- 12.5 & 10.7 & 8 \\
\hline \multirow[t]{4}{*}{ Female } & $\mathrm{S}$ & - & - & - & 5 & 5 & 1 \\
\hline & $M$ & 5.5 & 5.5 & 1 & - & - & - \\
\hline & $\mathrm{L}$ & 8.25 & 8.25 & 1 & 11 & 11 & 3 \\
\hline & $\Sigma$ & $5.5-8.25$ & 6.9 & 2 & 5- 11 & 9.5 & 4 \\
\hline \multirow[t]{4}{*}{ Mature Male } & $\mathrm{S}$ & 3- 3.5 & 3.25 & 2 & $4.5-4.75$ & 4.6 & 2 \\
\hline & M & 5-Apr & 4.5 & 2 & 5.5 & 5.5 & 1 \\
\hline & $\mathrm{L}$ & - & - & - & - & - & - \\
\hline & $\Sigma$ & 5-Mar & 3.9 & 4 & 4.5- 5.5 & 4.9 & 3 \\
\hline \multirow[t]{4}{*}{ Male } & $\mathrm{S}$ & - & - & - & 4.5 & 4.5 & 1 \\
\hline & $M$ & 4.25 & 4.25 & 1 & 7.5 & 7.5 & 1 \\
\hline & $\mathrm{L}$ & - & - & - & - & - & - \\
\hline & $\Sigma$ & 4.25 & 4.25 & 1 & $4.5-7.5$ & 6 & 2 \\
\hline \multirow[t]{4}{*}{ Juvenile } & $\mathrm{S}$ & $2.5-2.75$ & 2.63 & 2 & 5 & 5 & 1 \\
\hline & $M$ & 5.5 & 5.5 & 1 & 9- 9.25 & 9.13 & 2 \\
\hline & $\mathrm{L}$ & - & - & - & - & - & - \\
\hline & $\Sigma$ & 2.5- 5.5 & 3.6 & 3 & 5- 9.25 & 7.8 & 3 \\
\hline
\end{tabular}


Appendix 9. Table of each reproductive classifications distribution among the small, medium, and large size classes for site 3 .

Site 3 Austrolittorina antipodum

Site 3 Austrolittorina cincta

\begin{tabular}{|c|c|c|c|c|c|c|c|}
\hline $\begin{array}{l}\text { Reproductive } \\
\text { status }\end{array}$ & $\begin{array}{l}\text { Size } \\
\text { class }\end{array}$ & $\begin{array}{l}\text { Size } \\
\text { range }\end{array}$ & $\begin{array}{l}\text { Average } \\
\text { size }\end{array}$ & $\begin{array}{l}\text { Sample } \\
\text { size }\end{array}$ & $\begin{array}{l}\text { Size } \\
\text { range }\end{array}$ & $\begin{array}{l}\text { Averag } \\
\text { e size }\end{array}$ & $\begin{array}{l}\text { Sampl } \\
\text { e size }\end{array}$ \\
\hline \multirow[t]{4}{*}{ Mature female } & S & - & - & - & - & - & - \\
\hline & M & 5- 5.5 & 5.17 & 3 & 8.5 & 8.5 & 1 \\
\hline & L & 6- 9 & 7.5 & 2 & 11.75 & 11.75 & 1 \\
\hline & $\Sigma$ & 5- 9 & 6.1 & 5 & $\begin{array}{c}8.5- \\
11.75\end{array}$ & 10.1 & 2 \\
\hline \multirow[t]{4}{*}{ Female } & S & 2.75 & 2.75 & 1 & 4.5- 5 & 4.67 & 3 \\
\hline & M & 4- 5.5 & 4.71 & 6 & - & - & - \\
\hline & L & 7.25 & 7.25 & 1 & 11.25 & 10.4 & 2 \\
\hline & $\Sigma$ & $\begin{array}{l}2.75- \\
7.25\end{array}$ & 4.8 & 8 & $\begin{array}{c}4.5- \\
11.25\end{array}$ & 7 & 5 \\
\hline \multirow[t]{4}{*}{ Mature Male } & S & 3- 3.5 & 3.17 & 3 & 4- 5 & 4.56 & 4 \\
\hline & M & 4- 5.5 & 4.75 & 2 & 7.5- 9 & 8 & 5 \\
\hline & L & 7- 7.5 & 7.25 & 2 & 10.5 & 10.5 & 1 \\
\hline & $\Sigma$ & 3- 7.5 & 4.8 & 7 & 4- 10.5 & 6.9 & 10 \\
\hline \multirow[t]{4}{*}{ Male } & S & 2.75 & 2.75 & 1 & 3.5 & 3.5 & 1 \\
\hline & M & - & - & - & 6 & 6 & 1 \\
\hline & L & - & - & - & 11 & 11 & 1 \\
\hline & $\Sigma$ & 2.75 & 2.75 & 1 & 3.5- 11 & 6.8 & 3 \\
\hline \multirow[t]{4}{*}{ Juvenile } & S & 3- 3.75 & 3.4 & 2 & 3- 4.75 & 3.9 & 2 \\
\hline & M & 4.75 & 4.75 & 1 & - & - & - \\
\hline & L & - & - & - & - & - & - \\
\hline & $\Sigma$ & 3- 4.75 & 3.8 & 3 & $3-4.75$ & 3.9 & 2 \\
\hline
\end{tabular}


Appendix 10. Movement complete statistical results.

\begin{tabular}{|c|c|c|c|c|c|c|c|c|c|}
\hline \multirow[b]{2}{*}{ A. antipodum } & \multicolumn{3}{|c|}{ Final distance from release site } & \multicolumn{3}{|c|}{ Progress towards home } & \multicolumn{3}{|c|}{ Cumulative distance } \\
\hline & $\mathbf{P}$ & $\mathbf{H}$ & DF & $\mathbf{P}$ & $\mathbf{H}$ & DF & $\mathbf{P}$ & $\mathbf{H}$ & DF \\
\hline Site & $0.017^{*}$ & 8.12 & 2 & $0.021 *$ & 7.7 & 2 & 0.206 & 4.95 & 2 \\
\hline Shore height & $0.001 *$ & 10.42 & 1 & 0.627 & 0.24 & 1 & $<0.001^{*}$ & 15.61 & 1 \\
\hline Reproduction code & 0.795 & 1.68 & 4 & 0.434 & 3.8 & 4 & 0.204 & 5.94 & 4 \\
\hline Size class & 0.219 & 3.04 & 2 & 0.705 & 0.7 & 2 & 0.622 & 0.95 & 2 \\
\hline Control vs treatment & 0.593 & 0.29 & 1 & 0.221 & 1.5 & 1 & 0.137 & 2.22 & 1 \\
\hline Transplant treatment & $0.014^{*}$ & 10.57 & 3 & 0.351 & 3.27 & 3 & $0.001^{*}$ & 17.04 & 3 \\
\hline $\begin{array}{l}\text { Transplant treatment and } \\
\text { Reproductive class }\end{array}$ & $0.017^{*}$ & 30.13 & 16 & 0.79 & 11.31 & 16 & $0.014^{*}$ & 30.88 & 16 \\
\hline
\end{tabular}

Final distance from release site Progress towards home Cumulative distance

\begin{tabular}{|c|c|c|c|c|c|c|c|c|c|}
\hline A. cincta & $\mathbf{P}$ & $\mathbf{H}$ & DF & $\mathbf{P}$ & $\mathbf{H}$ & DF & $\mathbf{P}$ & $\mathbf{H}$ & DF \\
\hline Site & $0.033^{*}$ & 6.85 & 2 & 0.188 & 3.34 & 2 & 0.804 & 4.95 & 2 \\
\hline Shore height & $0.005^{*}$ & 7.9 & 1 & 0.679 & 0.17 & 1 & $0.011 *$ & 6.46 & 1 \\
\hline Reproduction code & 0.924 & 0.9 & 4 & 0.198 & 6.02 & 4 & 0.185 & 6.2 & 4 \\
\hline Size class & 0.701 & 0.71 & 2 & 0.666 & 0.81 & 2 & 0.6 & 1.02 & 2 \\
\hline Control vs treatment & 0.841 & 0.04 & 1 & 0.639 & 0.22 & 1 & 0.847 & 0.04 & 1 \\
\hline Transplant treatment & $0.045^{*}$ & 8.04 & 3 & 0.923 & 0.48 & 3 & 0.07 & 7.06 & 3 \\
\hline $\begin{array}{l}\text { Transplant treatment } \\
\text { and Reproductive class }\end{array}$ & 0.593 & 14.07 & 16 & 0.739 & 12.07 & 16 & 0.214 & 20.14 & 16 \\
\hline
\end{tabular}


